\title{
Die bernische Justizleitung auf dem verfassungsrechtlichen Prüfstand
}

\section{Zur Vereinbarkeit von Organisation und Aufgaben der Justizleitung mit dem Grundsatz der Gewaltenteilung und mit der Garantie der richterlichen Unabhängigkeit}

\begin{abstract}
Auf den 1. Januar 2011 schuf der Kanton Bern per Gesetz eine dreiköpfige Justizleitung. Diese nimmt als gemeinsames Organ von Obergericht, Verwaltungsgericht und Generalstaatsanwaltschaft Aufgaben im Bereich der JustizSelbstverwaltung wahr. Verschiedentlich wurde die Frage aufgeworfen, ob die Justizleitung mit den Vorgaben des übergeordneten Rechts (insb. Gewaltenteilung, Unabhängigkeit der Justiz) in Einklang stehe. Der Verfasser bejaht dies sowohl für die aktuelle gesetzliche Ausgestaltung (GSOG) als auch für die mit dem Projekt «Justizverfassung» (Vernehmlassungsvorlage 2019) angestrebte Verankerung der Justizleitung auf Stufe Kantonsverfassung.
\end{abstract}

Beitragsart: Science 


\section{Inhaltsübersicht}

I. Ausgangslage und Fragestellung

II. Die Justizleitung als «das gemeinsame Organ von Obergericht, Verwaltungsgericht und Generalstaatsanwaltschaft»

1. Regelungen zur Justizleitung in der bernischen Gesetzgebung

2. Stellung und Zusammensetzung der Justizleitung

a. $\quad$ Stellung der Justizleitung

b. Zusammensetzung der Justizleitung

3. Aufgaben und Instrumente der Justizleitung

a. Der Aufgabenkatalog im Überblick

b. Zwischenbemerkung: Zum Begriff der Justizverwaltung

c. Die Aufgaben der Justizleitung im Einzelnen

d. Nicht zu den Aufgaben der Justizleitung gehörende Tätigkeiten

e. Abgrenzung: Selbstverwaltungsaufgaben anderer Justizbehörden

f. Instrumente der Justizleitung

4. Organisation der Justizleitung sowie Verfahren der Beschlussfassung

5. Verhältnis zu anderen Organen

6. Zwischenergebnis: Charakterisierung der Justizleitung

a. $\quad$ Ein Organ der justiziellen Selbstverwaltung

b. Ein Selbstverwaltungsorgan mit begrenztem Aufgabenbereich

c. Ein Organ mit, aus schweizerischer Sicht, besonderer Zusammensetzung

d. Ein Kollegialorgan mit drei gleichberechtigten Mitgliedern

e. Ein Organ, dessen Mitglieder dem Gesamtinteresse verpflichtet sind

7. Exkurs: Zum Sprachgebrauch im (rechts)politischen Reformdiskurs

8. Ausblick: Die Justizleitung in der Vernehmlassungsvorlage 2019

III. Anlässlich der Reformprojekte geäusserte (verfassungs)rechtliche Bedenken betreffend die Justizleitung

1. Im Rahmen des Projekts «Justizreform 2011»

2. Im Rahmen der Vernehmlassungsvorlage 2019

3. Einordnung der geäusserten Bedenken und Zwischenfazit

IV. Allgemeine Bemerkungen zum Beurteilungsmassstab

1. Die im Zentrum stehenden rechtlichen Vorgaben

2. Charakterisierung der Überprüfung

V. Beurteilung der Justizleitung gemäss geltender Rechtslage (Justizreform 2011) unter dem Aspekt der Gewaltenteilung

1. Gewaltenteilung in Theorie und Praxis

2. Bundesvorgaben betreffend die Ausgestaltung der Gewaltenteilung in den Kantonen (Art. $51 \mathrm{BV}$ )

3. Der kantonale Verfassungsgrundsatz der Gewaltenteilung (Art. $66 \mathrm{KV}$ )

4. Beurteilung der Kritikpunkte unter Gewaltenteilungsaspekten

a. Missachtung der staatsrechtlichen Stellung der Staatsanwaltschaft?

b. Vermischung von Staatsfunktionen?

c. Keine unkontrollierte und unbegrenzte Machtausübung

5. Ergebnis: Vereinbarkeit der geltenden Regelung mit dem Gewaltenteilungsgrundsatz (Art. 51 Abs. 1 BV und Art. 66 Abs. $1 \mathrm{KV}$ )

VI. Beurteilung der Justizleitung gemäss geltender Rechtslage (Justizreform 2011) unter dem Aspekt der richterlichen Unabhängigkeit

1. Überblick und weiteres Vorgehen

2. Zur Tragweite von Art. 191c BV

3. Zur Tragweite von Art. 30 Abs. 1 Satz 1 BV

4. Zur Tragweite von Art. 6 Ziffer 1 EMRK

5. Zur Tragweite von Art. 97 Abs. $1 \mathrm{KV}$ und von Art. 26 Abs. $1 \mathrm{KV}$

6. Beurteilung der Kritikpunkte unter dem Aspekt der richterlichen Unabhängigkeit

a. Bemerkungen allgemeiner Natur (Stellung und Aufgaben) 
b. Die Instrumente der Justizleitung im Lichte der richterlichen Unabhängigkeit c. Die Rolle der Justizleitung im Budgetprozess im Lichte der richterlichen Unabhängigkeit

d. Organisation und Verfahren im Lichte der richterlichen Unabhängigkeit: Gibt es ein «Vetorecht» der einzelnen Mitglieder der Justizleitung?

e. Bemerkungen zur Frage des äusseren Anscheins

7. Ergebnis: Vereinbarkeit der geltenden Regelung mit der Garantie der richterlichen Unabhängigkeit

VII. Beurteilung der Justizleitung gemäss Vernehmlassungsvorlage 2019

1. Ausgangslage und Fragestellung

2. Inhalt und Tragweite der geplanten Verfassungsänderungen

a. Der Justizleitung gewidmete neue Bestimmungen

b. Weitere vorgeschlagene Verfassungsänderungen

c. Zwischenergebnis

3. Insbesondere E-Art. 97a KV (Justizleitung)

4. Ergebnis: Vereinbarkeit der vorgesehenen Verankerung der Justizleitung in der Kantonsverfassung mit den übergeordneten Vorgaben

VIII. Zusammenfassung

Anhang

Abkürzungen

Ausgewählte Literatur

Ausgewählte Materialien

\section{Ausgangslage und Fragestellung}

[1] Im Kanton Bern trat am 1. Januar 2011 eine grundlegende Reform der Justizbehörden in Kraft (im Folgenden: Justizreform 2011). Ein Resultat dieser Reform ist das neu geschaffene Organ "Justizleitung». Dabei handelt es sich um ein mit Aufgaben im Bereich der (Justiz-) Selbstverwaltung betrautes dreiköpfiges Gremium, bestehend aus der Präsidentin oder dem Präsidenten des Obergerichts und des Verwaltungsgerichts sowie dem Generalstaatsanwalt oder der Generalstaatsanwältin. Das im Frühjahr 2019 vorgestellte Projekt «Justizverfassung» (Vernehmlassungsvorlage 2019) $)^{1}$ hat unter anderem zum Ziel, die heute im Gesetz über die Organisation der Gerichtsbehörden und der Staatsanwaltschaft (GSOG) vom 11. Juni 2009 geregelte Justizleitung auch in der bernischen Kantonsverfassung zu verankern. Im Rahmen der Vernehmlassung wurde die Frage aufgeworfen, ob die Zusammensetzung der Justizleitung mit dem Grundsatz der Unabhängigkeit der Justiz und dem Grundsatz der Gewaltenteilung vereinbar sei. Im vorliegenden Beitrag wird untersucht, ob die Einsetzung der Justizleitung, ihre Organisation und Zusammensetzung sowie ihre Kompetenzen und Aufgaben mit dem übergeordneten Recht vereinbar sind. Die Untersuchung erfasst zum einen die bernische Justizleitung in ihrer aktuellen gesetzlichen Ausgestaltung, zum anderen die vom bernischen Regierungsrat vorgeschlagene Verankerung der Justizleitung auf Verfassungsstufe.

[2] In einem ersten Schritt (Ziffer II.) wird das mit der Justizreform 2011 geschaffene Organ «Justizleitung» einer Analyse unterzogen (Stellung, Aufgaben, Organisation usw.). Es folgt ein Überblick über die im Rahmen der Reformdiskussion geäusserten (verfassungs)rechtlichen Bedenken gegenüber der Ausgestaltung der Justizleitung als gemeinsames Organ von Obergericht,

1 Vernehmlassungsvorlage (März 2019) zum Vortrag des Regierungsrates zur Änderung der Verfassung des Kantons Bern sowie zur Änderung des Gesetzes über die Organisation der Gerichtsbehörden und der Staatsanwaltschaft (GSOG). 
Verwaltungsgericht und Generalstaatsanwaltschaft (Ziffer III.). Nach einigen allgemeinen Bemerkungen zum Beurteilungsmassstab (Ziffer IV.) erfolgt eine Überprüfung der Justizleitung in ihrer aktuellen gesetzlichen Ausgestaltung (Justizreform 2011), zum einen unter dem Aspekt der Gewaltenteilung (Ziffer V.), zum anderen unter dem Aspekt der richterlichen Unabhängigkeit (Ziffer VI.). Sodann werden die im Rahmen der Vernehmlassungsvorlage 2019 vorgeschlagenen Verfassungsbestimmungen betreffend die Justizleitung einer Überprüfung unterzogen (Ziffer VII.). Abschliessend werden die wichtigsten Ergebnisse zusammengefasst (Ziffer VIII.).

\section{Die Justizleitung als «das gemeinsame Organ von Obergericht, Verwaltungsgericht und Generalstaatsanwaltschaft»}

\section{Regelungen zur Justizleitung in der bernischen Gesetzgebung}

[3] Die Schaffung der Justizleitung geht zurück auf die Justizreform 2011. Ein Hauptziel dieser Reform war es, die institutionelle Unabhängigkeit der Justiz im Kanton Bern zu stärken und den Gerichten mehr Befugnisse bei der Selbstverwaltung einzuräumen. ${ }^{2}$ Die Regelungen betreffend die Justizleitung als dem gemeinsamen Organ von Obergericht, Verwaltungsgericht und Generalstaatsanwaltschaft finden sich hauptsächlich im Gesetz über die Organisation der Gerichtsbehörden und der Staatsanwaltschaft (insb. Art. 17-19 GSOG, vgl. auch z.B. Art. 6 und Art. 13 GSOG) sowie im Justizleitungs-Reglement (JLR) vom 26. Mai 2010. Diese beiden Erlasse werden nachfolgend im Zentrum stehen. ${ }^{3}$ Art. 9 GSOG erklärt die Gesetzgebung über die Steuerung von Finanzen und Leistungen (ohne die Grundsätze der Wirkungsorientierung und der Erlösorientierung) für sinngemäss anwendbar, soweit das GSOG nichts anderes bestimmt. Erwähnung findet die Justizleitung darüber hinaus in verschiedenen weiteren Erlassen, so etwa in der Personalgesetzgebung, im Grossratsgesetz, im Finanzkontrollgesetz und in den Organisationsreglementen diverser Justizbehörden. Diese ausserhalb des GSOG und des JLR figurierenden Bestimmungen werden, soweit erforderlich, herangezogen. Die Bestandesaufnahme hinsichtlich Stellung und Aufgaben sowie Organisation und Verfahren der Justizleitung ergibt im Einzelnen den folgenden Befund.

\section{Stellung und Zusammensetzung der Justizleitung}

\section{a. Stellung der Justizleitung}

[4] Art. 17 Abs. 1 GSOG bezeichnet die Justizleitung ausdrücklich als «das gemeinsame Organ von Obergericht, Verwaltungsgericht und Generalstaatsanwaltschaft.» (ebenso Art. 1 JLR). Gemäss Art. 2 JLR vertritt die Justizleitung die Justiz «gegen aussen». Die Justizleitung befindet sich somit an der Schnittstelle zwischen der Justiz einerseits und anderen staatlichen Behörden wie Parlament, Regierung, Verwaltung andererseits.

2 Vgl. Lienhard, Die bernische Gerichtsbarkeit auf dem Weg zur Selbstverwaltung, 417 f. (m.w.H.).

3 Im Folgenden wird auf die deutschsprachige Fassung kantonaler Vorschriften Bezug genommen, wenn kein Anlass besteht, auch die französischsprachige Fassung heranzuziehen.

4 Darunter sind im Zusammenhang mit der Justizreform 2011 «die Gerichtsbehörden und die Staatsanwaltschaft» zu verstehen (vgl. Art. 2 JLR). 
[5] Mit Blick auf die Justiz ist die Stellung der Justizleitung eine herausgehobene. Bestimmungen wie Art. 18 Abs. 1 Bst. g GSOG - wonach die Justizleitung hinsichtlich der Steuerung von Finanzen und Leistungen gegenüber den übrigen Gerichtsbehörden und der Staatsanwaltschaft dieselbe Stellung einnimmt, wie sie der Regierungsrat für den Bereich der kantonalen Verwaltung innehat - stellen die Justizleitung gewissermassen an die «Spitze» der Justiz.

[6] Allerdings machen andere Bestimmungen deutlich, dass der Justizleitung im Bereich der Justiz keine exklusive «Spitzenstellung» zukommt. So unterstehen nicht nur die Justizleitung, sondern auch das Obergericht, das Verwaltungsgericht und die Generalstaatsanwaltschaft - direkt - der Oberaufsicht des Grossen Rates. Art. 13 GSOG nennt die Justizleitung, das Obergericht, das Verwaltungsgericht sowie die Generalstaatsanwaltschaft in einem Atemzug. Die Schaffung der Justizleitung im Rahmen der Justizreform 2011 hatte somit nicht zur Folge, dass alle Beziehungen zwischen Politik und Justiz über die Justizleitung laufen. Es findet mit anderen Worten keine generelle «Mediatisierung» der Justiz durch die Justizleitung statt. Die Vertretung «nach aussen» (Art. 2 JLR) bezieht sich auf bestimmte, im Gesetz festgelegte und im Reglement konkretisierte Angelegenheiten, welche - wie sich gleich zeigen wird (vgl. hinten 3.) - im Wesentlichen die hergebrachte Justizverwaltung betreffen. In Rechtsprechungsfragen und in Fragen der Strafverfolgung steht die Justizleitung nicht an der Spitze der Justiz.

\section{b. Zusammensetzung der Justizleitung}

[7] Die Justizleitung setzt sich aus drei Personen zusammen, nämlich «aus den Präsidentinnen oder Präsidenten des Obergerichts und des Verwaltungsgerichts sowie der Generalstaatsanwältin oder dem Generalstaatsanwalt» (Art. 17 Abs. 2 GSOG; so auch Art. 10 Abs. 1 JLR). Der Leiter der Stabsstelle für Ressourcen nimmt an den Sitzungen der Justizleitung mit beratender Stimme teil (Art. 10 Abs. 2 JLR), ist jedoch kein Mitglied der Justizleitung.

[8] Die Stellung als Mitglied der Justizleitung nehmen die drei genannten Amtsträger ex officio ein. Eines besonderen Einsetzungs-, Ernennungs- oder Wahlakts bedarf es nicht. Die gesetzliche Regelung macht auch klar, dass die drei Mitglieder der Justizleitung ihre angestammte Funktion als Gerichtspräsident bzw. Generalstaatsanwalt behalten. Sie nehmen somit eine Doppelrolle ein. Aus einer solchen Doppelrolle können gewisse Spannungen resultieren - wie man dies von anderen Konstellationen her kennt (z.B. Doppelrolle als Regierungsmitglied und Vorsteher oder Vorsteherin einer Direktion). Darauf wird zurückzukommen sein.

\section{Aufgaben und Instrumente der Justizleitung}

[9] Das GSOG listet die Aufgaben der Justizleitung in einem Katalog einzeln auf (Art. 18 Abs. 1 Bst. a-m GSOG). Aufgrund der Formulierung im Einleitungssatz («nimmt die folgenden Aufgaben wahr») könnte man zunächst denken, dass die Aufzählung abschliessenden Charakter hat. Die gewählte Regelungstechnik schliesst allerdings nicht aus, dass im GSOG an anderer Stelle oder in einem anderen Gesetz weitere Aufgaben der Justizleitung festgelegt werden. Ein Beispiel dafür 
ist Art. 23 Abs. 2 GSOG. Danach obliegt der Justizleitung die Vereidigung der (nicht durch den Grossen Rat zu vereidigenden) «übrigen Richterinnen und Richter». ${ }^{5}$

[10] Im Übrigen macht die gewählte Regelungstechnik deutlich, dass es nicht zulässig wäre, die Aufgaben der Justizleitung auf der Stufe des untergesetzlichen Rechts (d.h. durch Verordnung, Reglement usw.) um zusätzliche (d.h. auf Gesetzesstufe nicht vorgesehene) Aufgaben zu erweitern. Unter diesem Aspekt erscheint Art. 4 Abs. 1 JLR auf den ersten Blick etwas missverständlich formuliert. Gemäss Bst. a nimmt die Justizleitung «die Aufgaben gemäss Artikel 18 Absatz 1 GSOG wahr». Dann folgt eine Auflistung weiterer Aufgaben (Bst. b-e). Bei einer oberflächlichen Lektüre von Art. 4 Abs. 1 JLR könnte der Eindruck aufkommen, dass sich die Justizleitung in dem von ihr selbst erlassenen Reglement zusätzliche Aufgaben (Bst. b-e) zuweist. Eine nähere Betrachtung zeigt aber, dass die Bestimmung nicht so verstanden werden darf. Art. 4 Abs. 1 Bst. a JLR hat vielmehr den Charakter einer Auffangklausel, die bewirken soll, dass alle in Art. 18 Abs. 1 GSOG vorgesehenen Aufgaben im Justizleitungs-Reglement «abgebildet» sind und keine «vergessen» geht.

[11] Die nachfolgenden Ausführungen wollen einerseits - ausgehend von Art. 18 GSOG - einen Überblick über die gesetzlichen Aufgaben der Justizleitung vermitteln (a.-c.), andererseits aber auch deutlich machen, was nicht zu den Aufgaben der Justizleitung gehört (d.-e.).

\section{a. Der Aufgabenkatalog im Überblick}

[12] Gemäss Art. 18 Abs. 1 GSOG (geltende Fassung ${ }^{6}$ ) nimmt die Justizleitung die folgenden Aufgaben wahr:

a Sie ist Ansprechpartnerin des Grossen Rates und des Regierungsrates bei allen Fragen, die sowohl die Gerichtsbehörden als auch die Staatsanwaltschaft betreffen.

$b$ Sie erstellt den Voranschlag, den Aufgaben- und Finanzplan und den Geschäftsbericht der Gerichtsbehörden und der Staatsanwaltschaft.

c Sie nimmt Stellung zu Regelungen des Regierungsrates, welche die Gerichtsbehörden oder die Staatsanwaltschaft betreffen.

$d$ Sie regelt die Ausgabenbefugnisse der Gerichtsbehörden und der Staatsanwaltschaft im Rahmen der Vorschriften der Gesetzgebung über die Steuerung von Finanzen und Leistungen.

e Sie unterbreitet dem Grossen Rat jährlich einen Tätigkeitsbericht.

$f$ Sie vertritt im Grossen Rat den Voranschlag, den Aufgaben- und Finanzplan, den Geschäftsbericht und den Tätigkeitsbericht und bezeichnet zu diesem Zweck eine Vertreterin oder einen Vertreter.

g Sie nimmt die Verwaltungsaufgaben, welche die Gesetzgebung über die Steuerung von Finanzen und Leistungen dem Regierungsrat für den Bereich der kantonalen Verwaltung

5 Für weitere Beispiele vgl. den Ingress des Justizleitungs-Reglements, wo neben Art. 12 und Art. 17 Abs. 3 GSOG auch Art. 7 des Personalgesetzes (PG) vom 16. September 2004 (BSG 153.01) sowie Art. 22 des Informationsgesetzes (IG) vom 2. November 1993 (BSG 107.1) als Ermächtigungsgrundlage genannt werden.

6 Die geltende Fassung wurde gegenüber der ursprünglichen Fassung in einzelnen Punkten modifiziert (Bst. b, e, f); zudem wurden Bst. i und Bst. I neu eingefügt, was dazu führte, dass der ursprüngliche Bst. i zu Bst. k wurde und der ursprüngliche Bst. k zu Bst. m. 
einräumt, für die Bereiche der Gerichtsbarkeit und der Staatsanwaltschaft wahr, soweit dieses Gesetz nichts anderes bestimmt.

$h$ Sie kann mit Zustimmung der Justizkommission des Grossen Rates nachkreditpflichtige Abweichungen der im Voranschlag beschlossenen Saldi bewilligen, wenn diese eine Million Franken pro Produktgruppe nicht übersteigen.

$i$ Sie kann mit Zustimmung der Justizkommission des Grossen Rates bereits vor der Bewilligung eines Nachkredits Verpflichtungen eingehen, wenn ein Aufschub für den Kanton erhebliche nachteilige Folgen hätte.

$k$ Sie ist im Rahmen der gesetzlichen Vorgaben verantwortlich für die strategischen Leitlinien in den Bereichen Personal-, Finanz- und Rechnungswesen sowie Informatikmanagement und führt darüber ein Controlling. Sie kann den Gerichtsbehörden und der Staatsanwaltschaft entsprechende Weisungen erteilen sowie die notwendigen Reglemente erlassen.

$l$ Sie koordiniert in Zusammenarbeit mit den zuständigen Stellen der Polizei- und Militärdirektion und der Bau-, Verkehrs- und Energiedirektion den Erlass von strategischen Leitlinien auf dem Gebiet der Sicherheit.

$m$ Sie leitet die Stabsstelle für Ressourcen, regelt deren Organisation und Aufgaben durch Reglement und stellt deren Leitung sowie deren übriges Personal an.

[13] Den Ausgabenbefugnissen der Justizleitung widmet Art. 18 GSOG einen eigenen Absatz. Danach beschliesst die Justizleitung über (Abs. 2):

a neue einmalige Ausgaben bis eine Million Franken,

$b$ neue wiederkehrende Ausgaben bis 200000 Franken,

c gebundene Ausgaben.

[14] Als gemeinsamer Nenner des gesetzlichen Aufgabenkatalogs lässt sich ausmachen: Keine der erwähnten Aufgaben hat direkt mit der Rechtsprechung zu tun (d.h. der Kernaufgabe oder Stammfunktion der Gerichte) und keine direkt mit der Strafverfolgung (d.h. der Kernaufgabe der Staatsanwaltschaft). Es handelt sich vielmehr um Aufgaben, die mit der Selbstverwaltung der Justiz zu tun haben.

\section{b. Zwischenbemerkung: Zum Begriff der Justizverwaltung}

[15] Zur Gerichtsverwaltung (oder Justizverwaltung) zählt man hergebrachterweise jene behördlichen Tätigkeiten, die weder Rechtsprechung noch Rechtsetzung sind und dazu dienen, die sachlichen und personellen Voraussetzungen zu schaffen, damit die Gerichte ihre Rechtsprechungsfunktion überhaupt ausüben können (insb. Bereitstellung von Gebäuden, Informatik und weiteren Sachmitteln, Personalverwaltung, Rechnungswesen usw.). ${ }^{7}$ Aufgaben der Justizverwaltung wurden früher häufig nicht durch die Justiz selbst (im Sinne der Selbstverwaltung), sondern

7 Vgl. statt vieler KIENER, Richterliche Unabhängigkeit, 292 («jene verwaltende Tätigkeit, welche die sachlichen und persönlichen Voraussetzungen für die Wahrnehmung der Rechtsprechung schafft und erhält»); Lienhard/Kettiger, Selbstverwaltung, Rz. 13 ff.; Eichenberger, Justizverwaltung, 31 ff. 
durch der Exekutive angehörende Verwaltungsbehörden wahrgenommen ${ }^{8}$, so auch im Kanton Bern. ${ }^{9}$

[16] In der Schweiz zeigt sich in jüngerer Zeit ein Trend zur Etablierung und Stärkung der Selbstverwaltung der Justiz, unter anderem in Gestalt von verfassungsrechtlichen Selbstverwaltungsgarantien (für das Bundesgericht: Art. 188 Abs. 3 BV). Die «justizfremde» Wahrnehmung der Justizverwaltung ist allgemein im Rückzug begriffen. Dies bedeutet indes nicht, dass eine «justizfremde» Justizverwaltung heute nicht mehr zulässig wäre. Die verfassungs- bzw. menschenrechtlichen Unabhängigkeitsgarantien stellen eine solche «Fremdverwaltung» nicht grundsätzlich infrage. ${ }^{10}$ Dies hat nicht zuletzt damit zu tun, dass sich die Garantie der richterlichen Unabhängigkeit (wie sie in Art. 30 Abs. 1 und Art. 191c BV sowie in Art. 6 Ziffer 1 EMRK verankert ist) auf die rechtsprechende Tätigkeit der Justiz bezieht. Die verfassungs- bzw. völkerrechtlichen Unabhängigkeitsgarantien lassen somit von ihrem Anwendungsbereich her grundsätzlich Raum für «justizfremde» Justizverwaltung. Es gilt jedoch zu beachten, dass es auch gewisse rechtsprechungsnahe Administrativangelegenheiten gibt, wie beispielsweise die interne Geschäftsverteilung, die Spruchkörperbildung, die Handhabung der Fallbearbeitung, die Verhängung von Disziplinarmassnahmen gegenüber Amtsträgern u.a.m. ${ }^{11}$ Die Justizverwaltung muss so organisiert werden, dass eine mit Justizverwaltungsaufgaben betraute nicht-gerichtliche Behörde weder direkt noch indirekt auf die Rechtsprechungstätigkeit Einfluss nehmen kann (vgl. Ziffer VI.). ${ }^{12}$

\section{c. Die Aufgaben der Justizleitung im Einzelnen}

[17] Die einzelnen Aufgaben der Justizleitung sind auf Gesetzesstufe unterschiedlich dicht umschrieben. Manche Aufgabenzuweisungen sind punktuell und spezifisch (z.B. Art. 18 Abs. 1 Bst. e GSOG: jährlicher Tätigkeitsbericht). Andere Aufgaben sind offen formuliert bzw. verweisen auf Regelungen in anderen Gesetzen (z.B. Art. 18 Abs. 1 Bst. g GSOG: Wahrnehmung bestimmter Verwaltungsaufgaben gemäss Gesetzgebung über die Steuerung von Finanzen und Leistungen, FLG).

[18] Im Justizleitungs-Reglement werden die gesetzlichen Aufgaben weiter spezifiziert (Art. $4 \mathrm{ff}$. JLR). Dem Aufgabenkatalog vorangestellt ist eine mit «Auftrag» überschriebene Bestimmung (Art. 2 JLR). Dieser Auftrag umfasst zwei Aspekte. Zum einen vertritt die Justizleitung «die Gerichtsbehörden und die Staatsanwaltschaft (Justiz) gegen aussen» (Abs. 1). Zum anderen soll die Justizleitung «die koordinierte und vernetzte Aufgabenerfüllung in der Gerichtsbarkeit und der Strafverfolgung» gewährleisten, dies «im Bestreben, die Qualität und Effizienz der Aufgabenerfüllung zu fördern» (Abs. 2). Dieser Gewährleistungsauftrag (Abs. 2) erscheint ambitioniert und ist - gemessen am gesetzlichen Aufgabenkatalog (siehe vorne) - recht allgemein formuliert. Da das (von der Justizleitung erlassene) Justizleitungs-Reglement keine neuen, gesetzlich nicht vorgesehenen Aufgaben schaffen kann (siehe Rz. 10), ist der Gewährleistungsauftrag als Zielvorgabe

Vgl. KIENER, Richterliche Unabhängigkeit, $291 \mathrm{ff}$.

Vgl. Hurni, Rz. 3; Müller-Graf, Rz. 33.

10 Vgl. Kiener, Richterliche Unabhängigkeit, 291 f., 321.

11 Der Begriff «rechtsprechungsnah» hat sich in der Schweiz bisher, soweit ersichtlich, nicht als klar konturierter rechtsdogmatischer Begriff etabliert, er ist aber im vorliegenden Zusammenhang als Orientierungshilfe nützlich. Vgl. z.B. KeEL, 272 ff. («rechtsprechungsnahe Justizverwaltung»); MüLler-Graf, Rz. 23; vgl. auch Reiter, 217 (Spruchkörperbildung).

12 Vgl. KIENER, Richterliche Unabhängigkeit, 293 (m.w.H.). 
zu verstehen, die sich auf die gesetzlichen Aufgaben (insb. Art. 18 GSOG) bezieht und sich nur (aber immerhin) in diesem Rahmen entfaltet.

[19] Im 2. Abschnitt des Justizleitungs-Reglements (Überschrift «Aufgaben»; Art. 4-9 JLR) werden die gesetzlichen Aufgaben nach Sachthemen gruppiert und konkretisiert. Dabei werden die folgenden Aufgabenfelder unterschieden:

- Allgemeines (Art. 4 JLR)

- Personal (Art. 5 JLR)

- Finanz- und Rechnungswesen (Art. 6 JLR)

- Infrastruktur (Art. 7 JLR)

- Öffentlichkeitsarbeit (Art. 8 JLR)

- Aufsicht (Art. 9 JLR)

[20] Zur Veranschaulichung sei hier exemplarisch die Aufgabenkonkretisierung für den Personalbereich (Art. 5 JLR) kurz vorgestellt. Die Justizleitung soll:

- die Personalstrategie für die Justiz festlegen (auf der Grundlage der regierungsrätlichen Personalpolitik) und für deren Umsetzung sorgen,

- die Grundsätze und Ziele der Aus- und Weiterbildung festlegen,

- die Personalkosten- und Stellenplanung führen,

- die Schaffung neuer Stellen für Richter und Staatsanwältinnen beantragen und über die Schaffung neuer unbefristeter sonstiger Stellen beschliessen,

- die Bewilligung von Nebenbeschäftigungen für die Mitglieder des Obergerichts, des Verwaltungsgerichts und der Generalstaatsanwaltschaft beantragen,

- die Koordination bezüglich Rekrutierung, Einreihung und dergleichen sichern.

[21] Im Bereich des Finanz- und Rechnungswesens obliegt der Justizleitung (Art. 6 JLR; vgl. auch Art. 18 Abs. 1 Bst. b sowie Art. 18 Abs. 2 GSOG):

- die Festlegung der Finanzstrategie der Justiz und deren Umsetzung,

- die Regelung der Art und Weise der Rechnungsführung und der Ausgabenbefugnisse,

- die Verantwortung für den Voranschlag sowie den Aufgaben- und Finanzplan der Justiz,

- die Führung des Finanz- und Rechnungswesens der Justiz und die Definition des Controllings.

[22] Ohne hier weiter ins Detail gehen zu müssen, lässt sich festhalten, dass die im JustizleitungsReglement genannten Aufgaben - nicht anders als die im Gesetz aufgezählten Aufgaben - durchweg zur hergebrachten Selbstverwaltung gehören: Personalwesen, Finanz- und Rechnungswesen, Infrastruktur usw. (unter Einschluss der damit verbundenen «Aussen»-Vertretung gegenüber Parlament und Regierung).

[23] Weiter lässt sich festhalten, dass der Justizleitung vor allem Aufgaben obliegen, welche die Justiz als Ganzes betreffen (in diesem Sinne ausdrücklich Art. 8 JLR betreffend die Öffentlichkeitsarbeit). 
[24] Schliesslich lässt sich festhalten, dass keine dieser Aufgaben als rechtsprechungsnah einzustufen ist.

[25] Auch die gesetzlich festgelegten Zuständigkeiten und Aufgaben der Stabsstelle für Ressourcen der Justizleitung (Art. 19 GSOG) betreffen einzig bestimmte Fragen der Justizselbstverwaltung, die nicht rechtsprechungsnah sind (Personaladministration, Finanz- und Rechnungswesen, Informatikwesen; vgl. Art. 19 Abs. 1 GSOG; vgl. auch Art. 20 und 21 JLR). Die gesetzlich eingeräumte Befugnis, Weisungen zu erteilen, erstreckt sich (in sachlicher Hinsicht) einzig auf "personal- und finanztechnische» Fragen und (in persönlicher Hinsicht) einzig auf die Ressourcenverantwortlichen der Gerichtsbehörden und der Staatsanwaltschaft (Art. 19 Abs. 3 GSOG).

[26] Dieser Befund bestätigt sich, wenn man in die übrigen Erlasse blickt, in denen von der Justizleitung die Rede ist. ${ }^{13}$

\section{d. Nicht zu den Aufgaben der Justizleitung gehörende Tätigkeiten}

[27] Der Charakter der Justizleitung und ihrer Aufgaben tritt noch etwas deutlicher hervor, wenn man sich vergegenwärtigt, was alles nicht zum Tätigkeitsbereich der Justizleitung gehört. ${ }^{14}$

- Die Justizleitung hat, wie bereits kurz erwähnt, keine Aufgaben im Bereich der Rechtsprechung. Das Gesetz stellt vielmehr ausdrücklich klar, dass das Obergericht die oberste kantonale rechtsprechende Behörde in Zivil- und Strafsachen ist und das Verwaltungsgericht die oberste kantonale rechtsprechende Behörde in öffentlich-rechtlichen Angelegenheiten (Art. 35 und 47 GSOG, jeweils Abs. 1). Für die Einheitlichkeit der Rechtsprechung zu sorgen, ist Aufgabe der obersten Gerichte (Obergericht, Verwaltungsgericht) bzw. ihrer Abteilungen (Art. 43 Abs. 1 bzw. 54 Abs. 3 GSOG), nicht Aufgabe der Justizleitung.

- In Angelegenheiten der Justizverwaltung führt der Rechtsweg gegen Verfügungen des Verwaltungsgerichts zum Obergericht, für Verfügungen des Obergerichts und der Generalstaatsanwaltschaft zum Verwaltungsgericht (Art. 95 GSOG), nicht zur Justizleitung.

- Das Gesetz sieht keine Beteiligung der Justizleitung an den Wahlen der Richterinnen und Richter vor. Wahl und Wiederwahl sind Sache des Grossen Rates, soweit das Gesetz nichts anderes bestimmt (Art. 21 GSOG). ${ }^{15}$ Die Wahlvorbereitung obliegt der Justizkommission des Grossen Rates. Anzuhören sind das Obergericht, das Verwaltungsgericht, die Generalstaatsanwaltschaft u.a.m. (Art. 21a GSOG); die Justizleitung wird im Gesetz nicht erwähnt.

- Das Gesetz sieht keine Beteiligung der Justizleitung an der Wahl der Präsidien des Obergerichts und des Verwaltungsgerichts vor (Art. 25 GSOG: Wahlzuständigkeit beim Grossen Rat). Das jeweilige Gericht (nicht die Justizleitung) kann einen Wahlvorschlag unterbreiten.

13 Beispielhaft seien hier erwähnt: das Personalgesetz (PG) vom 16. September 2004 (BSG 153.01), die Personalverordnung [des Regierungsrats] (PV) vom 18. Mai 2005 (BSG 153.011.1), das von der Justizleitung erlassene Personalreglement der Gerichtsbehörden und der Staatsanwaltschaft (JPersR) vom 22. Dezember 2010 (BSG 161.16), das von der Justizleitung erlassene Reglement über Steuerung von Finanzen und Leistungen der Justiz (JFinR) vom 27. April 2010 (BSG 161.111.2).

14 In der nachstehenden Liste wird auf die obersten kantonalen Gerichte (Obergericht, Verwaltungsgericht) und die Staatsanwaltschaft Bezug genommen. Für die nicht speziell erwähnten übrigen kantonalen bzw. regionalen Gerichtsbehörden (Art. 59 ff. GSOG) gilt gewöhnlich Entsprechendes.

15 Das Gesetz sieht nirgends eine solche Zuständigkeit der Justizleitung vor. 
- Die Festlegung der Höchstzahl der Stellen für die hauptamtlichen Richterinnen und Richter sowie für weitere Richterkategorien ist Sache des Grossen Rates (Art. 21 Abs. 2 Bst. a und b GSOG), ebenso die Regelung der Wahlvoraussetzungen, soweit sie nicht schon durch das GSOG bestimmt sind (Art. 21 Abs. 2 Bst. c GSOG). Im Rahmen des Voranschlags kann die Justizleitung die Schaffung neuer Stellen für Richterinnen und Richter beantragen (Art. 5 Abs. 1 Bst. d JLR), was ihr eine gewisse «Filterfunktion» verschafft.

- Die Justizleitung ist nicht beteiligt bei der Zuweisung der einzelnen Richterinnen und Richter des Obergerichts an die Abteilungen oder bei der Wahl der Abteilungspräsidentinnen und Abteilungspräsidenten. Dies obliegt dem Plenum des Obergerichts (Art. 38 Abs. 2 Bst. c und d GSOG). Die Richterinnen und Richter des Verwaltungsgerichts werden vom Grossen Rat an die einzelnen Abteilungen gewählt (Art. 48 Abs. 1 GSOG).

- Die Justizleitung hat keinen Einfluss auf die Bestellung der Spruchkörper (für das Obergericht Art. 45 GSOG; für das Verwaltungsgericht Art. 56 GSOG).

- Die Justizleitung hat keine Aufgaben im Bereich der Strafverfolgung.

- Die Justizleitung ist nicht beteiligt an der Wahl des Generalstaatsanwalts und seiner Stellvertreter. Diese obliegt dem Grossen Rat (Art. 22 Abs. 1 GSOG). Die übrigen Staatsanwältinnen und Staatsanwälte usw. werden von der Generalstaatsanwaltschaft angestellt.

- Die Festlegung der Höchstzahl der Stellen im Bereich der Strafverfolgung obliegt dem Grossen Rat nach Anhörung der Justizkommission und nach Anhörung der Generalstaatsanwältin oder des Generalstaatsanwaltes (vgl. Art. 22 GSOG, wo die Justizleitung nicht erwähnt wird). Die Justizleitung kann die Schaffung neuer Stellen für Staatsanwälte usw. im Rahmen des Voranschlags beantragen (Art. 5 Abs. 1 Bst. d JLR), was ihr eine gewisse «Filterfunktion» verschafft.

- Das Gesetz sieht keine Beteiligung der Justizleitung bei der Bestellung von ausserordentlichen Richterinnen und Richtern sowie Staatsanwältinnen und Staatsanwälten vor (Art. 26 GSOG; Zuständigkeit des Obergerichts, des Verwaltungsgerichts bzw. der Generalstaatsanwaltschaft).

- Das Gesetz sieht keine Beteiligung der Justizleitung vor im Zusammenhang mit der strafrechtlichen Verantwortlichkeit (Verfolgung) eines Mitglieds des Obergerichts, des Verwaltungsgerichts oder der Generalstaatsanwaltschaft wegen Verbrechen oder Vergehen im Amt. Ermächtigungsinstanz ist der Grosse Rat (Art. 32 GSOG).

- Die Justizleitung hat keine Zuständigkeiten im Bereich des Disziplinarwesens (es sei denn betreffend das Personal der Stabsstelle für Ressourcen im Rahmen der Personalgesetzgebung).

[28] Zusammenfassend kann man festhalten, dass eine lange Reihe zentraler Angelegenheiten des Gerichtswesens und der Strafverfolgung - wie z.B. Bestellung und Zuteilung der Richterinnen und Richter, Geschäftszuteilung, Bildung der Spruchkörper usw. - nicht in das Aufgabenfeld der Justizleitung fallen.

[29] Die Aufgaben der Justizleitung liegen, wie bereits erwähnt, fast durchweg im Bereich der hergebrachten Justizverwaltung. Einzelne Ausnahmen, wie z.B. die Mitwirkung an der Rechtsetzung in Form von Stellungnahmen zu Regelungen des Regierungsrates, welche die Gerichtsbehörden oder die Staatsanwaltschaft betreffen (vgl. Art. 18 Abs. 1 Bst. c GSOG), sind nicht rechtsprechungsnah. 


\section{e. Abgrenzung: Selbstverwaltungsaufgaben anderer Justizbehörden}

[30] Weiter ist festzuhalten, dass die Justiz(selbst)verwaltung nicht einfach pauschal der Justizleitung zugewiesen ist. Vielmehr gilt: «Die Gerichtsbehörden [d.h. die einzelnen - obersten, kantonalen, regionalen - Gerichtsbehörden; vgl. Art. 2 GSOG] und die Staatsanwaltschaft verwalten sich selbst, soweit dieses Gesetz nichts anderes bestimmt» (Art. 5 Abs. 1 GSOG). Das Verhältnis «Regel-Ausnahme» greift somit zugunsten der einzelnen Gerichtsbehörden und der Staatsanwaltschaft, nicht zugunsten der Justizleitung. Im Einzelnen ergibt sich:

- Das Gesetz weist die Aufgabe der Gerichtsleitung ausdrücklich den jeweiligen Gerichten bzw. ihren dafür zuständigen Organen zu (Art. 36 GSOG für das Obergericht; Art. 49 GSOG für das Verwaltungsgericht). Es ist Aufgabe der Präsidentin oder des Präsidenten des Obergerichts bzw. des Verwaltungsgerichts, für den ordnungsgemässen Geschäftsgang der Zivilund Straf- bzw. der Verwaltungsgerichtsbarkeit zu sorgen (Art. 37 und Art. 50 GSOG).

- Gemäss Art. 10 GSOG obliegt es ausdrücklich dem Obergericht, dem Verwaltungsgericht und der Generalstaatsanwaltschaft, jährlich ihre jeweiligen Leistungsziele festzulegen und daraus den Ressourcenbedarf abzuleiten. ${ }^{16}$

- Für die (Haushalts-)Produktgruppe «Zivil- und Strafgerichtsbarkeit» ist das Obergericht, für die Produktgruppe «Verwaltungsgerichtsbarkeit» das Verwaltungsgericht und für die Produktgruppe «Staatsanwaltschaft» die Generalstaatsanwaltschaft verantwortlich (Art. 11 Abs. 2 GSOG).

- Das Obergericht, das Verwaltungsgericht und die Generalstaatsanwaltschaft - nicht die Justizleitung - schliessen mit den unter ihrer Aufsicht stehenden Behörden jährlich Ressourcenvereinbarungen ab (Art. 14 GSOG).

- Das Gesetz legt eine ganze Reihe von weiteren Aufgaben der Gerichtsverwaltung in die Hände des Obergerichts (Art. 38 ff. GSOG), des Verwaltungsgerichts (Art. 51 ff. GSOG) und der weiteren Gerichtsbehörden (Art. 59 ff. GSOG).

- Die Leitung der Staatsanwaltschaft obliegt der Generalstaatsanwältin oder dem Generalstaatsanwalt; sie oder er ist für die fachgerechte und effiziente Strafverfolgung verantwortlich (Art. 90 Abs. 2 GSOG), nicht die Justizleitung. Die Befugnis, im Bereich der Staatsanwaltschaft Weisungen zu erteilen, weist das Gesetz ausdrücklich dem Generalstaatsanwalt oder der Generalstaatsanwältin zu (Art. 90 Abs. 3 GSOG), nicht der Justizleitung.

- Die Generalsekretärin oder der Generalsekretär des Obergerichts bzw. des Verwaltungsgerichts stehen der jeweiligen Gerichtsverwaltung vor; sie sind zuständig für das Personal-, Finanz- und Rechnungswesen, die übrigen zentralen Dienste und die Infrastruktur, vorbehältlich der - begrenzten - Zuständigkeiten der Stabsstelle für Ressourcen der Justizleitung (Art. 41 bzw. Art. 53 GSOG). Entsprechendes gilt für den Fachverantwortlichen in der Generalstaatsanwaltschaft (Art. 90 Abs. 5 GSOG).

[31] Mit der geplanten Justizreform 2019 (Vernehmlassungsvorlage) sollen verschiedene Klärungen und Präzisierungen erfolgen, nicht jedoch eigentliche Verschiebungen bei der Aufgabentei-

16 Der Ressourcenbedarf fliesst in die Justizleitung ein, was dieser eine gewisse «Filterfunktion» verschafft. 
lung gemäss geltendem Recht vorgenommen werden. ${ }^{17}$ Insbesondere ist nicht ersichtlich, dass die Justizleitung im Rahmen der geplanten Reform zusätzliche Befugnisse erhalten soll, die es ihr erlauben würden, auf die Rechtsprechungs- bzw. Strafverfolgungstätigkeit einzuwirken.

\section{f. Instrumente der Justizleitung}

[32] Das Gesetz (GSOG) und das Reglement (JLR) gehen nicht systematisch darauf ein, welche Instrumente der Justizleitung zur Verfügung stehen, um ihre Aufgaben zu erfüllen. Auf Gesetzesstufe finden folgende Instrumente Erwähnung:

- Das GSOG ermächtigt und verpflichtet die Justizleitung, ihre Organisation und das Verfahren der Entscheidfällung durch Reglement zu regeln (Art. 17 Abs. 3 GSOG).

- Der Aufgabenkatalog im GSOG (Art. 18 Abs. 1) sieht an verschiedenen Stellen ausdrücklich oder implizit vor, dass die Justizleitung generell-abstrakte Regelungen zu treffen hat (Bst. d, k und m). Dafür wird die Form des Reglements genutzt. In der Bernischen Systematischen Gesetzessammlung (BSG) finden sich - neben dem bereits erwähnten JustizleitungsReglement - das Reglement über Steuerung von Finanzen und Leistungen der Justiz vom 27. April 2010 (JFinR; gestützt auf Art. 18 Abs. 1 Bst. d, i [heute Bst. k] und k [heute Bst. m] GSOG sowie Art. 36a Abs. 2 FLG) sowie das Personalreglement der Gerichtsbehörden und der Staatsanwaltschaft vom 22. Dezember 2010 (JPersR; gestützt auf Art. 18 Abs. 1 Bst. i [heute Bst. k] GSOG sowie Art 2 Abs. 3 Bst. b und Art. 167 PV).

- Gemäss Art. 18 Abs. 1 Bst. h GSOG kann die Justizleitung im Rahmen ihrer Verantwortung für die strategischen Leitlinien in den Bereichen Personal-, Finanz- und Rechnungswesen sowie Informatikmanagement den Gerichtsbehörden und der Staatsanwaltschaft Weisungen erteilen (sowie die notwendigen Reglemente erlassen).

- Art. 18 Abs. 1 Bst. 1 GSOG sieht vor, dass die Justizleitung zusammen mit den zuständigen Stellen der kantonalen Verwaltung den «Erlass von strategischen Leitlinien auf dem Gebiet der Sicherheit» koordiniert.

- Die Stabsstelle für Ressourcen der Justizleitung ist gesetzlich befugt, den Ressourcenverantwortlichen der Gerichtsbehörden und der Staatsanwaltschaft personal- und finanztechnische Weisungen zu erteilen (Art. 19 Abs. 3 GSOG; vgl. auch Art. 7 Abs. 2 JPersR).

[33] Auf Reglementsstufe werden folgende Instrumente erwähnt:

- Das Justizleitungs-Reglement hält in Art. 4 Abs. 1 Bst. e JLR (nachdoppelnd) fest, dass die Justizleitung zur Erfüllung ihrer Aufgaben die erforderlichen Reglemente und Weisungen erlässt und die nötigen Massnahmen trifft.

17 Vgl. Vernehmlassungsentwurf «Vortrag Justizverfassung», Ziffer 3 Bst. A. Von den Reformbestrebungen erfasst werden - neben dem GSOG - auch das GRG und das FLG. Die Präzisierungen und Ergänzungen betreffen Themen wie: Geschäftsverkehr zwischen Justizleitung, Regierung und Grossem Rat; Verankerung des Antragsrechts der Justizleitung im Grossen Rat; Regelung der Kreditanträge der Justiz; Präzisierung des Vertretungsrechts der Justizleitung; Verzicht auf die Möglichkeit, Postulate an die Justizleitung zu richten. - Zu den Anpassungen auf Verfassungsstufe näher hinten Ziffer VII. 
- In Art. 7 JPersR ruft die Justizleitung (als erlassende Behörde) in Erinnerung, dass sie zur Umsetzung ihrer strategischen Leitlinien im Personalbereich «Weisungsbefugnis gegenüber den Gerichtsbehörden und der Staatsanwaltschaft» hat.

[34] Bewusst verzichtet hat man im Rahmen der Justizreform 2011 auf die Einführung von Instrumenten, die als heikel gelten (z.B. Abschluss einer Leistungsvereinbarung zwischen Gerichtsbehörden und Grossem Rat oder Regierungsrat). ${ }^{18}$

[35] Für die erwähnten Instrumente gilt generell: Sie dürfen von der Justizleitung (bzw. der Stabsstelle) nur eingesetzt werden, um die gesetzlich übertragenen Aufgaben zu erfüllen. Dabei handelt es sich, wie gesehen, durchweg um Aufgaben der Selbstverwaltung, nicht um Aufgaben im Bereich der Rechtsprechungs- oder der Strafverfolgungstätigkeit (die aufgrund von spezifischen Unabhängigkeitsgarantien gegen Fremdeinwirkungen abzuschirmen sind; vgl. Ziffer VI.).

\section{Organisation der Justizleitung sowie Verfahren der Beschlussfassung}

[36] Das Gesetz überträgt die Regelung der Organisation im Einzelnen sowie die Regelung des internen Entscheidverfahrens - im Sinne der Selbstverwaltung - der Justizleitung (Art. 17 Abs. 3 GSOG: «Sie regelt ihre Organisation und das Verfahren der Entscheidfällung durch Reglement.»). [37] Das Justizleitungs-Reglement befasst sich mit der Wahl und den Aufgaben des Vorsitzenden der Justizleitung (Art. 11 JLR), mit der Stellvertretung (Art. 12 JLR) sowie mit der Beschlussfassung im Rahmen der - ausdrücklich als nicht öffentlich bezeichneten - Sitzungen (Art. 13 JLR) und im Rahmen des - ausnahmsweise zulässigen - Zirkulationsverfahrens (Art. 16 Abs. 3 JLR).

[38] Etwas ungewöhnlich ist, dass die Justizleitung ihren Sitz selbst bestimmt (Art. 3 JLR). Im Rahmen der hier zu untersuchenden Fragen (insb. Gewaltenteilung, Unabhängigkeit der Justiz) bedarf diese Besonderheit keiner weiteren Vertiefung. Eher ungewöhnlich, aber grundsätzlich zulässig, ist auch, dass das Reglement (und nicht schon das Gesetz) festlegt, dass die Justizleitung ihre Beschlüsse einstimmig fasst (Art. 16 Abs. 1 JLR), dies in Anwesenheit aller drei Mitglieder bzw. der jeweiligen Stellvertretung (Art. 16 Abs. 2 JLR). Auf die praktische Bedeutung und Tragweite der Einstimmigkeitsregel wird zurückzukommen sein (vgl. Ziffer VI.6.d).

[39] Der Justizleitung ist eine Stabsstelle für Ressourcen beigegeben (Art. 19 GSOG; vgl. auch Art. 20 ff. JLR). Diese besorgt die Personaladministration, das Finanz- und Rechnungswesen sowie das Informatikwesen für die Gerichtsbehörden und die Staatsanwaltschaft in Zusammenarbeit mit den dortigen Ressourcenverantwortlichen. Der Leiter oder die Leiterin der Stabsstelle für Ressourcen nimmt mit beratender Stimme an den Sitzungen der Justizleitung teil. Auf die organisatorischen Regelungen betreffend die Stabsstelle für Ressourcen braucht hier nicht näher eingegangen zu werden. ${ }^{19}$

18 Verzichtet wurde auch darauf, von den Gerichten die Einhaltung der Grundsätze der Wirkungsorientierung oder der Erlösorientierung (gemäss NEF) zu verlangen. Vgl. Regierungsrat, Vortrag «Justizreform II», Ziff. 3.5.4.2, wonach solche «Vorgaben seitens der ersten oder der zweiten Gewalt [... ] die Gewaltenteilung verletzen [würden]».

19 Gemäss Art. 22 Abs. 3 JLR regelt die Leiterin oder der Leiter der Stabsstelle für Ressourcen die Organisation und die Abläufe in einer Geschäftsordnung. 


\section{Verhältnis zu anderen Organen}

[40] Die Justizleitung ist gemäss Art. 18 Abs. 1 Bst. a GSOG «Ansprechpartnerin des Grossen Rates und des Regierungsrates bei allen Fragen, die sowohl die Gerichtsbehörden als auch die Staatsanwaltschaft betreffen». Die Justizleitung soll gemäss Art. 2 JLR «die Gerichtsbehörden und die Staatsanwaltschaft (Justiz) gegen aussen» vertreten. Was dies im Einzelnen bedeutet, kommt in verschiedenen Gesetzes- und Reglementsbestimmungen zum Ausdruck (worauf hier nicht im Detail einzugehen ist).

[41] Im Verhältnis zum Grossen Rat gehört es zu den Aufgaben und Befugnissen der Justizleitung, den Voranschlag, den Aufgaben- und Finanzplan, den Geschäftsbericht und den Tätigkeitsbericht zu vertreten und entsprechende Anträge zu stellen. Bei Sitzungen der ständigen Kommissionen kann sich die Vertretung der Justizleitung durch Sachverständige begleiten lassen (Art. 17 Abs. 4 GSOG). Mit Zustimmung der Justizkommission des Grossen Rates kann die Justizleitung nachkreditpflichtige Abweichungen der im Voranschlag beschlossenen Saldi bewilligen, wenn diese eine Million Franken pro Produktgruppe nicht übersteigen (Art. 18 Abs. 1 Bst. h GSOG), sowie im Dringlichkeitsfall bereits vor der Bewilligung eines Nachkredits Verpflichtungen eingehen (Art. 18 Abs. 1 Bst. i GSOG). Einschlägig sind auch diverse Bestimmungen des Grossratsgesetzes (vgl. insb. Art. 40, 48, 60, 61, 64 ff. GRG).

[42] In Konkretisierung von Art. 78 KV legt Art. 13 GSOG fest, dass (auch) die Justizleitung unter der Oberaufsicht des Grossen Rates steht (so wie gemäss Art. 13 GSOG auch das Obergericht, das Verwaltungsgericht und die Generalstaatsanwaltschaft). Aus der entsprechenden (und in dieser Hinsicht präziseren) Bestimmung des Grossratsgesetzes (Art. 4 GRG) geht hervor, dass sich die Oberaufsicht auf die Geschäftsführung der Justizleitung bezieht (Abs. 1) und dass dabei der Grundsatz der Gewaltenteilung zu respektieren ist (Abs. 4). Die parlamentarische Oberaufsicht erstreckt sich auf sämtliche Handlungen und Unterlassungen der Justizleitung (Abs. 3), umfasst aber nicht die Befugnis, anstelle des beaufsichtigten Organs zu handeln, Entscheide zu ändern oder aufzuheben (Abs. 4).

[43] Was das Verhältnis zum Regierungsrat betrifft, bestimmt Art. 11 Abs. 5 GSOG, dass Letzterer den durch die Justizleitung erarbeiteten Voranschlag und den Aufgaben- und Finanzplan unverändert in den Voranschlag und in den Aufgaben- und Finanzplan des Kantons zu übernehmen hat. Die Verordnung über das Vernehmlassungs- und das Mitberichtsverfahren (VMV; BSG 152.025) vom 26. Juni 1996 regelt den Einbezug der Justizleitung (Art. 3b VMV). ${ }^{20}$

[44] Was das Verhältnis zu den zuständigen Direktionen der Verwaltung betrifft, legt Art. 6 Abs. 2 GSOG fest, dass die Justizleitung den Bedarf der Gerichtsbehörden und der Staatsanwaltschaft im Bereich der Infrastruktur frühzeitig bei der zuständigen Direktion anzumelden hat. Für die Bereitstellung, die Bewirtschaftung und den Unterhalt der benötigten Grundstücke und Gebäude sowie Informatik- und Kommunikationssysteme - alles Aufgaben der Justizverwaltung - sind die zuständigen Direktionen der kantonalen Verwaltung verantwortlich (Art. 6 Abs. 1 GSOG). Der Justizleitung obliegt es, in Zusammenarbeit mit den zuständigen Stellen der Polizei- und Militärdirektion und der Bau-, Verkehrs- und Energiedirektion den Erlass von strategischen Leitlinien auf dem Gebiet der Sicherheit zu koordinieren (Art. 18 Abs. 1 Bst. 1 GSOG). Das Gesetz sieht überdies vor, dass die Gerichtsbehörden und die Staatsanwaltschaft im Rahmen der Selbstverwaltung mit den zuständigen Direktionen vereinbaren können, dass diese Verwaltungsaufgaben (insb. in den

20 Vgl. auch Art. 25a VMV (Vertraulichkeit der Stellungnahmen der Justizleitung). 
Bereichen Personaladministration sowie Finanz- und Rechnungswesen) in ihrem Auftrag erfüllen; ausgenommen sind hoheitliche Verwaltungsaufgaben, namentlich Verfügungsbefugnisse (Art. 5 Abs. 3 GSOG). Gemäss Art. 4 Abs. 1 Bst. c JLR obliegt es der Justizleitung, über die externe Erfüllung von Verwaltungsaufgaben zu beschliessen.

[45] Für das Verhältnis zu den Gerichten und zur Staatsanwaltschaft kann auf das bereits Ausgeführte verwiesen werden (vgl. Ziffer II.3.). Ergänzend sei erwähnt, dass das Gesetz dem Plenum bzw. der Geschäftsleitung von Obergericht und Verwaltungsgericht die Verabschiedung bestimmter Geschäfte (z.B. Voranschlag, Aufgaben und Finanzplan, Geschäftsbericht) «zuhanden der Justizleitung» auferlegt (vgl. z.B. Art. 38 Abs. 2 Bst. h, Art. 39 Abs. 2 Bst. a, Art. 51 Abs. 2 Bst. g GSOG). Gestützt auf Art. 12 GSOG erlassen das Obergericht, das Verwaltungsgericht und die Staatsanwaltschaft ihre Organisationsreglemente für den Bereich der Geschäftsführung jeweils selbstständig; eine Genehmigung oder sonstige Mitwirkung seitens der Justizleitung ist nicht vorgesehen.

\section{Zwischenergebnis: Charakterisierung der Justizleitung}

\section{a. $\quad$ Ein Organ der justiziellen Selbstverwaltung}

[46] Zusammenfassend ist festzuhalten, dass die Justizleitung ein Organ der justiziellen Selbstverwaltung ist. ${ }^{21}$ Bei den Aufgaben geht es im Kern um Angelegenheiten der hergebrachten Justizverwaltung, die als nicht rechtsprechungsnah einzustufen sind (Finanz- und Rechnungswesen, Logistik, Personalwesen). Die Wahrnehmung der Aufgaben, die der Justizleitung übertragen sind, hat keinen direkten Einfluss auf die (durch Verfassung und EMRK spezifisch geschützte) Rechtsprechungstätigkeit oder auf die (ebenfalls in spezifischer Unabhängigkeit wahrzunehmende) Strafverfolgungstätigkeit der Staatsanwaltschaft.

\section{b. Ein Selbstverwaltungsorgan mit begrenztem Aufgabenbereich}

[47] Weiter ist festzuhalten, dass die Justizleitung ein Selbstverwaltungsorgan mit begrenztem Aufgabenbereich ist. Sie ist weit davon entfernt, eine «Regierung der Justiz» zu sein. ${ }^{22}$ Selbstverwaltungsaufgaben verbleiben in erheblichem Umfang bei den einzelnen Gerichtsbehörden bzw. der Staatsanwaltschaft. Bestimmte Aufgaben der Justizverwaltung (wie die Bereitstellung, die Bewirtschaftung und den Unterhalt der benötigten Grundstücke und Gebäude) obliegen von Gesetzes wegen (weiterhin) den zuständigen Direktionen der kantonalen Verwaltung (Art. 6 Abs. 1 GSOG). Auch besteht die Möglichkeit, die Wahrnehmung weiterer Aufgaben der Justizverwaltung der Zentralverwaltung zuzuweisen (vgl. z.B. Art. 5 Abs. 3 GSOG).

\section{c. Ein Organ mit, aus schweizerischer Sicht, besonderer Zusammensetzung}

[48] In organisatorischer Hinsicht reicht das Aufgabenfeld der Justizleitung - infolge des Einbezugs der Staatsanwaltschaft - über den Bereich der gerichtlichen Behörden hinaus. Im binnen-

21 Vgl. auch HurNi, Rz. 3 («Selbstverwaltungsorgan»).

22 So aber Keel, 229, unter Bezugnahme auf Lienhard/Kettiger, Selbstverwaltung, Rz. 87. 
schweizerischen Rechtsvergleich stellt diese Ausgestaltung der Selbstverwaltung im Justizbereich eine Besonderheit dar. ${ }^{23}$

[49] Im europäischen Rechtsvergleich allerdings ist es nicht ungewöhnlich, dass im Bereich der Selbstverwaltung Gerichte und Strafverfolgungsbehörden unter einem organisatorischen Dach zusammengefasst werden. So besteht zum Beispiel in Italien von Verfassungsrechts wegen (Art. 104 ital. Verf.) ein Oberster Justizrat (Consiglio superiore della magistratura) als Selbstverwaltungsorgan der Justiz unter Einschluss der Staatsanwaltschaft (pubblico ministero). Der Oberste Justizrat ist zuständig für Einstellungen, Zuteilungen, Versetzungen, Beförderungen und Disziplinarmassnahmen hinsichtlich der zur Magistratur gehörenden Amtsträger (Art. 105 ital. Verf.). Der formelle Vorsitz obliegt dem Präsidenten der Republik. Dem Obersten Justizrat gehören von Amtes wegen der Präsident des Kassationsgerichts und der Generalstaatsanwalt (procuratore generale) beim Kassationsgericht sowie 24 gewählte Mitglieder an, wovon sechzehn aus dem Kreis der Magistratur (Richter und Staatsanwälte) sowie acht Externe (membri laici). ${ }^{24}$ Auch in weiteren europäischen Staaten gibt es «gemischte» Selbstverwaltungsorgane mit Zuständigkeiten für die Gerichte und die Staatsanwaltschaft. ${ }^{25}$

\section{d. Ein Kollegialorgan mit drei gleichberechtigten Mitgliedern}

[50] Die Justizleitung des Kantons Bern ist, in organisatorischer Hinsicht, als Kollegialorgan ausgestaltet mit drei gleichberechtigten Mitgliedern, die dem Selbstverwaltungsorgan von Amtes wegen angehören. Die drei Mitglieder der Justizleitung nehmen ihr Amt nebenamtlich wahr. Sie verbleiben hauptamtlich an der Spitze des Obergerichts, des Verwaltungsgerichts bzw. der Staatsanwaltschaft. Diese Doppelrolle kann - wie man dies aus vergleichbaren Doppelrollen-Konstellationen kennt - zu Spannungen führen.

\section{e. $\quad$ Ein Organ, dessen Mitglieder dem Gesamtinteresse verpflichtet sind}

[51] Bei der Bewältigung allfälliger Spannungen ist zu beachten, dass es sich bei der Justizleitung nach dem Konzept, das dem GSOG zugrunde liegt, um ein eigenständiges Organ mit eigenen Aufgaben und Befugnissen handelt. Die Mitglieder der Justizleitung sind nicht «Delegierte» der «entsendenden» Behörde, sondern nehmen ein zusätzliches, eigenständiges (Neben-)Amt wahr. Als Träger dieses zusätzlichen Amts sind die drei Amtsträger dem Gesamtinteresse (Gemeinwohl) verpflichtet. Die einzelnen Mitglieder der Justizleitung haben daher bei der Aufgabenerfüllung jeweils die Interessen des gesamten Justizsystems - Gerichtsbehörden und Staatsanwaltschaft - zu wahren. Mit anderen Worten: Sie nehmen ihr (Neben-)Amt nicht als «Interessenvertreter» der sie «entsendenden» Behörde wahr. Die Mitglieder der Justizleitung dürfen dementsprechend bei der Ausübung ihres Amts nicht einfach nur die spezifischen (partikularen) Interessen der «entsen-

23 Vgl. Keel, 326; Lienhard/Kettiger, Selbstverwaltung, Rz. 84 ff.

24 Näher dazu z.B. Roberto Bin/Giovanni Pitruzzella, Diritto costituzionale, 20. Aufl., Torino 2019, 311 ff., sowie die Kommentierungen zu den einschlägigen Verfassungsbestimmungen in: Francesco Clementi et al. (Hrsg.), La Costituzione italiana, Commento articolo per articolo, Vol. II, Bologna 2018, 255 ff. (Titolo IV: La magistratura, Art. 101 ff.).

25 Hinweise z.B. in: Venice Commission, Compilation of Venice Commission Opinions and Reports concerning Courts and Judges, CDL-PI(2019)008, Ziff. V.; Venice Commission, Report on European Standards as Regards the Independence of the Judicial System: Part II - The Prosecution Service, CDL-AD(2010)040, Ziff. X. 
denden» Behörde vertreten. Dies ist nicht nur eine wichtige faktische Voraussetzung für das gute Funktionieren der im Rahmen der Justizreform 2011 beschlossenen Lösung ${ }^{26}$, sondern rechtlich geboten.

[52] Bei der Ermittlung des Gesamtinteresses gibt es gewöhnlich gewisse Beurteilungs- und Bewertungsspielräume, so auch hier. Nicht zulässig (amtspflichtwidrig) wäre es jedoch, bei einem bestimmten Geschäft - z.B. bei der Verabschiedung des Voranschlags zuhanden des Grossen Rats - die Zustimmung zu verweigern, bloss um die eigene («entsendende») Behörde einseitig - zulasten des Gesamtinteresses - zu fördern. Damit ist auch gesagt, dass das (auf Stufe JustizleitungsReglement festgelegte) Einstimmigkeitsprinzip nicht dazu missbraucht werden darf, Beschlüsse der Justizleitung aus «eigennützigen» Motiven, d.h. im blossen Interesse der «entsendenden» Behörde zu blockieren.

\section{Exkurs: Zum Sprachgebrauch im (rechts)politischen Reformdiskurs}

[53] In amtlichen Dokumenten und sonstigen Beiträgen zur Reformdiskussion findet sich für die im Rahmen der Justizreform 2011 geschaffene Justizleitung eine Vielzahl von Charakterisierungen. So ist die Rede von einem «Koordinationsorgan», «Entscheidungsgremium» oder «Führungsorgan», das mit der «Interessenwahrung», «Steuerung», «Führung» im Bereich der Justiz betraut sei. ${ }^{27}$ Die Begrifflichkeit mag aus der Perspektive der Reformdiskussion verständlich sein. Aus etwas grösserer Distanz betrachtet, zeigt sich, dass die verwendeten Begriffe geeignet sind, Missverständnisse hervorzurufen. Dies wird deutlich, wenn man sich den Aufgabenbereich der Justizleitung vor Augen führt.

- Von der Art der wahrzunehmenden Aufgaben her ist der im Namen des Selbstverwaltungsorgans enthaltene Begriff «Leitung» zutreffend, denn in ihrem Zuständigkeitsbereich nimmt die Justizleitung in der Tat gewisse leitende Funktionen wahr. Der Begriff ist jedoch insofern nicht ganz glücklich gewählt, weil der Eindruck entstehen kann, dass die Justizleitung über umfassende Leitungsbefugnisse im Bereich der Justiz (inkl. Staatsanwaltschaft) verfüge, was, wie gesehen (Ziffer II.1.-6), nicht zutrifft. ${ }^{28}$ Die Aufgaben und damit auch die Leitungsbefugnisse der Justizleitung sind auf bestimmte Aspekte der Selbstverwaltung beschränkt; sie umfassen bei weitem nicht alle Aufgaben im Bereich der Justizverwaltung.

- Problematisch ist es auch, wenn - ohne nähere Erläuterung und Präzisierung - von «Steuerung» oder «Führung» bzw. von einem «Steuerungsorgan» oder «Führungsorgan» gesprochen wird. Wiederum mag die Verwendung solcher Begriffe im engeren Fachdiskurs zweckmässig sein. Im allgemeinen politischen Diskurs erscheint die Begriffsverwendung hingegen heikel, weil dadurch bei mit dem Kontext nicht näher vertrauten Personen (Bürgerinnen und Bürger bzw. Stimmberechtigte) der Eindruck entstehen kann, dass es sich bei der Justizleitung um ein Organ handle, das im gesamten Justizbereich - unter Einschluss der

26 Dazu Regierungsrat, Vortrag «Justizreform II», Ziff. 3.5.2.

27 Auf Einzelbelege wird hier verzichtet.

28 In diese Richtung Ecoplan/Wenger Plattner, Evaluation «Justizreform II», S. 85: «Die Justizleitung ist gesetzlich als Koordinations- und nicht als Entscheidgremium ausgestaltet». 
Strafverfolgung - «nach dem Rechten schauen» und gegebenenfalls «durchgreifen» kann. Die Entstehung solcher Missverständnisse sollte man tunlichst vermeiden.

- Ähnliches gilt mit Blick auf die Bezeichnung der Justizleitung als «Gesicht der Justiz». Diese Bezeichnung mag aus der Perspektive der politischen Behörden (Grosser Rat, Regierungsrat) stimmig sein. Aus Sicht der Bürgerinnen und Bürger ist sie es wohl nicht.

- Missverständnisträchtig ist schliesslich die Verwendung des Begriffs «Veto(recht)» im Zusammenhang mit dem Einstimmigkeitsprinzip bei der Beschlussfassung in der Justizleitung (siehe vorne Ziffer II.4. sowie hinten Ziffer VI.6.). Der Begriff erweckt den (falschen) Eindruck, dass ein Mitglied der Justizleitung seine Zustimmung zu einem Beschluss nach Belieben - z.B. aus rein «eigennützigen» Motiven bzw. im blossen Interesse der «entsendenden» Behörde - verweigern und auf diese Weise die Entscheidfindung bei bestimmten Geschäften blockieren kann. Das trifft nicht zu (vgl. vorne Ziffer II.4.). Die Mitglieder der Justizleitung sind dem Gesamtinteresse verpflichtet und haben ihr Stimmrecht entsprechend auszuüben (vgl. auch hinten Ziffer VI.6.d.).

\section{Ausblick: Die Justizleitung in der Vernehmlassungsvorlage 2019}

[54] Die im Rahmen der Vernehmlassungsvorlage 2019 angestrebten Neuerungen im Bereich der Justizleitung sollen in erster Linie Kongruenz innerhalb der Rechtsordnung schaffen - insbesondere durch Nachführung der Kantonsverfassung im Sinne der Justizreform 2011 (Gesetzesstufe) - sowie die institutionelle Stellung der Justiz klären und die bestehenden Rechtsgrundlagen präzisieren (Beseitigung gewisser Rechtsunsicherheiten). Dazu gehören Einzelpunkte wie: ${ }^{29}$

- Bekräftigung der Selbstverwaltungsbefugnisse der Justiz in der Kantonsverfassung (Budgetantragsrecht, Ausgabenbefugnisse);

- verfassungsrechtliche Verankerung der Justizleitung als gemeinsames (Selbstverwaltungs-) Organ von Obergericht, Verwaltungsgericht und Generalstaatsanwaltschaft;

- Regelung der Befugnisse der Justizleitung im Verhältnis zum Grossen Rat in Anlehnung an die Regelungsstruktur, wie sie in Art. $83 \mathrm{KV}$ mit Blick auf die «Stellung des Regierungsrates im Grossen Rat» vorgezeichnet ist;

- Beseitigung von Unklarheiten im Zusammenwirken der Staatsgewalten (Geschäftsverkehr der Justizleitung mit Parlament und Regierung);

- Regelung des Vorgehens bei Kreditanträgen, welche die Ausgabenbefugnisse der Justiz übersteigen (GSOG), sowie Klarstellung der Vorgaben betreffend Ausgabenbewilligungen (FLG);

- Präzisierung des Vertretungsrechts der Justizleitung im Grossen Rat (Teilnahme- und Äusserungsrecht);

- Verzicht auf die Möglichkeit, Postulate an die Justizleitung zu richten;

- Präzisierungen und terminologische Anpassungen im Gesetz.

29 Vgl. Vernehmlassungsentwurf «Vortrag Justizverfassung», Ziff. 3.A. 
[55] Auf Verfassungsstufe steht E-Art. 97a KV im Zentrum. Dort soll die Justizleitung als gemeinsames Organ von Obergericht, Verwaltungsgericht und Generalstaatsanwaltschaft verankert werden. Die Festlegung von Zusammensetzung und Zuständigkeiten der Justizleitung wird dem Gesetzgeber überantwortet (näher hinten Ziff. VII.).

[56] Weiter sollen in der Kantonsverfassung festgehalten werden:

- die Stellung der Justizleitung im Grossen Rat (E-Art. 83a KV: Antragsrecht, beratende Stimme),

- die Aufsicht über die Justizleitung (E-Art. 78 Abs. 1 Bst. b KV) sowie

- die Finanzbefugnisse der Justizleitung (E-Art. 97b KV; vgl. auch E-Art. 76 Abs. 1 Bst. e KV).

[57] Neu soll auch die Staatsanwaltschaft in der Kantonsverfassung verankert werden (vgl. insb. E-Art. 97 und E-Art. 100a KV).

[58] Die im Rahmen der Vernehmlassungsvorlage 2019 vorgeschlagenen Neuerungen bewirken vor allem eine Änderung hinsichtlich des rechtlichen Fundaments der Justizleitung (Regelungsstufe: Kantonsverfassung). Am Charakter der Justizleitung als einem gemeinsamen Organ der Justiz(selbst)verwaltung ändert die geplante Reform nichts.

\section{Anlässlich der Reformprojekte geäusserte (verfassungs)rechtliche Be- denken betreffend die Justizleitung}

[59] Bevor die geltende gesetzliche Regelung (Justizreform 2011) sowie die im Rahmen der Vernehmlassungsvorlage 2019 vorgeschlagene Verankerung der Justizleitung in der Kantonsverfassung auf ihre Vereinbarkeit mit dem übergeordneten Recht überprüft werden (Ziffern V.-VII.), soll hier kurz und ohne Anspruch auf Vollständigkeit dargelegt werden, welche (verfassungs)recht-

lichen Bedenken gegen die Ausgestaltung der Justizleitung als gemeinsames Organ von Obergericht, Verwaltungsgericht und Generalstaatsanwaltschaft bisher vorgebracht wurden. Nicht einzugehen ist hier auf praktische und (rechts)politische Bedenken gegen den gewählten Lösungsansatz (Praktikabilität, Wünschbarkeit der Regelung usw.).

\section{Im Rahmen des Projekts «Justizreform 2011»}

[60] Im Rahmen der Gesetzgebungsarbeiten an der Justizreform 2011 hatten verschiedene Vernehmlassungsteilnehmer die Frage aufgeworfen, ob die geplante Schaffung einer Justizleitung mit verbindlichen Entscheidkompetenzen durch den bernischen Gesetzgeber vor der Verfassung standhalte.

[61] Der Regierungsrat legte damals dar, dass die bernische Kantonsverfassung keine Regelung betreffend die Kompetenzen der Gerichte auf dem Gebiet der Gerichtsverwaltung (Finanz- und Haushaltführung, Logistik, Personalbefugnisse usw.) enthalte. Dem Gesetzgeber sei es ohne vorherige Verfassungsänderung erlaubt, für die Besorgung von administrativen Belangen eine gemeinsame, den Gerichten übergeordnete Institution zu schaffen, solange eine solche Institution keine Rechtsprechungsfunktionen wahrnehme. Der bernische Verfassungsgeber habe sich im Üb- 
rigen zur im Schrifttum kontrovers diskutierten Frage, ob die Staatsanwaltschaft zur Exekutive oder zur Judikative gehöre, nicht geäussert. Der Gesetzgeber habe die Staatsanwaltschaft in die Nähe der Justiz gerückt. Die Nähe zu den Gerichten ergebe sich nicht nur aus der Gesetzessystematik, sondern auch aus den Regeln über die Aufsicht. Vor diesem Hintergrund könne die Verfassungskonformität für eine auch die Staatsanwaltschaft einschliessende Justizleitung bejaht werden. ${ }^{30}$

\section{Im Rahmen der Vernehmlassungsvorlage 2019}

[62] Der im Rahmen der Vernehmlassungsvorlage 2019 unterbreitete Vorschlag, die Justizleitung auf der Verfassungsstufe zu verankern, stiess verschiedentlich auf Skepsis und Kritik (vgl. Ziffer V.4.). In diversen Vernehmlassungsantworten und weiteren Debattenbeiträgen wurde die Frage aufgeworfen, ob - angesichts der Zusammensetzung der Justizleitung - die institutionelle Unabhängigkeit der Gerichte gewahrt sei. ${ }^{31}$ Die vorgebrachten Sorgen bzw. Kritikpunkte lassen sich wie folgt zusammenfassen:

- Die Staatsanwaltschaft gehöre nicht zur Judikative, sondern zur Exekutive. Im Hauptverfahren vor den Strafgerichten, auch vor dem Obergericht, komme ihr Parteistellung zu. ${ }^{32}$

- Der Generalstaatsanwalt als «oberster Ankläger» und als «Vertreter [...] der Exekutive» habe als Mitglied der Justizleitung Einfluss auf die Judikative; umgekehrt habe die Justiz Einfluss auf die Staatsanwaltschaft. ${ }^{33}$

- Aufgrund des Einstimmigkeitsprinzips verfüge die Generalstaatsanwaltschaft in der Justizleitung über ein eigentliches «Vetorecht». ${ }^{34}$

- Es bestehe die Gefahr eines Eingriffs seitens der Justizleitung in betriebliche Abläufe der Justiz, z.B. aufgrund von Weisungen in Personal- oder Informatikangelegenheiten. ${ }^{35}$

- Aufgrund der Zusammensetzung der Justizleitung entstehe der Anschein einer Beeinträchtigung der Unabhängigkeit der Gerichte, worunter das Vertrauen in die Justiz leide. ${ }^{36}$

[63] Bei der Durchsicht der Argumente fällt auf, dass sich die Skepsis bzw. Kritik nicht auf konkrete Vorfälle oder Konflikte bezieht (obwohl die organisatorischen Strukturen inzwischen seit mehr als neun Jahren bestehen). Die geäusserten Bedenken sind insoweit genereller bzw. theoretischer Natur.

30 Vgl. Regierungsrat, Vortrag «Justizreform II», Ziff. 3.5.3 («Verfassungsrechtliche Fragen im Zusammenhang mit der Justizleitung»).

31 Z.B. Vernehmlassungsantwort SP Kanton Bern (vom 18. Juni 2019); Vernehmlassungsantwort Bernischer Anwaltsverband BAV AAB (vom 20. Juni 2019); HurnI, Rz. 17 ff. Vgl. auch Vernehmlassungsantwort SVP Kanton Bern (vom 21. Juni 2019).

32 Vgl. z.B. HurNi, Rz. 7 ff. (m.w.H.), Rz. 17. Vgl. auch Vernehmlassungsantwort GLP Kanton Bern (vom 20. Juni 2019); Vernehmlassungsantwort Demokratische Juristinnen und Juristen Bern (vom 21. Juni 2019); Vernehmlassung des Obergerichts (vom 3. Juni 2019).

33 Hurni, Rz. 17. Vgl. auch Vernehmlassungsantwort GLP Kanton Bern (vom 20. Juni 2019).

34 Vgl. Hurni, Rz. 18 f. Vgl. auch Vernehmlassung des Obergerichts (vom 3. Juni 2019).

35 Vgl. HurNi, Rz. 15 und $18 \mathrm{f}$.

36 Vgl. HurNi, Rz. 15 f. und 19. Vgl. auch Vernehmlassungsantwort Demokratische Juristinnen und Juristen Bern (vom 21. Juni 2019). 


\section{3. $\quad$ Einordnung der geäusserten Bedenken und Zwischenfazit}

[64] Im Zusammenhang mit der vorliegenden Untersuchung interessieren jene in Vernehmlassungsantworten und weiteren Debattenbeiträgen vorgebrachten Argumente, die auf einen möglichen Konflikt mit einschlägigen Vorgaben des übergeordneten Rechts verweisen. Vor diesem (verfassungs)rechtlichen Hintergrund lassen sich die geäusserten Bedenken wie folgt gruppieren:

[65] Gewaltenteilungsargumente:

- staatsrechtliche Stellung der Staatsanwaltschaft;

- Vermischung von Staatsfunktionen.

[66] Argumente mit Bezug zur Garantie der richterlichen Unabhängigkeit:

- Gefährdung der Unabhängigkeit im Zusammenhang mit den Aufgaben und Befugnissen der Justizleitung (insb. Rolle im Budgetprozess, Weisungsbefugnisse) bzw. im Zusammenhang mit der Ausgestaltung des Entscheidverfahrens («Vetorecht» der Generalstaatsanwaltschaft);

- äusserer Anschein einer Beeinträchtigung der Unabhängigkeit.

[67] Die nachfolgende Untersuchung wird sich an dieser Einteilung orientieren.

\section{Allgemeine Bemerkungen zum Beurteilungsmassstab}

\section{Die im Zentrum stehenden rechtlichen Vorgaben}

[68] Bei der Beurteilung der Rechtmässigkeit der bernischen Justizleitung in ihrer aktuellen gesetzlichen Ausgestaltung (Fragestellung 1) und bei der Beurteilung der Rechtmässigkeit der geplanten Verankerung der Justizleitung auf Verfassungsstufe (Fragestellung 2) stellen sich im Wesentlichen dieselben Rechtsfragen. Im Zentrum stehen die folgenden rechtlichen Vorgaben: Bundesverfassung: ${ }^{37}$

- Grundsatz der Gewaltenteilung (enthalten in Art. 51 BV),

- Grundsatz der richterlichen Unabhängigkeit (Art. 191c BV),

- Anspruch auf ein unabhängiges und unparteiisches Gericht (Art. 30 BV).

37 Zum übergeordneten Recht gehört nicht nur die Bundesverfassung, sondern auch das übrige Bundesrecht (Bundesgesetze, Verordnungen usw.). Konflikte mit der Bundesgesetzgebung werden allerdings nicht geltend gemacht und sind auch nicht ersichtlich. Es kann hier davon abgesehen werden, die Vereinbarkeit mit der Bundesgesetzgebung näher zu prüfen. 
EMRK: ${ }^{38}$

- Anspruch auf ein unabhängiges und unparteiisches Gericht (Art. 6 Ziffer 1 EMRK).

Kantonsverfassung:

- Grundsatz der Gewaltenteilung (Art. 66 Abs. $1 \mathrm{KV}$ ),

- Garantie der Unabhängigkeit der Richterinnen und Richter (Art. 26 Abs. $1 \mathrm{KV}$ ) bzw. der Gerichte (Art. 97 Abs. 1 KV).

[69] Die Verfassungsgarantie der richterlichen Unabhängigkeit steht in einem engen sachlichen Zusammenhang mit dem Grundsatz der Gewaltenteilung (Ziffer V.). Sie weist indes auch eigenständige Gehalte auf und kennt eine ausdifferenzierte eigene Dogmatik. Es empfiehlt sich daher, die Vereinbarkeit mit der Verfassungsgarantie der richterlichen Unabhängigkeit in einem separaten Schritt zu untersuchen (Ziffer VI.).

\section{Charakterisierung der Überprüfung}

[70] Die Beurteilung der Rechtmässigkeit erfolgt sowohl bei der Fragestellung 1 (Beurteilung des geltenden Rechts) als auch bei der Fragestellung 2 (Beurteilung der vorgeschlagenen Regelung) nicht aus Anlass eines Einzelfalls, sondern losgelöst von einem konkreten Konflikt, d.h. «abstrakt». Diese Ausgangslage ähnelt der Konstellation, mit der sich Gerichte (z.B. das Bundesgericht) im Rahmen einer abstrakten Normenkontrolle konfrontiert sehen.

[71] Eine solche abstrakte Überprüfung zeigt gewisse Eigenheiten. In den Worten des Bundesgerichts (Verweise entfernt):

«Steht die Verfassungsmässigkeit eines Erlasses in Frage, so ist im Rahmen der abstrakten Normenkontrolle massgebend, ob der betreffenden Norm nach anerkannten Auslegungsregeln ein Sinn beigemessen werden kann, der sie mit den angerufenen Verfassungsgarantien vereinbar erscheinen lässt. Das Bundesgericht hebt eine kantonale Norm nur auf, wenn sie sich jeder verfassungskonformen Auslegung entzieht, nicht jedoch, wenn sie einer solchen in vertretbarer Weise zugänglich ist [...]. Bei der abstrakten Normenkontrolle mitzuberücksichtigen bleiben die Schwere eines allfälligen Grundrechtseingriffs, die konkreten Umstände bei der Anwendung der angefochtenen Norm, die Möglichkeit eines hinreichenden verfassungsrechtlichen Schutzes im konkreten Anwendungsfall sowie allfällige Auswirkungen auf die Rechtssicherheit [...]. Zudem ist die Möglichkeit einer verfassungskonformen Auslegung nicht nur abstrakt zu untersuchen; die Wahrscheinlichkeit einer verfassungstreuen Anwendung der angefochtenen Norm ist in die Beurteilung mit einzubeziehen [...]. Der blosse Umstand, dass die Anwendung der angefochtenen Norm in besonders gelagerten Ein-

38 Die richterliche Unabhängigkeit ist auch Gegenstand weiterer völkerrechtlicher Verträge (z.B. Art. 14 UNO-Pakt II). Diese Garantien weisen in der vorliegenden Konstellation neben Art. 6 EMRK, soweit ersichtlich, keine eigenständige praktische Bedeutung auf (vgl. auch KIENER, Richterliche Unabhängigkeit, 42). Es kann hier darauf verzichtet werden, die Vereinbarkeit mit diesen weiteren völkerrechtlichen Garantien näher zu prüfen. 
zelfällen zu einem verfassungswidrigen Ergebnis führen könnte, rechtfertigt für sich alleine im Verfahren der abstrakten Normenkontrolle indes noch kein höchstrichterliches Eingreifen». (BGE 143 I 137 E. 2.2 S. 139).

«Bei der verfassungskonformen Auslegung dürfen auch die Erklärungen der kantonalen Behörden über die beabsichtigte künftige Anwendung der Vorschrift berücksichtigt werden» (BGE 144 I 1 E. 3.1.1 S. 6).

[72] Bei der abstrakten Beurteilung der Rechtmässigkeit einer Rechtsnorm darf gewöhnlich (so auch hier) davon ausgegangen werden, dass sich die für die Umsetzung und Anwendung zuständigen Behörden bzw. Amtsträger rechtskonform verhalten werden.

[73] Die folgende abstrakte Überprüfung der geltenden und der geplanten Regelung wird sich zweckmässigerweise an diesen allgemeinen Leitlinien orientieren.

\section{Beurteilung der Justizleitung gemäss geltender Rechtslage (Justiz- reform 2011) unter dem Aspekt der Gewaltenteilung}

\section{Gewaltenteilung in Theorie und Praxis}

[74] Die Gewaltenteilung als fundamentales Organisationsprinzip des modernen Verfassungsstaats zielt darauf ab, mittels Machtbegrenzung und Kontrolle Machtmissbrauch zu verhindern und Freiheit zu sichern. Zu diesem Zweck wird die staatliche Macht auf eine Mehrzahl von Organen aufgeteilt, die einander wechselseitig kontrollieren und im Zaum halten sollen. ${ }^{39}$

[75] In der Gewaltenteilungstheorie wird die Grundidee der Gewaltenteilung typischerweise mit der Lehre von den Staatsfunktionen verknüpft: Die drei hauptsächlichen Staatsfunktionen - Rechtsetzung, Vollzug und Rechtsprechung - sollen auf voneinander unabhängige Staatsorgane bzw. Organgruppen - Legislative, Exekutive, Judikative - aufgeteilt werden. Die organisatorischfunktionelle Gewaltenteilung wird zudem mit der personellen (subjektiven) Gewaltentrennung verknüpft, wonach eine Person nicht mehreren Gewalten angehören soll. Jeder Organgruppe ist in diesem Idealschema eine Stammfunktion zugedacht.

[76] Sowohl die Verfassungsordnung des Bundes als auch die Verfassungsordnungen der Kantone sind dem Grundsatz der Gewaltenteilung verpflichtet (für den Kanton Bern ausdrücklich Art. 66 $\mathrm{KV}$ ). In der schweizerischen Staatspraxis wird das theoretische Gewaltenteilungsschema allerdings nirgends mit letzter Konsequenz verwirklicht, dies aus guten Gründen..$^{40}$ Einmal wäre eine rigorose Umsetzung des Idealschemas wenig ratsam, da sie die Gefahr einer Blockierung des staatlichen Entscheidungsprozesses birgt. Hinzu kommt, dass das theoretische Leitbild aus praktischen Gründen nicht vollumfänglich in die Verfassungswirklichkeit umgesetzt werden kann. Zur Veranschaulichung genügt es, darauf hinzuweisen, dass sich wichtige staatliche Tätigkeiten wie Wahlen, Haushaltführung, Planung, Aussenpolitik einer eindeutigen Zuordnung entziehen. Ein Blick in moderne Verfassungen macht rasch deutlich, dass keine der drei traditionellen Staatsgewalten auf die ihr zugedachte Stammfunktion beschränkt ist. Häufig sind die verfassungsrechtlichen

39 Vgl. dazu und zum Folgenden Biaggini, Komm. BV, N 11 ff. zu Art. 51 sowie N 2 ff. vor Art. 143; MaHON, 1011 ff.; Martenet, 999 ff. (je m.w.H.).

40 Vgl. Biaggini, in: Staatsrecht, § 17, N. 7 ff.; Seiler, 66 ff. (je m.w.H.). 
Aufgaben und Befugnisse in einer Weise verteilt, die ein Zusammenwirken von zwei (oder mehr) Staatsorganen erfordert. Entsprechend gibt es in der Verfassungsordnung des Bundes zahlreiche Besonderheiten in Gestalt von «Relativierungen», «Abweichungen» oder «Durchbrechungen» gegenüber dem Idealschema. Dies gilt auch in organisatorischer Hinsicht. Man denke etwa an die Schweizerische Nationalbank (SNB), die Eidgenössische Finanzkontrolle (EFK), die Unabhängige Beschwerdeinstanz für Radio und Fernsehen (UBI) oder, im Bereich der Strafverfolgung, an die aus der Exekutive ausgegliederte Bundesanwaltschaft (BA) und die unabhängige Aufsichtsbehörde (ABBA). Kurz: Der Grundsatz der Gewaltenteilung verbietet es nicht a priori, Organe zu schaffen und ihnen eine Stellung zu geben, die im klassischen dreiteiligen Schema der Gewaltenteilung nicht vorkommen.

[77] Mit guten Gründen streng gehandhabt wird der Grundsatz der Gewaltenteilung im Bereich der Judikative. Grund dafür ist die spezifische Unabhängigkeitsgarantie (näher Ziffer VI.), mit der die rechtsprechende Tätigkeit der Gerichte gegen Einflussnahme von aussen abgeschirmt werden soll. ${ }^{41}$ Doch auch hier ist nicht zwingend eine durchgehende rigorose Abtrennung gefordert: Mit Blick auf die Behördenorganisation im Bereich der Gerichte verlangt der Grundsatz der Gewaltenteilung «eine spezifische Freistellung von den andere Staatsgewalten, nicht jedoch ihre grundsätzliche Separierung». ${ }^{42}$

\section{Bundesvorgaben betreffend die Ausgestaltung der Gewaltenteilung in den Kantonen (Art. 51 BV)}

[78] Vor diesem Hintergrund verwundert es nicht, dass der Bund auch bei den Vorgaben, die er den Kantonen in Sachen Gewaltenteilung macht, nicht von einem schematischen Gewaltenteilungsverständnis ausgeht.

[79] Die Bundesvorgaben resultieren in erster Linie aus Art. 51 BV. ${ }^{43}$ Gemäss Art. 51 Abs. 1 Satz 1 BV muss sich jeder Kanton «eine demokratische Verfassung» geben. Daraus leitet man in Praxis und Lehre ab, dass die kantonale Verfassung ein gewähltes Parlament vorsehen muss und den Grundsatz der Gewaltenteilung beachten muss.

[80] Den Grundsatz der Gewaltenteilung verstehen Praxis und Lehre in diesem Zusammenhang nicht schematisch, sondern im Sinne einer Leitidee, die sehr verschiedene kantonale Ausprägungen zulässt und vielfältige Relativierungen duldet. So besitzen die Kantone einen grossen Gestaltungsspielraum bei der Bestimmung ihres politischen Systems und des gegenseitigen Verhältnisses von Parlament, Regierung und Verwaltung. Die Kantone sind grundsätzlich frei, auch für die Schweiz (noch) atypische Institutionen einzurichten, so etwa einen Justizrat als unabhängige Aufsichtsbehörde über die Justiz (z.B. im Kanton Fribourg) oder einen unabhängigen Rechnungshof (z.B. im Kanton Genf).

[81] In den hier besonders interessierenden Bereichen der Justiz und der Strafverfolgung ist der Spielraum, den die Gewaltenteilungsvorgabe gemäss Art. 51 BV den Kantonen belässt, gross.

41 Dazu grundlegend EICHEnBerger, Richterliche Unabhängigkeit; KIENER, Richterliche Unabhängigkeit.

42 KIENER, Richterliche Unabhängigkeit, 30.

43 Zum Teil auch aus weiteren Bestimmungen wie Art. 5 Abs. 1 und Art. 36 Abs. 1 BV (Gesetzmässigkeitsprinzip, Delegationsgrundsätze) oder Art. 30 und Art. 191c BV (Unabhängigkeit der Justiz als Anliegen der Gewaltenteilung; dazu näher hinten Ziffer VI.). Vgl. statt vieler Auer, N. 122 ff., 586; Tschannen, § 18, N. 12. 
[82] Was die Organisation und Ausgestaltung der Justizverwaltung betrifft, lässt die Bundesvorgabe Raum für unterschiedliche, ja gegensätzliche Modelle.

- Den Kantonen ist es gestattet, Aufgaben wie das Personalwesen, das Rechnungswesen, die Bereitstellung von Infrastruktur zu wesentlichen Teilen der Exekutive zuzuweisen.

- Die Gewaltenteilungsvorgabe des Bundes gemäss Art. 51 BV lässt es umgekehrt ebenfalls zu, die Justizverwaltung im Wesentlichen den Gerichten zuzuweisen, um den Grundsatz der Selbstverwaltung in möglichst hohem Masse zu verwirklichen.

[83] Weit ist der Spielraum der Kantone auch bei der Festlegung der Stellung der Strafverfolgungsbehörden: ${ }^{4}$

- Die Gewaltenteilungsvorgabe gemäss Art. 51 BV lässt es grundsätzlich zu, dass ein Kanton die Strafverfolgungsbehörden als Teil der Exekutive versteht und organisationsrechtlich entsprechend positioniert.

- Die Kantone sind im Lichte von Art. 51 BV umgekehrt aber auch befugt, den Strafverfolgungsbehörden eine unabhängige Stellung zu geben, d.h. sie von der Exekutive zu trennen und in die Nähe der Justiz zu rücken.

- Auch eine doppelte Zuordnung bzw. Unterstellung - wie früher im Bund - erscheint unter dem Aspekt der Gewaltenteilungsvorgabe gemäss Art. 51 BV grundsätzlich zulässig (fachliche Aufsicht durch ein Organ der Justiz; administrativ-organisatorische Aufsicht durch die Exekutive).

[84] Kurz: Die Frage, ob die Staatsanwaltschaft zur Exekutive "gehört» oder nicht, lässt sich unter Gewaltenteilungsaspekten nicht abschliessend beantworten. Der Streit darüber ist müssig. Es kommt darauf an, welche Stellung der Verfassungs- bzw. Gesetzgeber ihr in der konkreten Rechtsordnung zugewiesen haben.

[85] Die hier angesprochenen Gestaltungsspielräume verschaffen den Kantonen keinen Freipass zu beliebigen Regelungen. Gewahrt werden muss insbesondere die bundesverfassungsrechtlich doppelt garantierte richterliche Unabhängigkeit (Art. 30 und Art. 191c BV; dazu Ziffer VI.). Und zu respektieren ist die grundlegende Leitidee der Gewaltenteilung, wonach - egal wie Justizverwaltung und Strafverfolgung positioniert und ausgestaltet sind - keine Behörde Macht unbegrenzt und unkontrolliert ausüben darf.

\section{Der kantonale Verfassungsgrundsatz der Gewaltenteilung (Art. 66 KV)}

[86] In der bernischen Kantonsverfassung ist der Grundsatz der Gewaltenteilung mit folgenden Worten verankert: «Die Organisation der Behörden richtet sich nach dem Grundsatz der Gewaltenteilung. Keine Behörde darf staatliche Macht unkontrolliert und unbegrenzt ausüben» (Art. 66 Abs. $1 \mathrm{KV}$ ). Diese Bestimmung verankert die Gewaltenteilung als Grundsatz, der gewisse Relativierungen und Abweichungen im Sinne eines «kooperativ-koordinierten Interdependen-

44 Vgl. Lienhard/Kettiger, Einordnung der Staatsanwaltschaft, insb. Rz. 20 ff. (m.w.H.). Vgl. auch Kiener/Cupa, 395 ff.; Mettler. 
zensystems» duldet. ${ }^{45}$ Zentrales Anliegen ist die Begrenzung staatlicher Macht: «Jede Behörde wird kontrolliert: der Grosse Rat durch das Volk (z.B. durch das Referendum), der Regierungsrat und die obersten Gerichtsbehörden durch den Grossen Rat (Art. 78), die Verwaltung [...] durch den Regierungsrat (Art. 87, 95) [... $] \gg{ }^{46}$ Der Grundsatz der Gewaltenteilung gemäss Art. 66 KV ist auch ein verfassungsmässiges Individualrecht (was für die vorliegende Untersuchung indes nicht weiter von Bedeutung sein wird, da es vorliegend nicht um Fragen der «Einklagbarkeit» des Grundsatzes geht). ${ }^{47}$

[87] In der Rechtsprechung spielt Art. 66 Abs. 1 KV, soweit ersichtlich, keine zentrale Rolle. Die Bestimmung wird in Entscheidungen des Verwaltungsgerichts gelegentlich beiläufig erwähnt, dies meist im Zusammenhang mit dem Gesetzmässigkeitsprinzip (Bestimmtheitsgebot, Delegation usw.). ${ }^{48}$ Anzeichen dafür, dass die Rechtsprechung aus Art. 66 Abs. $1 \mathrm{KV}$ eine strikte Ausrichtung der Gewaltenteilung im Sinne des theoretischen Idealschemas (vorne Ziffer 1.) verlangen würde, sind nicht ersichtlich. Der Grundsatz der Gewaltenteilung schützt «die Einhaltung der verfassungsmässigen Zuständigkeitsordnung» ${ }^{49}$, wie sie sich aus dem geltenden Recht ergibt, nicht das Idealschema. Ähnlich wie auf Bundesebene finden sich auch in der bernischen Kantonsverfassung vielfältige Verschränkungen und Relativierungen, so etwa im Zusammenhang mit der Haushaltführung und der Planung oder in Gestalt der generell vorgesehenen Möglichkeit einer Delegation von Befugnissen an andere Organe (Art. $69 \mathrm{KV}$ ), in organisatorischer Hinsicht etwa, indem für die Finanzaufsicht unabhängige Kontrollorgane vorgesehen sind (Art. $106 \mathrm{KV}$ ).

[88] Zusammenfassend darf davon ausgegangen werden, dass im Kanton Bern der Gesetzgeber nicht nur mit Blick auf die Bundesvorgaben (Art. 51 BV; siehe vorne Ziffer 2.), sondern auch mit Blick auf die Vorgaben der Kantonsverfassung in Sachen Gewaltenteilung (Art. 66 Abs. 1 KV) über einen weiten Gestaltungsspielraum verfügt, der es ihm erlaubt, vom Idealschema abzurücken. $\mathrm{Zu}$ beachten hat der Gesetzgeber, dass keine Behörde staatliche Macht unkontrolliert und unbegrenzt ausüben darf (vgl. Art. 66 Abs. 1 Satz 2 KV).

\section{Beurteilung der Kritikpunkte unter Gewaltenteilungsaspekten}

[89] Vorweg sei in Erinnerung gerufen, dass es sich bei der Justizleitung um ein Organ der justiziellen Selbstverwaltung mit begrenztem Aufgabenbereich und ohne jegliche richterliche Kompetenzen (Rechtsprechung) handelt (vgl. Ziffer. II.6.). Die Justizleitung hat keine Befugnis, auf die Rechtsprechungstätigkeit der Gerichte oder in die Strafverfolgungstätigkeit der Staatsanwaltschaft einzuwirken (weder direkt noch indirekt). Wie vorne dargelegt (vgl. Ziffer III.), stehen unter Gewaltenteilungsaspekten die folgenden Kritikpunkte im Raum: Es wird vorgebracht, dass die Staatsanwaltschaft Teil der Exekutive sei (staatsrechtliche Stellung) und dass es angesichts der Zusammensetzung der Justizleitung zu einer Vermischung von Staatsfunktionen komme.

45 So Nuspliger, in: Kälin/Bolz (Hrsg.), Handbuch, S. 149 («Gewaltenverbindungen ergänzen die Trennungen»). Vgl. auch Bolz, in: Kälin/Bolz (Hrsg.), Handbuch, N 1.c) zu Art. 66 KV, der auf die «vielfältigen Funktionsverschränkungen» hinweist.

46 Bolz, in: Kälin/Bolz (Hrsg.), Handbuch, N 1.b) zu Art. 66 KV.

47 Vgl. Bolz, in: Kälin/Bolz (Hrsg.), Handbuch, N 2. zu Art. 66 KV.

48 Vgl. z.B. Verwaltungsgericht, Urteil 100.2016.12 vom 24. Juni 2016.

49 Verwaltungsgericht, Urteil 100.2014.191 vom 21. Mai 2015, E. 5.1. 


\section{a. Missachtung der staatsrechtlichen Stellung der Staatsanwaltschaft?}

[90] Art. 51 BV schreibt den Kantonen nicht vor, die Staatsanwaltschaft als Teil der Exekutive zu konzipieren (siehe vorne Ziffer 2.). Dem Kanton Bern ist es daher, ohne die Bundesvorgaben in Sachen Gewaltenteilung zu verletzen, möglich, die Staatsanwaltschaft aus der Exekutive herauszulösen und ihr eine unabhängige Stellung zu verleihen, wie dies im geltenden Recht vorgesehen ist.

[91] Auch der Grundsatz der Gewaltenteilung gemäss der bernischen Kantonsverfassung stand und steht dieser Lösung nicht im Weg. Art. 66 Abs. 1 KV belässt dem kantonalen Gesetzgeber generell einen weiten Gestaltungsspielraum (vgl. vorne Ziffer 3.). Bei Schaffung der Kantonsverfassung waren die Staatsanwaltschaft und ihre staatsrechtliche Stellung, soweit ersichtlich, kein eingehend erörtertes Thema. ${ }^{50}$ Die Kantonsverfassung legt die Zuständigkeit für die Wahl der Generalprokuratorin oder des Generalprokurators (Generalstaatsanwalt) in die Hände des Grossen Rats (Art. 77 Abs. $1 \mathrm{KV}$ ). Die Staatsanwaltschaft als solche wird heute im Verfassungstext nicht erwähnt. Es gibt keinen Anhaltspunkt dafür, dass aus der fehlenden Erwähnung im Umkehrschluss gefolgert werden müsste, der Verfassungsgeber habe damit ein früher möglicherweise vorherrschendes Verständnis der Staatsanwaltschaft als Teil der Exekutive verfassungsrechtlich festschreiben wollen. Es gibt im Gegenteil Anzeichen dafür, dass der Verfassungsgeber die Staatsanwaltschaft als eine besondere Behörde eingestuft hat, denn in Art. 77 Abs. $1 \mathrm{KV}$, der die vom Grossen Rat zu wählenden Amtsträger auflistet, figuriert der Generalprokurator, nicht jedoch der Vorsteher einer anderen kantonalen Behörde (wenn man vom Regierungspräsidenten und vom Staatsschreiber absieht ${ }^{51}$ ). Der bernische Gesetzgeber hat denn auch im Anschluss an die Totalrevision der Kantonsverfassung die Staatsanwaltschaft in die Nähe der Justiz gerückt, indem er sie im Gesetz über die Organisation der Gerichtsbehörden (Art. 80 ff. GOG) sowie im Gesetz über das Strafverfahren (Art. 26 StrV) geregelt hat.

[92] Zusammenfassend kann man festhalten, dass Art. 66 Abs. 1 KV die staatsrechtliche Stellung der Staatsanwaltschaft nicht präjudiziert. Der kantonale Gesetzgeber ist nicht verpflichtet, die Staatsanwaltschaft der Exekutive zuzuordnen. ${ }^{52}$

\section{b. Vermischung von Staatsfunktionen?}

[93] Was die Frage einer allfälligen unzulässigen Vermischung von Staatsfunktionen betrifft, so ist vorweg festzuhalten, dass es sich bei den Aufgaben und Befugnissen der Justizleitung ganz überwiegend um typische Fragen der Justizverwaltung handelt (siehe vorne Ziffern II.3. und 6.). Es bereitet mitunter gewisse Schwierigkeiten, den Begriff «Justizverwaltung» exakt abzugrenzen. ${ }^{53}$ So kann man sich fragen, ob es um Justizverwaltung geht, wenn die Justizleitung - wie in Art. 3b

50 Jedenfalls finden sich im Handbuch des bernischen Verfassungsrechts keine Hinweise, abgesehen von einer kurzen Notiz betreffend die Wahlkompetenz des Grossen Rats in Bezug auf den Generalprokurator. Vgl. Bolz, in: Kälin/Bolz (Hrsg.), Handbuch, N 7 zu Art. 77 KV.

51 Gemäss Art. 77 Abs. 2 KV kann das Gesetz dem Grossen Rat weitere Wahlen übertragen (so z.B. im Fall der oder des Beauftragten für Datenschutz).

52 Der Verfasser teilt somit die Auffassung des Regierungsrats (vgl. Vortrag «Justizreform II», Ziffer 3.5.3), wonach der bernische Verfassungsgeber sich zu der in der Literatur kontrovers diskutierten Frage, ob die Staatsanwaltschaft zur Exekutive oder zur Judikative gehöre, nicht geäussert hat.

53 Vgl. Vernehmlassung des Obergerichts (vom 3. Juni 2019). 
VMV vorgesehen ${ }^{54}$ - bei Erlassentwürfen und anderen Geschäfte, welche die Gerichtsbehörden oder die Staatsanwaltschaft betreffen, Stellung nimmt. Entscheidend ist allerdings nicht, wie man den (in der bernischen Kantonsverfassung nicht vorkommenden) Begriff «Justizverwaltung» im Einzelnen versteht und abgrenzt, sondern dass die vom Verfassungsgrundsatz der Gewaltenteilung gezogenen Grenzen (siehe vorne Ziffern 2. und 3.) nicht überschritten werden.

[94] Vorliegend werden diese Grenzen nicht überschritten. Die sich aus Art. 51 BV ergebende Gewaltenteilungsvorgabe des Bundes schreibt den Kantonen nicht vor, wie die Justizverwaltung organisatorisch zuzuordnen ist (siehe vorne Ziffer 2.).

- Der Kanton Bern durfte und darf, ohne die Bundesvorgaben in Sachen Gewaltenteilung zu verletzen, Aufgaben der Justizverwaltung der Exekutive (z.B. einer Direktion der kantonalen Verwaltung) zuweisen, wie dies früher der Fall war - sofern dabei die Unabhängigkeit der Justiz in ihrer rechtsprechenden Tätigkeit nicht beeinträchtigt wird (dazu Ziffer VI.). Für Verwaltungsangelegenheiten der Staatsanwaltschaft gilt Entsprechendes.

- Umgekehrt war und ist es dem Kanton Bern unbenommen, Aufgaben und Befugnisse der Justizverwaltung im Sinne der Selbstverwaltung in die Hände der Gerichte bzw. der Staatsanwaltschaft zu legen, wie dies im Rahmen der Justizreform 2011 geschah.

- Aus der Gewaltenteilungsvorgabe der Bundesverfassung resultiert keine Verpflichtung des Kantons Bern, die Justizverwaltung vollständig den einzelnen Gerichten bzw. der Staatsanwaltschaft zu übertragen. Zulässig ist es daher auch, bestimmte Aufgaben und Befugnisse der Justizverwaltung bei der Exekutive (z.B. einer Direktion der kantonalen Verwaltung) zu belassen oder einem speziell geschaffenen Organ zuzuweisen, wie dies in Bern im Rahmen der Justizreform 2011 geschah (vgl. vorne Ziffer II.).

- Wenn es, wie gesehen, prinzipiell zulässig ist, die Erledigung von Verwaltungsangelegenheiten der Gerichte und der Staatsanwaltschaft einer Behörde der Exekutive zuzuweisen (siehe vorne), so kann es einem Kanton nicht prinzipiell verwehrt sein, bestimmte Justizverwaltungsaufgaben statt einer Exekutivbehörde einem Organ ausserhalb der Exekutive zu übertragen. Nichts anderes gilt unter dem Aspekt der sehr weiten Gewaltenteilungsvorgabe gemäss Art. $51 \mathrm{BV}$, wenn es sich bei dieser ausserhalb der Exekutive angesiedelten Behörde um ein verwaltungsunabhängiges Organ mit «gemischtem» Charakter handelt wie im Fall der bernischen Justizleitung (vgl. Ziffer II.2.).

[95] Der Umstand, dass von den drei Mitgliedern der Justizleitung zwei aus der Judikative stammen und eines aus der Staatsanwaltschaft, ist somit unter dem Aspekt von Art. 51 BV nicht zu beanstanden. Dies gilt erst recht, wenn man berücksichtigt, dass die Staatsanwaltschaft im Kanton Bern aus der Exekutive herausgelöst wurde, d.h. ihrerseits von der Exekutive unabhängig ist. Wiederum steht all dies unter dem Vorbehalt, dass die Unabhängigkeit der Justiz in ihrer rechtsprechenden Tätigkeit nicht beeinträchtigt wird (dazu Ziffer VI.).

[96] Nichts anderes ergibt sich bei einer Beurteilung unter dem Aspekt des kantonalen Grundsatzes der Gewaltenteilung gemäss Art. 66 Abs. 1 KV. Die Kantonsverfassung enthält keine Regelung betreffend die Zuordnung der Justiz- bzw. Gerichtsverwaltung. Sie belässt dem Gesetzgeber ei-

54 Vgl. Art. 3b der Verordnung über das Vernehmlassungs- und das Mitberichtsverfahren (VMV; BSG 152.025) vom 26. Juni 1996. Vgl. auch Art. 18 Abs. 1 Bst. c GSOG. 
nen grossen Gestaltungsspielraum, dies auch in der Frage der Zuordnung der Justizverwaltung. ${ }^{55}$ Dass anlässlich der Justizreform 2011 bestimmte Aufgaben und Befugnisse der Justizverwaltung einem neu geschaffenen Organ ausserhalb der Exekutive zugewiesen wurden, ist unter dem Aspekt von Art. 66 Abs. 1 KV nicht zu beanstanden. Dass es sich dabei um ein «gemischtes» Organ handelt, ist aus den bereits genannten Gründen ebenfalls nicht zu beanstanden.

[97] Zusammenfassend kann man festhalten, dass die Justizverwaltung (wie immer man sie im Detail abgrenzt) keine festgefügte Staatsfunktion ist; es geht vielmehr um Aufgaben und Befugnisse, für die unter Gewaltenteilungsaspekten unterschiedliche Zuordnungen und Aufteilungen infrage kommen. Daher findet keine von vornherein unzulässige Vermischung der Staatsfunktionen statt, wenn man bestimmte Justizverwaltungsaufgaben einem gemeinsamen, «gemischten» Organ überträgt.

\section{c. Keine unkontrollierte und unbegrenzte Machtausübung}

[98] Der Spielraum des Kantons Bern bei der Ausgestaltung seiner Staatsorganisation unter dem Aspekt der Gewaltenteilung ist gross. Eine allgemeine Grenze bildet die in Art. 66 Abs. 1 Satz 2 KV ausgesprochene Vorgabe, dass keine Behörde staatliche Macht unkontrolliert und unbegrenzt ausüben darf. Dieser Vorgabe genügt die vom kantonalen Gesetzgeber im GSOG geschaffene Regelung betreffend die Justizleitung. Als «Dachorgan» im Bereich der Justizverwaltung steht die Justizleitung zwar nicht unter der Kontrolle einer anderen Justizbehörde. Die Justizleitung agiert jedoch nicht in einem unkontrollierten Raum. Sie untersteht - wie alle staatlichen Aufgabenträger (inkl. Justiz) - der (Ober-) Aufsicht des Grossen Rats (generell: Art. 78 KV; speziell mit Blick auf die Justizleitung: Art. 13 Abs. 1 GSOG) ${ }^{56}$ Im Rahmen der Justizreform 2011 wurde zwar darauf verzichtet, «ein Eskalationsorgan vorzusehen, das vermittelnd und ordnend eingreift, wenn sich die Mitglieder der Justizleitung nicht verständigen können». ${ }^{57}$ Dies lässt jedoch die Oberaufsichtsverantwortung des Grossen Rats (Art. 78 KV) nicht entfallen. Spätestens im Fall einer eigentlichen Blockade aktualisiert sich die Verantwortung des Grossen Rats sowie der ihn bei der Ausübung der Oberaufsicht unterstützenden parlamentarischen Organe (vgl. auch Ziffer VI.6.d). ${ }^{58}$

\section{Ergebnis: Vereinbarkeit der geltenden Regelung mit dem Gewalten- teilungsgrundsatz (Art. 51 Abs. 1 BV und Art. 66 Abs. $1 \mathrm{KV}$ )}

[99] Weder die Bundesverfassung noch die Kantonsverfassung verpflichten den Gesetzgeber des Kantons Bern dazu, das theoretische Idealschema der Gewaltenteilung streng umzusetzen. Die im Rahmen der Justizreform 2011 beschlossene Übertragung bestimmter Aufgaben und Befugnisse

55 Der Verfasser teilt mit anderen Worten die Auffassung des Regierungsrats (Vortrag «Justizreform II», Ziffer 3.5.3), wonach der bernische Verfassungsgeber davon ausgegangen ist, dass diese Frage auf Gesetzesstufe zu regeln sei.

56 Siehe auch die vorgesehene Präzisierung in E-Art. 78 Abs. 1 Bst. b KV: «Der Grosse Rat beaufsichtigt: [... $] b$ die Geschäftsführung der Justizleitung». Dazu hinten Ziffer VII.

57 Regierungsrat, Vortrag «Justizreform II», Ziff. 3.5.2.

58 Der Justizkommission kommt die Aufgabe zu, «die Angemessenheit der Entscheidfindung der Justizleitung zu beobachten und korrigierend einzuschreiten, wenn ein Bereich dauernd und unbegründet benachteiligt würde» (Regierungsrat, Vortrag «Justizreform II», Ziff. 3.5.2). 
der Justizverwaltung auf ein neu geschaffenes, «gemischtes» Organ ist mit Art. 51 Abs. 1 BV bzw. Art. 66 Abs. $1 \mathrm{KV}$ vereinbar.

[100] Ausgehend von einem traditionellen Gewaltenteilungsverständnis mag diese "gemischte» Lösung etwas ungewöhnlich erscheinen. Ungewöhnlich heisst aber nicht "gewaltenteilungswidrig» und unzulässig. Die geltende gesetzliche Regelung ist vielmehr Ausdruck eines nicht genau dem theoretischen Idealschema entsprechenden Gewaltenteilungsverständnisses (das nirgends verwirklicht ist), das jedoch im Rahmen der Bundesvorgaben und der Vorgaben gemäss Art. 66 Abs. $1 \mathrm{KV}$ verbleibt und somit als grundsätzlich zulässig anzusehen ist. Dieses Gewaltenteilungsverständnis hat sich in Art. 2 JLR niedergeschlagen, wo «die Gerichtsbehörden und die Staatsanwaltschaft» unter dem Oberbegriff «Justiz» zusammengefasst werden. ${ }^{59}$ Ein in diesem Sinne weit verstandener Begriff von «Justiz» mag in Schweizer Juristen-Ohren etwas ungewohnt klingen (zum europäischen Kontext siehe vorne Ziffer II.6.); er ist jedoch dem Alltagssprachgebrauch und auch dem juristischen Sprachgebrauch nicht fremd ${ }^{60}$ und macht die organisatorische Lösung des geltenden Rechts nicht gewaltenteilungswidrig.

[101] Eine andere Frage ist, ob die «gemischte» Lösung des geltenden Rechts - im Vergleich beispielsweise mit einer Lösung, bei der die Justizleitung nur aus Exponenten der Judikative zusammengesetzt ist ${ }^{61}$ - die bestmögliche Lösung darstellt. Dies ist eine rechtspolitische Frage, nicht eine (verfassungs)rechtliche, und im Rahmen dieses Beitrags nicht zu untersuchen.

\section{Beurteilung der Justizleitung gemäss geltender Rechtslage (Justiz- reform 2011) unter dem Aspekt der richterlichen Unabhängigkeit}

\section{1. Überblick und weiteres Vorgehen}

[102] Die Garantie der richterlichen Unabhängigkeit ist in der Bundesverfassung doppelt verankert, nämlich

- in Art. 30 Abs. 1 BV: als grundrechtliche Individualgarantie,

- in Art. 191c BV: als grundsatzartige Garantie der institutionellen Unabhängigkeit.

[103] Der Kanton Bern kennt entsprechende Garantien in Art. 26 Abs. 1 KV und Art. 97 Abs. 1 KV.

[104] Diese doppelte - sowohl grundrechtliche als auch institutionelle - Absicherung der richterlichen Unabhängigkeit ist ein zentrales Merkmal moderner Verfassungsstaatlichkeit. Die grosse Bedeutung der Unabhängigkeit der Justiz für einen funktionierenden Rechtsstaat wird durch entsprechende völkerrechtliche Garantien unterstrichen. Im Zentrum steht aus schweizerischer

59 In diesem Sinne auch der im Rahmen der Vernehmlassungsvorlage 2019 vorgeschlagene Gliederungs-Titel nach Art. $96 \mathrm{KV}$, welcher «Gerichte und Staatsanwaltschaft» (5.5) zusammenfasst und somit die Staatsanwaltschaft von der «Verwaltung» (5.4) abtrennt.

60 Vgl. z.B. Art. 66 Abs. 3 KV: «Kantonale Erlasse, die höherrangigem Recht widersprechen, dürfen von den Justizbehörden nicht angewandt werden.» Mit Justizbehörden sind nicht nur Gerichte gemeint, sondern alle Organe, die auf Klage oder Beschwerde hin Rechtsstreitigkeiten entscheiden, d.h. «auch die Regierung und Verwaltungsbehörden [...], falls sie als Verwaltungsjustizbehörden tätig sind» (Bolz, in: Kälin/Bolz (Hrsg.), Handbuch, N 8 a) zu Art. $66 \mathrm{KV})$.

61 Vgl. z.B. Hurni, Rz. 21. 
Sicht Art. 6 Ziffer 1 EMRK. Dabei handelt es sich um einen menschenrechtlichen Mindeststandard in Gestalt einer Individualgarantie, der auch eine institutionelle Dimension innewohnt (vgl. Ziffer 4.).

[105] Im Folgenden werden zunächst die Vorgaben der Bundesverfassung, dann die Vorgaben gemäss Art. 6 Ziffer 1 EMRK kurz vorgestellt. Dieses Vorgehen liegt nahe, zumal der mit der neuen Bundesverfassung geschaffene Grundrechtskatalog erklärtermassen das Ziel hatte, den Grundrechtsschutz mindestens auf dem Niveau des für die Schweiz verbindlichen völkerrechtlichen Mindeststandards (insb. EMRK) zu verbürgen (was sich in der Praxis zu Art. 30 Abs. 1 BV grundsätzlich bestätigt hat). ${ }^{62}$ Zudem ist der Anwendungsbereich von Art. 6 Ziffer 1 EMRK (zivilrechtliche Ansprüche und Verpflichtungen; strafrechtliche Anklagen) enger als jener von Art. 30 BV. Bei einer - wie hier - losgelöst von einem konkreten Einzelfall erfolgenden («abstrakten») Beurteilung (vgl. Ziffer IV.2.) darf man im Sinne einer Faustregel davon ausgehen: Ist die zu überprüfende Regelung mit Art. 30 Abs. 1 BV und Art. 191c BV vereinbar, dann dürfte sie auch vereinbar sein mit Art. 6 Ziffer 1 EMRK. Dennoch werden auch die Konkretisierungen von Art. 6 Ziffer 1 EMRK, wie sie vor allem aus der Rechtsprechung des Europäischen Gerichtshofs für Menschenrechte (EGMR) resultieren, im Blick zu behalten sein (vgl. Ziffer 4.).

\section{Zur Tragweite von Art. 191c BV}

[106] Art. 191c BV legt fest, dass die richterlichen Behörden «in ihrer rechtsprechenden Tätigkeit unabhängig und nur dem Recht verpflichtet» sind. ${ }^{63}$

[107] Die aus Art. 191c BV resultierende zentrale Forderung ist, dass richterliche Behörden im Rahmen ihrer rechtsprechenden Tätigkeit von keiner gerichtsfremden Person oder Institution Befehle oder Weisungen entgegennehmen dürfen. Sowohl der Spruchkörper als auch die einzelnen Richterinnen und Richter sind von jeder «justizfremden» Einbindung freizuhalten. Die Judikative soll ihre Kernaufgabe, die Rechtsprechung, in der gebotenen Unabhängigkeit erfüllen können. Es sollen «keine Umstände, welche ausserhalb des Prozesses liegen, in sachwidriger Weise zugunsten oder zulasten einer Partei auf das Urteil einwirken; es soll mit andern Worten verhindert werden, dass jemand als Richter tätig wird, der unter solchen Einflüssen steht und deshalb kein 〈rechter Mittler〉 [...] mehr sein kann» (BGE 114 Ia 50 E. 3.b, S. 54). Nach herrschender Rechtsprechung und Lehre ist bei der Beurteilung der richterlichen Unabhängigkeit auch das gesamte äussere Erscheinungsbild der urteilenden Instanz zu berücksichtigen.

[108] In den Anwendungsbereich von Art. 191c BV fallen (nur) «richterliche Behörden». Erfasst sind damit alle staatlichen Gerichte, unabhängig von ihrer Stellung im Instanzenzug. Nicht zu den richterlichen Behörden im Sinne von Art. 191c BV zählen die Staatsanwaltschaften ${ }^{64}$, was nicht ausschliesst, die Staatsanwaltschaften mit einer spezifischen Unabhängigkeit auszustatten. ${ }^{65}$

62 Vgl. Biaggini, Komm. BV, N 4 zu Art. 30; zum Verhältnis BV-EMRK vgl. auch KiEnER, Richterliche Unabhängigkeit, 44 .

63 Dazu und zum Folgenden eingehend KIENER, Richterliche Unabhängigkeit, 55 ff., 225 ff.; vgl. auch BIAGGINI, Komm. BV, N 2 ff. zu Art. 191c; Reich, BS-Komm. BV, Art. 191c, N 1 ff.; Steinmann, SG-Komm. BV, Art. 191c, N 1 ff.; Uebersax, Rz. $10 \mathrm{ff}$.

64 Vgl. Steinmann, SG-Komm. BV, Art. 191c, N 3, m.w.H.

65 Vgl. Biaggini, Komm. BV, N 4 zu Art. 191c. 
[109] Die Unabhängigkeitsgarantie nimmt eine Vielzahl von Akteuren in die Pflicht. Dazu gehören namentlich die politischen Behörden (Parlament, Regierung) und die Verwaltung sowie die jeweiligen Amtsträger. ${ }^{66} \mathrm{Zu}$ respektieren ist die richterliche Unabhängigkeit aber auch von den verschiedenen Akteuren in der Justiz selbst. So haben beispielsweise die mit Aufsichtsaufgaben betrauten oberen Gerichte (Bundesgericht, oberste kantonale Gerichte) bei der Wahrnehmung ihrer Aufsichtstätigkeit die Unabhängigkeit der unteren Gerichte zu wahren. Entsprechendes gilt auch für die in der Justiz tätigen einzelnen Amtsträger. ${ }^{67}$

[110] Die Verfassungsgarantie der richterlichen Unabhängigkeit schirmt die richterlichen Behörden nicht in jeder Hinsicht ab. Einwirkungen anderer Staatsgewalten auf den Bereich der Justiz sind nicht a priori ausgeschlossen. Bekannte Beispiele dafür sind im schweizerischen Kontext:

- die Einwirkung durch Erlass generell-abstrakter Normen (Gesetze, Verordnungen usw.);

- die parlamentarische Oberaufsicht über die Justiz (vgl. im Bund Art. 169 BV; im Kanton Bern Art. $78 \mathrm{KV})$;

- die Budgethoheit des Parlaments;

- die Wahrnehmung bestimmter Belange der Justizverwaltung durch Exekutivbehörden (siehe vorne Ziffer V.).

[111] Diese «vielfältigen Einbindungen der Justiz in staatliche Handlungs- und Wirkungseinheit» sind «systemimmanent»; sie vermögen, wie sich Regina KIENER ausdrückt, «ihre institutionelle Unabhängigkeit deshalb nicht grundsätzlich in Frage zu stellen». ${ }^{68}$ Die prinzipielle Zulässigkeit der genannten Einwirkungen ergibt sich zum einen daraus, dass die richterlichen Behörden «dem Recht verpflichtet» sind (Art. 191c BV), d.h. als Organe der Rechtsanwendung den Akten der Rechtsetzungsorgane (Gesetzgeber, Verordnungsgeber) Rechnung zu tragen haben. Zum anderen erfasst die Garantie der richterlichen Unabhängigkeit gemäss Art. 191c BV die richterlichen Behörden nur «in ihrer rechtsprechenden Tätigkeit».

- Die parlamentarische Oberaufsicht über die Justiz ${ }^{69}$ ist prinzipiell zulässig, wenn und soweit es um den ordnungsgemässen Geschäftsgang der Gerichte geht. Unzulässig ist sie, wenn sie sich der rechtsanwendenden richterlichen Tätigkeit im Einzelfall (Rechtsprechung) zuwendet. In diesem Sinne hält auf Bundesebene das Parlamentsgesetz ausdrücklich fest: «Die inhaltliche Kontrolle richterlicher Entscheide ist ausgeschlossen»(Art. 26 Abs. 4 ParlG).

- Entsprechendes gilt bei der Wahrnehmung von Aufgaben und Befugnissen der Justizverwaltung durch die Exekutive (siehe vorne Ziffer V.) oder bei der Ausübung der Budgethoheit durch das Parlament. Die Budgethoheit darf nicht dazu missbraucht werden, die Gerichte gefügig zu machen bzw. die rechtsprechende Tätigkeit zu disziplinieren. Aus der Garantie

66 Vgl. z.B. GPK-S, Bericht vom 10. Juli 2006 (betreffend öffentliche Aussagen des Vorstehers EJPD zu Gerichtsurteilen). Vgl. auch Kiener, Richterliche Unabhängigkeit, 380 ff.; Biaggini, Komm. BV, N 6 zu Art. 169.

67 Zur Bedeutung der Unabhängigkeitsgarantie innerhalb der Judikative vgl. REITER, $66 \mathrm{ff}$.

68 KiEner, Richterliche Unabhängigkeit, 229.

69 Vgl. z.B. Kiener, Aspekte der parlamentarischen Justizaufsicht im Kanton Bern, in: BVR 1997, 385 ff. 
der richterlichen Unabhängigkeit ergibt sich eine Verpflichtung des Trägers der Budgethoheit (Parlament), für eine ausreichende Ausstattung der Gerichte zu sorgen. ${ }^{70}$

[112] In der Praxis sind solche (Einwirkungs-) Befugnisse anderer Staatsgewalten dann nicht weiter problematisch, wenn sie die rechtsanwendende richterliche Tätigkeit im Einzelfall (Rechtsprechung) unberührt lassen (was gewöhnlich der Fall ist). Die Garantie der richterlichen Unabhängigkeit ist jedoch verletzt, wenn an sich legitime (Einwirkungs-) Befugnisse dazu missbraucht werden, um indirekt (oder gar direkt) auf die rechtsprechende Tätigkeit einzuwirken. Problematisch kann die Situation auch bereits dann sein, wenn von aussen betrachtet der Eindruck entsteht, dass ein Fall vom zuständigen Gericht nicht unvoreingenommen beurteilt wird. Rechtsprechung und Lehre unterstreichen mit gutem Grund, dass bei der Beurteilung der richterlichen Unabhängigkeit auch dem äusseren Anschein Bedeutung zukommt, wenn objektiv berechtigte Zweifel an der Unabhängigkeit der richterlichen Entscheidfindung bestehen. ${ }^{71}$ Darauf wird zurückzukommen sein.

\section{Zur Tragweite von Art. 30 Abs. 1 Satz 1 BV}

[113] Ähnlich verhält es sich beim verfassungsmässigen «Anspruch auf ein durch Gesetz geschaffenes, zuständiges, unabhängiges und unparteiisches Gericht». Dieser durch Art. 30 Abs. 1 Satz 1 BV vermittelte Individualanspruch dient der Konkretisierung und der grundrechtlichen Absicherung der Garantie der richterlichen Unabhängigkeit und des Grundsatzes der Gewaltenteilung. ${ }^{72}$

[114] Auch unter dem Aspekt von Art. 30 Abs. 1 Satz 1 BV ist der Gestaltungsspielraum der Kantone bei der Ausgestaltung der Judikative gross. Wie die Umschreibung des Grundrechtsanspruchs in der Bundesverfassung deutlich macht, geht es um den Schutz des Individuums, dessen (Streit-)Sache in einem gerichtlichen Verfahren beurteilt wird. Wie bei der institutionell ausgerichteten Unabhängigkeitsgarantie gemäss Art. 191c BV geht es um die rechtsprechende Tätigkeit, ausgeübt durch richterliche Behörden. Und wie bei der Garantie gemäss Art. 191c BV ist auch bei der Anwendung von Art. 30 Abs. 1 Satz 1 BV das äussere Erscheinungsbild der urteilenden Instanz zu berücksichtigen.

[115] In Rechtsprechung und Lehre hat der Individualanspruch konkretere Konturen erlangt. Ohne allzu sehr ins Detail zu gehen, ist hier festzuhalten, dass eine rechtsprechende Behörde bestimmte Eigenschaften aufweisen muss, wenn sie mit dem Anspruch auftritt, als Gericht im Sinne von Art. 30 BV zu agieren:

- Sie muss durch Gesetz geschaffen sein; dazu gehört u.a., dass die Zuständigkeit und die Zusammensetzung «soient déterminées par des normes générales et abstraites» (BGE 129 V 196 E. 4.1 S. 198).

- Sie muss örtlich, zeitlich und sachlich zuständig sein.

70 Vgl. Biaggini, Komm. BV, N 7 zu Art. 191c; Kiener, Richterliche Unabhängigkeit, 309. Vgl. auch Vernehmlassungsentwurf «Vortrag Justizverfassung», Ziff. 4.1.

71 Vgl. Biaggini, Komm. BV, N 2 zu Art. 191c sowie N 10 zu Art. 30.

72 Dazu und zum Folgenden eingehend Kiener, Richterliche Unabhängigkeit, 55 ff.; vgl. auch BIAGginI, Komm. BV, N 10 zu Art. 30; Reich, BS-Komm. BV, Art. 30, N 1 ff.; Steinmann, SG-Komm. BV, Art. 30, N 1 ff. 
- Sie muss unabhängig und unparteiisch sein.

[116] Vorliegend interessiert vor allem die zuletzt genannte verfassungsrechtliche Vorgabe (die in ähnlicher Weise auch in Art. 6 Ziffer 1 EMRK normiert ist). Aus dieser Vorgabe resultiert ein Anspruch des Individuums, dass seine Sache «ohne Einwirken sachfremder Umstände entschieden wird» (BGE 127 I 196 E. 2.b S. 198). Unparteilichkeit meint das Fehlen von Voreingenommenheit und Befangenheit. ${ }^{73}$ Ein solcher innerer Zustand lässt sich nur schwer beweisen. Praxis und Lehre begegnen diesem Problem dadurch, dass Art. 30 Abs. 1 Satz 1 BV (bereits) dann als verletzt gilt, wenn «bei objektiver Betrachtungsweise Gegebenheiten vor[liegen], die den Anschein der Befangenheit und die Gefahr der Voreingenommenheit zu begründen vermögen»; ein Nachweis tatsächlicher Befangenheit wird mit anderen Worten nicht verlangt. ${ }^{74}$

[117] Der Anschein der Voreingenommenheit kann in der Person des betreffenden Richters liegen (z.B. familiäre Beziehung), aber auch auf äussere Gegebenheiten zurückzuführen sein. ${ }^{75}$ Auch organisatorische Strukturen können den Anschein der Voreingenommenheit hervorrufen. ${ }^{76}$ Ein Beispiel dafür ist die sog. Vorbefassung eines Richters (Rollenkumulation). Das Bundesgericht hat ab Mitte der 1980er Jahre - nicht zuletzt in Anbetracht der Rechtsprechung des EGMR zu Art. 6 Ziffer 1 EMRK - mehrere Leiturteile mit weitreichenden Konsequenzen für Gesetzgebung und Gerichtsorganisation gefällt. ${ }^{77}$

[118] Ein solcher Anschein darf indes nicht leichthin angenommen werden. Es müssen Umstände vorliegen, die - so das Bundesgericht - «bei objektiver Betrachtung geeignet sind, Misstrauen in die Unparteilichkeit des Richters zu erwecken [...]. Bei der Beurteilung solcher Umstände ist nicht auf das subjektive Empfinden einer Partei abzustellen. Das Misstrauen in die Unvoreingenommenheit muss vielmehr in objektiver Weise begründet erscheinen.» ${ }^{78}$

[119] Zusammenfassend muss eine richterliche Behörde, um den Anforderungen von Art. 30 BV gerecht zu werden, «organisatorisch und personell, nach der Art [der] Ernennung [der Richter], der Amtsdauer, dem Schutz vor äusseren Beeinflussungen und nach ihrem äusseren Erscheinungsbild sowohl gegenüber anderen Behörden als auch gegenüber den Parteien unabhängig und unparteiisch» sein. ${ }^{79}$ Darauf wird zurückzukommen sein (vgl. Ziffer VI.6.).

[120] Trotz der vielfältigen verfassungsrechtlichen Anforderungen verbleibt den Kantonen auch unter dem Aspekt des Anspruchs auf richterliche Unabhängigkeit gemäss Art. 30 Abs. 1 Satz $1 \mathrm{BV}$ ein erheblicher Gestaltungsspielraum, dies namentlich auch in organisatorischen Fragen, unter Einschluss der Justizverwaltung (Selbstverwaltung der einzelnen Gerichte bzw. der Justiz insgesamt).

[121] Abschliessend sei noch kurz darauf hingewiesen, dass die Staatsanwaltschaft bzw. die einzelnen Staatsanwältinnen und Staatsanwälte als Organe der Strafverfolgung nach herrschender Auffassung nicht unter die bundesverfassungsrechtliche Unabhängigkeitsgarantie gemäss Art. 30

\footnotetext{
73 Eingehend Steinmann, SG-Komm. BV, Art. 30, N 16 ff.; vgl. auch M. Müller, Innere Unabhängigkeit, 527 ff.

74 BGE 127 I 196 E. 2.b S. 198.

75 Vgl. Biaggini, Komm. BV, N 8 ff. zu Art. 30.

76 Vgl. z.B. BGE 136 I 207 E. 3. S. 210 f.; ReIter, Gerichtsinterne Organisation, 70.

77 BGE 112 Ia 290; BGE 113 Ia 72; BGE 114 Ia 50; BGE 114 Ia 275; BGE 115 Ia 217 u.a.m. Überblick: REICH, BSKomm. BV, Art. 30, N 25 ff.; Steinmann, SG-Komm., Art. 30, N 24 ff.

78 BGE 136 I 207 E. 3.1 S. 210. Vgl. auch KIENER, Richterliche Unabhängigkeit, 61.

79 BGE 139 III 98 E. 4.2 S. 104. Vgl. auch ReICH, BS-Komm. BV, Art. 30, N 11 ff., m.w.H.
} 
Abs. 1 Satz 1 BV fallen. Dies bedeutet nicht, dass die unparteiische, unabhängige Amtsausübung kein Thema wäre, ganz im Gegenteil: Auch die Strafverfolgungstätigkeit der Staatsanwaltschaften ist gegen sachwidrige Einflussnahme durch andere Staatsorgane abzuschirmen. Die Rechtsprechung des Bundesgerichts ordnet die entsprechenden Garantien (bzw. Ausstandspflichten) bei Art. 29 Abs. 1 BV ein; die Beurteilungskriterien für die Unparteilichkeit bzw. Unbefangenheit sind im Ergebnis ähnlich wie bei Art. 30 Abs. 1 BV. ${ }^{80}$ Im Übrigen ist es den Kantonen unbenommen, die spezifische Unabhängigkeit der Staatsanwaltschaft als Strafverfolgungsbehörde durch gesetzliche oder verfassungsrechtliche Garantien förmlich abzusichern, wie dies heute in Art. 4 GSOG geschieht und wie dies die Vernehmlassungsvorlage 2019 mit E-Art. 97 Abs. 1 KV auf Verfassungsstufe anstrebt (vgl. hinten Ziffer VII.2.).

\section{Zur Tragweite von Art. 6 Ziffer 1 EMRK}

[122] Gemäss Art. 6 Ziffer 1 EMRK hat jede Person «ein Recht darauf, dass über Streitigkeiten in Bezug auf ihre zivilrechtlichen Ansprüche und Verpflichtungen oder über eine gegen sie erhobene strafrechtliche Anklage von einem unabhängigen und unparteiischen, auf Gesetz beruhenden Gericht in einem fairen Verfahren, öffentlich und innerhalb angemessener Frist verhandelt wird.»

[123] Das Verständnis der richterliche Unabhängigkeit gemäss Art. 6 Ziffer 1 EMRK ist stark durch die Rechtsprechung des Europäischen Gerichtshofs für Menschenrechte (EGMR) geprägt. ${ }^{81}$ Eine gewisse Rolle spielen auch Empfehlungen und Stellungnahmen von Organen und Gremien wie dem Ministerrat, der Venedig-Kommission oder dem Conseil consultatif de juges européens (CCJE). ${ }^{82}$ Ohne hier ins Detail gehen zu müssen, kann festgehalten werden, dass die Rechtsprechung des EGMR stark einzelfallorientiert ist, aber durchaus gewisse grössere Linien erkennen lässt. In der Literatur wird mit Blick auf die Garantie richterlicher Unabhängigkeit und Unparteilichkeit ${ }^{83}$ gewöhnlich Folgendes hervorgehoben: ${ }^{84}$

[124] Die Unabhängigkeit eines Gerichts ${ }^{85}$ ist namentlich zu beurteilen aufgrund

- der Art und Weise der Ernennung seiner Mitglieder und ihrer Amtsdauer,

- des Bestands von Garantien gegen äussere Beeinflussungen und

- des äusseren Erscheinungsbildes. ${ }^{86}$

80 Zur Unparteilichkeit nicht-gerichtlicher Justizbehörden vgl. z.B. BGE 141 IV 178 E. 3.2.2 S. 179 f., m.w.H. (mit Differenzierung nach Verfahrensstadien). Vgl. auch KIENER, Richterliche Unabhängigkeit, $23 \mathrm{f}$.

81 Dazu und zum Folgenden statt vieler Grabenwarter/Pabel, § 24, Rz. 29 ff.; Kiener, Richterliche Unabhängigkeit, $37 \mathrm{ff}$.

82 Vgl. Helen Keller, Schweizerische Rechtsstaatlichkeit im internationalen Vergleich, in: Verfassungsrecht der Schweiz, Bd. II. IV.2., Rz. 13. Vgl. auch Stephan Gass/Regina Kiener/Thomas Stadelmann (Hrsg.), Standards on Judicial Independence, Bern 2012, sowie die im Materialienverzeichnis erwähnten Dokumente (insb. der VenedigKommission, m.w.H.).

83 In der Literatur wird regelmässig erwähnt, dass die Unterscheidung von Unabhängigkeit und Unparteilichkeit mitunter schwierig ist. Vgl. z.B. Grabenwarter/Pabel, § 24, Rz. 41.

84 Vgl. statt vieler Frowein/Peukert, Art. 6, Rz. 205 ff.; Grabenwarter/Pabel, § 24, Rz. 29 ff.; Meyer-Ladewig/ Harrendorf/König, in: Meyer-Ladewig et al., EMRK, Art. 6, Rz. 65 ff.

85 Die EMRK enthält keine spezifische Vorgabe in Bezug auf die staatsrechtliche Stellung bzw. Unabhängigkeit der Staatsanwaltschaft (vgl. LienHARD/KetTiger, Einordnung der Staatsanwaltschaft, Rz. 20). Vgl. immerhin die im Materialienverzeichnis erwähnte Zusammenstellung von Stellungnahmen der Venedig-Kommission (Compilation of Venice Commission Opinions and Reports concerning Prosecutors, CDL-PI(2018)001). 
[125] Mit Blick auf die Unparteilichkeit wird gewöhnlich zwischen zwei Aspekten unterschieden. Gegeben sein muss: ${ }^{87}$

- die subjektive Unparteilichkeit: die Unvoreingenommenheit des entscheidenden Richters in einem bestimmten Fall wird bis zum Beweis des Gegenteils vermutet. ${ }^{88}$

- die objektive Unparteilichkeit: Art. 6 Ziffer 1 EMRK ist verletzt, «wenn Umstände vorliegen, die die Gefahr der Voreingenommenheit zu begründen vermögen». ${ }^{89}$ Objektiv berechtigte Zweifel an der Unparteilichkeit können etwa aufgrund öffentlicher Äusserungen eines Richters zu einem Fall, bei einem Abhängigkeitsverhältnis von einer Verfahrenspartei oder im Fall der Vorbefassung bestehen. ${ }^{90}$

[126] Weder persönliche noch organisatorisch-strukturelle Faktoren dürfen dazu führen, dass Richterinnen und Richter bei ihrer rechtsprechenden Tätigkeit Beeinflussungen ausgesetzt sind, die eine unabhängige und unparteiliche Beurteilung der Streitsache infrage stellen. Wie im Rahmen der Bundesverfassung (vgl. Ziffer VI.2. und 3.) ist auch im Rahmen der EMRK der äussere Anschein bzw. das gesamte Erscheinungsbild in die Beurteilung der richterlichen Unabhängigkeit einzubeziehen. Es darf nicht der Eindruck entstehen, ein Richter bzw. eine Richterin könne sich «schon abschliessend eine Meinung über den Fall gebildet haben». ${ }^{91}$ Wie die Literatur und die dort beispielhaft angeführte Judikatur des EGMR zeigen, ${ }^{92}$ zielt Art. 6 Ziffer 1 EMRK auf den Schutz der rechtsprechenden Tätigkeit. Eine «justizfremde» Wahrnehmung von Aufgaben der Justizverwaltung bleibt grundsätzlich möglich..$^{93}$

\section{Zur Tragweite von Art. 97 Abs. $1 \mathrm{KV}$ und von Art. 26 Abs. $1 \mathrm{KV}$}

[127] Art. 97 Abs. 1 KV legt fest: «Die Unabhängigkeit der Gerichte ist gewährleistet.» Art. 4 GSOG doppelt nach und weitet die Garantie der institutionellen Unabhängigkeit auf die Staatsanwaltschaft aus: «Die Gerichtsbehörden und die Staatsanwaltschaft sind in der Rechtsprechung und Strafverfolgung unabhängig und nur dem Recht verpflichtet.»

[128] Die zitierte Verfassungsbestimmung wird in der Literatur als Gewährleistung der institutionellen Unabhängigkeit der Gerichte verstanden. Eine konkrete Folge dieser Gewährleistung ist, dass «kein richterliches Urteil von der gesetzgebenden Behörde oder von einer Verwaltungsbehörde aufgehoben oder abgeändert werden» darf. ${ }^{94}$ Die parlamentarische «Aufsicht über die Geschäftsführung der Gerichte» ist mit Art. 97 Abs. 1 KV vereinbar. ${ }^{95}$ Der Umstand, dass die Ge-

7 Statt vieler Grabenwarter/Pabel, § 24, Rz. $41 \mathrm{ff}$.

88 Frank Meyer, in: Karpenstein/Mayer (Hrsg.), EMRK, Art. 6, Rz. 49.

89 Grabenwarter/Pabel, § 24, Rz. 48.

90 Vgl. Grabenwarter/Pabel, § 24, Rz. 49; Meyer-Ladewig/Harrendorf/König, in: Meyer-Ladewig et al., EMRK, Art. 6, Rz. 75 ff. (mit Beispielen aus der Rechtsprechung des EGMR).

91 So Frank Meyer, in: Karpenstein/Mayer (Hrsg.), EMRK, Art. 6, Rz. 46.

92 Siehe die in den vorstehenden Anmerkungen zitierte Literatur (m.w.H.).

93 Vgl. KIENER, Richterliche Unabhängigkeit, 291.

94 Bolz, in: Kälin/Bolz (Hrsg.), Handbuch, N 3. zu Art. 97 KV.

95 Bolz, in: Kälin/Bolz (Hrsg.), Handbuch, N 3. zu Art. 97 KV. Vgl. auch Vernehmlassungsentwurf «Vortrag Justizverfassung», Ziff. 4.1, wo aus Art. 97 Abs. $1 \mathrm{KV}$ und dem darin enthaltenen Grundsatz der institutionellen Unabhängigkeit ein selbständiges Budgetantragsrecht und der Grundsatz der Selbstverwaltung abgeleitet werden. 
richtsbehörden bei Erlass der neuen Kantonsverfassung in finanzieller und personeller Hinsicht «in die Verwaltungsstruktur (Justizverwaltung) eingebunden» waren, wurde damals nicht als Beeinträchtigung der richterliche Unabhängigkeit ${ }^{96}$ oder der Gewaltenteilung eingestuft. Art. 97 Abs. $1 \mathrm{KV}$ spielt in der Rechtsprechung des Verwaltungsgerichts (ähnlich wie Art. 66 Abs. $1 \mathrm{KV}$ ) keine zentrale Rolle. ${ }^{97}$ Es gibt keine Anzeichen dafür, dass die institutionelle Unabhängigkeit gemäss Art. 97 Abs. 1 KV strenger zu verstehen wäre als die entsprechenden Vorgaben der Bundesverfassung (dazu vorne Ziffer VI.2.).

[129] Die Kantonsverfassung enthält daneben auch eine individualrechtliche Garantie der richterlichen Unabhängigkeit: «Jede Person hat ein unantastbares Recht auf unabhängige, unparteiische und vom Gesetz vorgesehene Richterinnen und Richter.» (Art. 26 Abs. 1 KV). Diese Garantie ist (wie Art. 30 BV und Art. 6 Ziffer 1 EMRK) auf die rechtsprechende Tätigkeit der Gerichte beziehungsweise der Richterinnen und Richter ausgerichtet. Soweit ersichtlich, geht der Gehalt dieser Bestimmung nicht über das hinaus, was bereits durch die Bundesverfassung gewährleistet ist. ${ }^{98}$ Vom sachlichen Anwendungsbereich her geht Art. 26 Abs. 1 (wie Art. 30 Abs. 1 BV) weiter als Art. 6 Ziffer 1 EMRK. Das Adjektiv «unantastbar» soll (nur, aber immerhin) unterstreichen, dass sich «keine Situation denken [lässt], in welcher sich ein gesetzlich nicht vorgesehenes, befangenes und parteiisches Gericht als verfassungsmässig erweisen könnte» ${ }^{99}$ - eine Anforderung, die inhaltlich auch schon durch Art. 30 Abs. 1 BV abgedeckt ist.

[130] Zusammenfassend kann festgehalten werden, dass die Vorgaben der Kantonsverfassung (Art. 26 Abs. 1 und Art. 97 Abs. $1 \mathrm{KV}$ ) im vorliegenden Zusammenhang keine eigenständige Bedeutung haben. Im Zentrum der Aufmerksamkeit stehen die Garantien der Bundesverfassung (Art. 191c BV sowie Art. 30 Abs. 1 Satz 1 BV), ausgelegt im Lichte von Art. 6 Ziffer 1 EMRK.

\section{Beurteilung der Kritikpunkte unter dem Aspekt der richterlichen Unabhängigkeit}

[131] Wie vorne dargelegt (vgl. Ziffer III.), stehen unter dem Aspekt der richterlichen Unabhängigkeit die folgenden Kritikpunkte im Raum: Es wird vorgebracht, dass die Befugnisse und Entscheidverfahren der Justizleitung (insb. Budgetkompetenzen und Weisungsbefugnisse; «Vetorecht» der Generalstaatsanwaltschaft) die richterliche Unabhängigkeit gefährdeten und dass der äussere Anschein einer Beeinträchtigung der Unabhängigkeit bestehe.

[132] Diese Kritikpunkte geben Anlass zu einigen Bemerkungen allgemeiner Natur betreffend Stellung und Aufgaben der Justizleitung (a.) sowie zu Bemerkungen zu den Instrumenten (b.), zur Rolle im Budgetprozess (c.), zu Organisation und Verfahren (d.) sowie zur Frage des äusseren Anscheins (e.), dies aufbauend auf der Analyse der Stellung der Justizleitung gemäss Justizreform 2011 (Ziffer II.).

96 Vgl. Bolz, in: Kälin/Bolz (Hrsg.), Handbuch, N 3. zu Art. 97 KV.

97 Beiläufig erwähnt wird Art. 97 Abs. 1 KV z.B. in den Urteilen 200.2018.314 vom 21. August 2018, 200.2017.1037 vom 23. Mai 2018 bzw. 200.2017.882 vom 6. Dezember 2017.

98 Vgl. z.B. Verwaltungsgericht, Urteil 100.2016.257/258U vom 12. Juni 2018, E. 4.2 (wo Art. 30 Abs. 1 BV, Art. 26 Abs. $1 \mathrm{KV}$ und Art. 6 Ziffer 1 EMRK in einem Atemzug genannt werden). Aus entstehungszeitlicher Perspektive Bolz, in: Kälin/Bolz (Hrsg.), Handbuch, N 2. ff. zu Art. 26 KV. 


\section{a. Bemerkungen allgemeiner Natur (Stellung und Aufgaben)}

[133] Den Ausgangspunkt bildet die Feststellung, dass die Garantie der richterlichen Unabhängigkeit - sowohl als Grundsatz (Art. 191c BV; Art. 97 Abs. $1 \mathrm{KV}$ ) wie auch als Individualrecht (Art. 30 Abs. 1 Satz 1 BV; Art. 6 Ziffer 1 EMRK; Art. 26 Abs. 1 KV) - sich jeweils auf die rechtsprechende Tätigkeit beziehen (Ziffern VI.2.-5.).

[134] Die Aufgaben der Justizleitung bewegen sich allesamt nicht in diesem Bereich. Es handelt sich im Wesentlichen um hergebrachte Angelegenheiten der Justizverwaltung (siehe vorne Ziffer II.3.). Zudem geht es nur um einen begrenzten Teil der justiziellen Selbstverwaltung, denn das Gesetz weist verschiedene administrative Aufgaben den einzelnen Gerichten bzw. der Staatsanwaltschaft zu (vgl. vorne Ziffer II.3.). Die der Justizleitung zugewiesenen Selbstverwaltungsaufgaben sind allesamt nicht als rechtsprechungsnah einzustufen. Vor diesem Hintergrund ist die folgende im Rahmen der Evaluation «Justizreform II» getroffene Feststellung aufschlussreich:

«Die Justizleitung wird aktuell vor allem gegen aussen als gemeinsamer Ansprechpartner der Justiz wahrgenommen. Im Innenverhältnis ist sie zwar bei den Geschäftsleitungen der Justizbehörden bekannt. Bereits eine Hierarchiestufe tiefer spielt sie im Alltagsgeschäft sowohl seitens der Gerichte als auch der Staatsanwaltschaften praktisch keine Rolle und ihre Zusammensetzung und ihre Aufgaben sind wenig bekannt.» 100

[135] Man mag die mangelnde Bekanntheit der Justizleitung «vor Ort» unter dem Aspekt der Justizverwaltung bedauern: Unter dem Aspekt der Wahrung der richterlichen Unabhängigkeit (und der Unabhängigkeit der Strafverfolgung) allerdings ist es beruhigend zu wissen, dass die Justizleitung im Alltagsgeschäft der Gerichte (insbesondere der jeweiligen Spruchkörper) nicht spürbar präsent ist.

[136] Bei einzelnen Aufgaben der Justizleitung - z.B. Mitwirkung an der Rechtsetzung in Form von Stellungnahmen zu Regelungen des Regierungsrates (vgl. Art. 18 Abs. 1 Bst. c GSOG) - kann man sich fragen, ob die Einordnung unter den Begriff der Justizverwaltung passt. Dies spielt indes für die hier vorzunehmende Beurteilung keine entscheidende Rolle, denn auch bei diesen Aufgaben handelt es sich nicht um rechtsprechungsnahe Tätigkeiten, bei denen eine Einwirkung auf die rechtsprechende Tätigkeit der einzelnen Gerichte drohen könnte. Die Unabhängigkeitsgarantien des übergeordneten Rechts zugunsten der einzelnen Gerichte werden durch solche nichtadministrative Aufgaben nicht beeinträchtigt. ${ }^{101}$

[137] Als rechtsprechungsnah einzustufen wären beispielsweise Aufgaben und Befugnisse wie die Einstellung, Zuteilung, Versetzung, Beförderung von Amtsträgern oder die Möglichkeit der Verhängung von Disziplinarmassnahmen. Wie kurz erwähnt, gibt es in einigen europäischen Staaten Selbstverwaltungsorgane mit «gemischter» Zusammensetzung, die Zuständigkeiten dieser Art besitzen. Derartige Lösungen sind nicht immer unproblematisch, sie werden jedoch offenbar unter dem Aspekt von Art. 6 Ziffer 1 EMRK (richterliche Unabhängigkeit) nicht per se als unzulässig angesehen (siehe vorne Ziffer II.6.). Die Existenz solcher «gemischter» Selbstverwaltungsorgane

100 Ecoplan/Wenger Plattner, Evaluation «Justizreform II», S. 4.

101 Insofern spielt es auch keine entscheidende Rolle, dass der Begriff «Justizverwaltung» nicht leicht abzugrenzen ist (dazu Vernehmlassung des Obergerichts vom 3. Juni 2019). 
hat jedenfalls bisher, soweit ersichtlich, weder in der Rechtsprechung des EGMR zu Art. 6 Ziffer 1 EMRK noch in der Begutachtungspraxis der Venedig-Kommission des Europarats zu prinzipiellen Einwänden geführt. Anlass zu Kritik boten allenfalls die spezifische Ausgestaltung oder die Handhabung im Einzelfall. Die begrenzten Aufgaben und Befugnisse der bernischen Justizverwaltung sind weit entfernt von solchen rechtsprechungsnahen Selbstverwaltungsangelegenheiten. Eine direkte Einwirkung der Justizleitung auf die Rechtsprechungstätigkeit der Gerichte oder die Strafverfolgungstätigkeit der Staatsanwaltschaft ist unter diesen Umständen nicht zu befürchten. Auch der Umstand, dass die Justizleitung nicht nur aus Angehörigen von Gerichtsbehörden besteht, führt nicht zu einer unzulässigen «Fremdeinwirkung» auf die rechtsprechende Tätigkeit der einzelnen Gerichte. ${ }^{102}$ Dies gilt umso mehr, als die drei Mitglieder der Justizleitung als Amtsträger ihrerseits an die Garantie der richterlichen Unabhängigkeit gebunden sind (siehe vorne Ziffer VI.2.). Der Versuch, die Zuständigkeiten und Instrumente der Justizleitung bzw. die eigene Stellung als Mitglied der Justizleitung zu missbrauchen, um auf die (verfassungs- und völkerrechtlich spezifisch geschützte) rechtsprechende Tätigkeit der Gerichte einzuwirken, wäre klarerweise als Amtspflichtverletzung einzustufen und wäre wohl auch ein Fall für die parlamentarische Oberaufsicht über die Geschäftsführung der Justizleitung (vgl. Ziffern II.5. und V.4.c.). ${ }^{103}$ So weit dürfte es allerdings kaum kommen, denn man darf wohl davon ausgehen, dass sich die Justizleitung und ihre Mitglieder bei der Wahrnehmung ihrer Aufgaben (verfassungsund völker-) rechtskonform verhalten. Davon durfte der bernische Gesetzgeber vernünftigerweise ausgehen, als er die Justizreform 2011 beschloss, und darauf darf auch die vorliegende abstrakte Überprüfung (vgl. Ziffer IV.2.) der Rechtmässigkeit der geltenden Gesetzgebung (und der vorgeschlagenen Verfassungsänderungen; vgl. Ziffer VII.) abstellen.

[138] Zusammenfassend kann festgehalten werden, dass aus einer allgemeinen Perspektive eine Beeinträchtigung der Unabhängigkeit im Bereich der Rechtsprechungstätigkeit nicht ersichtlich ist. Dieser Befund bestätigt sich bei der nun folgenden näheren Betrachtung einzelner Aspekte der Justizleitung und ihrer Stellung (Bst. b.-d.).

[139] Ein Problem unter dem Aspekt der richterlichen Unabhängigkeit könnte sich, wenn überhaupt, allenfalls dann ergeben, wenn der äussere Anschein der Unabhängigkeit beeinträchtigt sein sollte. Auf diese Frage wird noch einzugehen sein (vgl. hinten e.).

\section{b. Die Instrumente der Justizleitung im Lichte der richterlichen Unabhängigkeit}

[140] Die Justizleitung ist befugt und verpflichtet, im Rahmen ihrer - begrenzten - Zuständigkeiten bestimmte Rechtsvorschriften zu erlassen (vgl. Ziffer II.3.). Es ist nicht zu erkennen, dass die zu erlassenden generell-abstrakten Normen von der Justizleitung als Hebel benutzt werden könnten, um - über ihren Zuständigkeitsbereich (Selbstverwaltung) hinaus - in unzulässiger Weise auf die Rechtsprechungstätigkeit der Gerichte (bzw. die Strafverfolgungstätigkeit der Staatsanwaltschaft) einzuwirken.

[141] Die einschlägige Gesetzgebung sieht verschiedentlich vor, dass die Justizleitung Weisungen erlässt bzw. erlassen kann (vgl. Ziffer II.3.). Die Freiheit von Weisungen gehört zu den zen-

102 Ebenso wenig kann von einer «Fremdeinwirkung» auf die Strafverfolgung die Rede sein.

103 Dass (auch) die Justizleitung unter der Oberaufsicht des Grossen Rates steht, ergibt sich heute aus Art. 13 GSOG (und implizit aus Art. $78 \mathrm{KV}$ ) und soll künftig in der Kantonsverfassung ausdrücklich festgehalten werden (VE-Art. 78 Abs. 1 Bst. b KV). 
tralen Aspekten der richterlichen Unabhängigkeit gemäss Art. 191c bzw. Art. 30 Abs. 1 Satz 1 BV sowie Art. 6 Ziffer 1 EMRK (vgl. Ziffer VI.2.). Die verfassungs- und völkerrechtlich gebotene Weisungsfreiheit der Judikative bezieht sich, wie gesehen, jeweils auf die rechtsprechende Tätigkeit. Der Spruchkörper als solcher und ebenso die einzelnen urteilenden Richterinnen und Richter sind von jeder Fremdeinwirkung freizuhalten. Weisungen sind jedoch im Bereich der Justiz, verfassungs- und völkerrechtlich gesehen, nicht prinzipiell unzulässig: «Besteht kein Zusammenhang mit der Rechtsprechung (etwa bei Weisungen im Zusammenhang mit der Justizverwaltung), ist die Unabhängigkeit der Justiz nicht in Frage gestellt.» ${ }^{104}$

[142] Die Weisungsbefugnisse der Justizleitung beziehen sich ausschliesslich auf definierte Angelegenheiten im Bereich der Selbstverwaltung (siehe Ziffer II.3.), sie betreffen nicht die Rechtsprechungstätigkeit der einzelnen Gerichte (oder die Strafverfolgungstätigkeit). Die Befugnisse der Justizleitung sind daher in keiner Weise vergleichbar mit dem generellen Weisungsrecht des Generalstaatsanwalts gemäss Art. 90 Abs. 3 GSOG («Sie oder er kann im Bereich der Staatsanwaltschaft Weisungen erteilen.»). Das Gesetz stellt dem Generalstaatsanwalt mit dem generellen Weisungsrecht ein Instrument zur Verfügung, das es ihm - an der Spitze der hierarchisch strukturierten Strafverfolgungsbehörden stehend - ermöglichen soll, die gesetzlich zugewiesene Verantwortung «für die fachgerechte und effiziente Strafverfolgung» wahrzunehmen (Art. 90 Abs. 2 GSOG). Eine derartige Verantwortung besitzt die Justizleitung nicht, weder im Bereich der Strafverfolgung noch im Bereich der rechtsprechenden Tätigkeit.

[143] Zusammenfassend kann festgehalten werden, dass die der Justizleitung zugewiesenen Instrumente die Unabhängigkeit im Bereich der Rechtsprechungstätigkeit nicht beeinträchtigen. Ein Problem unter dem Aspekt der richterlichen Unabhängigkeit könnte sich, wenn überhaupt, allenfalls dann ergeben, wenn der äussere Anschein der Unabhängigkeit beeinträchtigt sein sollte, was aber nicht der Fall ist (dazu hinten e.).

\section{c. Die Rolle der Justizleitung im Budgetprozess im Lichte der richterlichen Unabhängigkeit}

[144] Die Justizleitung hat verschiedene Aufgaben und Befugnisse im Bereich der Finanzen und des Rechnungswesens (vgl. vorne Ziffer II.3.). Anlass zu gewissen Sorgen betreffend die richterliche Unabhängigkeit gibt offenbar die Rolle der Justizleitung im Budgetprozess (vgl. Ziffer III.). So wird etwa befürchtet, dass die Budgetkompetenzen der Justizleitung zur «Sanktionierung nicht genehmer Rechtsprechung durch Mittelkürzungen» genutzt werden könnten. ${ }^{105}$

[145] Eine nähere Analyse macht deutlich, dass diese (abstrakte) Sorge nicht berechtigt ist. Grund dafür ist zum einen die rechtlich vorgegebene Rolle des Grossen Rats im Budgetprozess: ${ }^{106}$

- Die Justizleitung beschliesst nicht selbst über den Voranschlag der Justiz. Die Beschlussfassung obliegt vielmehr dem Grossen Rat (Art. 76 KV). Die Justizleitung stellt Antrag (Art. 48

104 KIENER, Richterliche Unabhängigkeit, 238. Vgl. ReIter, Gerichtsinterne Organisation, 77.

105 Hurni, Rz. 15; vgl. auch Rz. 18, wonach (angesichts des Einstimmigkeitserfordernisses gemäss Art. 16 Abs. 1 JLR) «[m]it der Zustimmung der Generalstaatsanwaltschaft [...] das Budget der Justiz» stehe oder falle.

106 In der Praxis des Budgetprozesses hat das Antragsrecht der Justizleitung (und wie es konkret ausgeübt wird) naturgemäss eine stark prägende Kraft. Für die hier vorzunehmende rechtliche Beurteilung unter dem Aspekt der richterlichen Unabhängigkeit ist indes von zentraler Bedeutung, dass der Grosse Rat über Instrumente verfügt, die ihm gegenüber dem Antrag der Justizleitung Korrekturmöglichkeiten verschaffen. 
Abs. 4 GRG) und vertritt diesen vor dem Grossen Rat bzw. vor der vorberatenden Kommission.

- Der Grosse Rat ist nicht verpflichtet, dem Antrag der Justizleitung zu folgen. Dies bedeutet allerdings nicht, dass der Grosse Rat bei der Beschlussfassung über das Budget gänzlich frei wäre, denn aus der Garantie der richterlichen Unabhängigkeit resultiert unter anderem die Verpflichtung der Trägers der Budgethoheit, für eine ausreichende Ausstattung der Gerichte zu sorgen (vgl. Ziffer VI.2.). Daraus folgt, dass der Grosse Rat bei der Festsetzung des Voranschlags der Judikative einen gewissen Entscheidungsspielraum besitzt, dass er das Budget jedoch nicht beliebig tief ansetzen darf.

- Im Übrigen verfügt der Grosse Rat bei der Festsetzung des Justizbudgets über Differenzierungsmöglichkeiten, zumal der Voranschlag für den Bereich «Gerichtsbehörden und Staatsanwaltschaft (JUS)» vier Produktegruppen unterscheidet, nämlich: «Führungsunterstützung» (Justizleitung, inkl. Stabsstelle für Ressourcen), «Zivil- und Strafgerichtsbarkeit», «Verwaltungsgerichtsbarkeit» sowie «Staatsanwaltschaft». ${ }^{107}$ Der Grosse Rat hat grundsätzlich die Möglichkeit, produktegruppenspezifische Anpassungen zu beschliessen, d.h. «Kürzungen» bzw. «Aufstockungen» (gegenüber dem Antrag der Justizleitung) nur bei bestimmten Produktegruppen vorzunehmen.

[146] Zu berücksichtigen sind auch die folgenden Faktoren, die mit der rechtlich vorgegebenen Rolle der Justizleitung im Budgetprozess zusammenhängen:

- Die Justizleitung ist nicht nur berechtigt, sondern auch verpflichtet, im Rahmen des Budgetprozesses einen Antrag für den Bereich «Gerichtsbehörden und Staatsanwaltschaft (JUS)» zu stellen. ${ }^{108}$

- Die Justizleitung ist bei der Antragstellung (und auch schon bei der Antragsvorbereitung) nicht frei, sondern dem Gesamtinteresse verpflichtet. Die einzelnen Mitglieder der Justizleitung dürfen, wie bereits ausgeführt, bei der Ausübung ihres Amts als Mitglied der Justizleitung nicht einfach nur die spezifischen (partikularen) Interessen der «entsendenden» Behörde vertreten (vgl. Ziffer II.6.). Bei der Ermittlung des Gesamtinteresses gibt es zwar gewisse Beurteilungs- und Bewertungsspielräume. Es wäre jedoch nicht zulässig, die $\mathrm{Zu}$ stimmung zum Budgetantrag zu verweigern, bloss um Interessen der eigenen («entsendenden») Behörde zu verfolgen.

- Die Justizleitung ist bei der Antragstellung überdies auch deshalb nicht frei, weil sowohl sie selbst (als Selbstverwaltungsorgan) als auch ihre Mitglieder der Garantie der richterlichen Unabhängigkeit verpflichtet sind. Die Justizleitung muss ihren Beitrag dazu leisten, dass die Gerichte eine ausreichende Ausstattung erhalten. Diese Verpflichtung darf nicht dadurch unterlaufen werden, dass die Justizleitung einen zu tiefen Antrag stellt - weder für den Gesamtbereich «Gerichtsbehörden und Staatsanwaltschaft (JUS)» noch für einzelne Produktegruppen wie «Zivil- und Strafgerichtsbarkeit» oder «Verwaltungsgerichtsbarkeit».

107 Für ein Beispiel: Voranschlag 2020 und Aufgaben-/Finanzplan 2021-2023 des Kantons Bern, Teil «Berichterstattung», Ziffer 13 «Gerichtsbehörden und Staatsanwaltschaft (JUS)».

108 Das Einstimmigkeitserfordernis gemäss Art. 16 Abs. 1 JLR darf nicht zum Grund werden, dieser Verpflichtung nicht nachzukommen (vgl. auch hinten Bst. d). 
- Sollte der Budgetantrag der Justizleitung unter einem Mangel leiden, so stehen parlamentsseitig die nötigen Instrumente zur Verfügung, um dem Mangel abzuhelfen: Der Grosse Rat und seine vorberatende Kommission sind nicht an einen zu tiefen oder zu einseitigen Antrag der Justizleitung gebunden. Der Grosse Rat ist in solchen Fällen nicht nur berechtigt, sondern auch verpflichtet, die unter dem Aspekt der richterlichen Unabhängigkeit nötigen Korrekturen vorzunehmen, zumal er sonst seiner eigenen Verantwortung nicht gerecht würde, das Gesamtinteresse (auch im Bereich der Justiz) zu wahren und der Justiz die erforderliche Ausstattung zur Verfügung zu stellen (vgl. Ziffer VI.2.).

[147] Im Schlussbericht zur Evaluation der «Justizreform II» wurde verschiedentlich thematisiert, dass die «Bewährungsprobe» der «Umsetzung einer allfälligen Budgetkürzung» noch ausstehe. ${ }^{109}$ In der Literatur wird das Problem mitunter noch zugespitzt, indem gesagt wird, die «Nagelprobe der Durchsetzung von einschneidenden Budgetkürzungen» stehe noch aus. ${ }^{110} \mathrm{Zu}$ solchen einschneidenden «Budgetkürzungen» dürfte es allerdings wohl kaum je kommen, wenn man sich vor Augen führt, dass «einschneidende Kürzungen» die Funktionsfähigkeit der Justiz nicht unberührt lassen dürften und daher wohl unzulässig (verfassungswidrig) sein dürften. Dies heisst nicht, dass es im Rahmen des Budgetprozesses nicht zu schwierigen Situationen kommen kann. Wenn Kompromisse gesucht werden müssen, kann ein gewisser (Entscheidungs-)Druck entstehen. Aber: Solche Auseinandersetzungen finden innerhalb eines vorgegebenen rechtlichen Rahmens statt, der nach allgemeinen Erfahrungen dafür sorgen dürfte, dass der Budgetprozess in geordneten Bahnen verläuft und verfassungskonforme Ergebnisse herbeiführt.

[148] Sind, wie gesehen, die Aufgaben und Befugnisse der Justizleitung im Bereich des Budgetprozesses mit der Garantie der richterliche Unabhängigkeit prinzipiell vereinbar, so wird man dies erst recht für die übrigen, allgemein als weniger heikel angesehenen Aufgaben und Befugnisse im Finanzbereich annehmen dürfen (vgl. vorne Ziffer II.3.c.): Erstellung des Aufgabenund Finanzplans, Regelung der Ausgabenbefugnisse der Gerichtsbehörden und der Staatsanwaltschaft, Bewilligung bestimmter nachkreditpflichtiger Abweichungen und Eingehung dringlicher Verpflichtungen (beides mit Zustimmung der Justizkommission des Grossen Rates), Verantwortung für die strategischen Leitlinien im Finanz- und Rechnungswesen und Führung des Controllings.

[149] Zusammenfassend kann festgehalten werden, dass die Rolle, welche die Justizreform $2011 \mathrm{im}$ Budgetprozess für die Justizleitung vorsieht, sich mit der Garantie der Unabhängigkeit der Rechtsprechungstätigkeit vereinbaren lässt. Ein Problem unter dem Aspekt der richterlichen Unabhängigkeit könnte sich im Bereich der finanzbezogenen Zuständigkeiten der Justizleitung, wenn überhaupt, allenfalls dann ergeben, wenn der äussere Anschein der Unabhängigkeit beeinträchtigt sein sollte, was aber nicht der Fall ist (dazu hinten e.).

109 Vgl. Ecoplan/Wenger Plattner, Evaluation «Justizreform II», z.B. S. 4, 5, 85, 112.

110 Hurni, Rz. 19 (dort Fn. 56); beiläufig auch Ecoplan/Wenger Plattner, Evaluation «Justizreform II», S. 80 und 85. Das Wort «Budgetkürzungen» ist insofern nicht präzise, weil unklar bleibt, was genau die Bezugsgrösse ist: Geht es um «Kürzungen» gegenüber dem Antrag der Justizleitung? Oder geht es (was nicht zwingend dasselbe ist und nicht zwingend dieselben Fragen aufwirft) um «Kürzungen» gegenüber dem Vorjahresbudget? 
d. Organisation und Verfahren im Lichte der richterlichen Unabhängigkeit: Gibt es ein «Vetorecht» der einzelnen Mitglieder der Justizleitung?

[150] Im Zusammenhang mit dem Budgetprozess, aber auch bei der allgemeinen Beschreibung des Verfahrens der Beschlussfassung ist in Vernehmlassungsantworten und in der Literatur verschiedentlich davon die Rede, dass das reglementarische Einstimmigkeitserfordernis (Art. 16 Abs. 1 JLR) den einzelnen Mitgliedern der Justizleitung ein «Vetorecht» verschaffe.

[151] Der Begriff «Vetorecht» kommt in der bernischen Gesetzgebung nicht vor. ${ }^{111}$ Er ist geeignet, Missverständnisse zu wecken, und sollte im vorliegenden Zusammenhang vermieden werden. Denn dieser Begriff lässt denken, dass die Mitglieder der Justizleitung bei der Beschlussfassung im Kollegium eine Beschlussvorlage (z.B. die Verabschiedung des Antrags betreffend den Voranschlag zuhanden des Grossen Rats) aus beliebigen Motiven ablehnen könnten - ja sogar ein «Recht» darauf hätten. Dies trifft, wie gesehen, nicht zu.

[152] Die Mitglieder der Justizleitung sind bei der Ausübung ihres Stimmrechts dem Recht verpflichtet. Sie müssen das Gesamtinteresse der Justiz wahren und die Garantie der richterlichen Unabhängigkeit respektieren (siehe vorne Ziffern II.6.e und VI.2.). Ein «Vetorecht» gibt es im Bereich der Aufgaben und Befugnisse der Justizleitung nicht, weder in finanziellen noch in anderen Angelegenheiten. Die Verweigerung der Zustimmung aus sachfremden Motiven ist kein Recht, sondern bedeutet ganz im Gegenteil eine Verletzung der Amtspflicht, bei der Aufgabenerfüllung das Gesamtinteresse zu wahren (Ziffer II.6.e).

[153] Dies heisst nicht, dass es im Rahmen der Beschlussfassung in der Justizleitung nicht zu schwierigen Situationen kommen kann. Sollte es in einzelnen Fällen infolge der Einstimmigkeitsregel zu Blockierungsversuchen oder sogar zur Blockierung von erforderlichen Beschlüssen kommen, so müsste man den Ursachen nachgehen und nach geeigneten Massnahmen zur Überwindung des Problems suchen. Möglicherweise stellt sich dabei heraus, dass eine Blockade ein Fall für die parlamentarische Oberaufsicht ist (der auch die Justizleitung untersteht), dies insbesondere dann, wenn die Blockade die Funktionsfähigkeit der Gerichte oder der Strafverfolgung in Mitleidenschaft ziehen sollte (vgl. auch vorne Ziffer V.4.c). Möglicherweise muss man eine Modifikation der Einstimmigkeitsregel in Erwägung ziehen.

\section{e. Bemerkungen zur Frage des äusseren Anscheins}

[154] Das zentrale Anliegen der Garantie der richterlichen Unabhängigkeit besteht darin, die Richterinnen und Richter in ihrer rechtsprechenden Tätigkeit gegenüber Fremdbeeinflussung abzuschirmen. Die Unabhängigkeitsgarantie ist gemäss Rechtsprechung und Lehre nicht nur dann verletzt, wenn ein Richter oder eine Richterin in dem zu entscheidenden Fall subjektiv voreingenommen ist, sondern auch schon dann, wenn objektiv der Anschein besteht, dass ein Richter bzw. eine Richterin voreingenommen sein könnte bzw. sachfremde Überlegungen in den zu treffenden Entscheid einfliessen könnten (siehe Ziffer VI.2.). Der Grund dafür kann auch in äusseren Gegebenheiten (z.B. organisatorischer Natur) liegen.

[155] In Rechtsprechung und Lehre lässt man richtigerweise nicht jeden Anschein genügen. Es müssen vielmehr berechtigte Zweifel bestehen, dass das fragliche Gericht nicht allein nach Recht und Gesetz entscheidet (sondern sachfremde Überlegungen einbezieht). Wie das Bundesgericht

111 Ergebnis einer Volltextsuche in BELEX - Gesetzessammlungen des Kantons Bern (28. Februar 2020). 
in einer bereits zitierten Entscheidung festhielt: Es müssen Umstände vorliegen, die «bei objektiver Betrachtung geeignet sind, Misstrauen in die Unparteilichkeit des Richters zu erwecken [...]. Das Misstrauen in die Unvoreingenommenheit muss vielmehr in objektiver Weise begründet erscheinen.» ${ }^{112}$

[156] Gibt es mit Blick auf die Justizleitung, wie sie mit der Justizreform 2011 geschaffen und eingerichtet wurde, derartige berechtigte Zweifel? Im Rahmen einer abstrakten Überprüfung, d.h. losgelöst von einem konkreten Konfliktfall, wie sie hier vorzunehmen ist (vgl. Ziffer IV.), ist die Frage zu verneinen.

- Der Umstand, dass die Justizleitung die Befugnis hat, bestimmte Weisungen zu erlassen, genügt nicht, um berechtigte Zweifel entstehen zu lassen, denn diese Weisungen haben - wie man auch Aussenstehenden leicht plausibel machen kann - nicht die Rechtsprechung und auch nicht rechtsprechungsnahe Angelegenheiten zum Gegenstand. Für die unabhängige und unparteiliche Beurteilung der zu entscheidenden Streitfälle bedeuten die Weisungsbefugnisse der Justizleitung auch dem äusseren Anschein nach keine reelle Gefahr.

- Entsprechendes gilt mit Blick auf den Budgetprozess. Es ist unter heutigen Rahmenbedingungen - auch für Aussenstehende - schwer vorstellbar, dass ein Richter ein Urteil gegen seine Rechtsüberzeugung fällen könnte, bloss weil er die Sorge hat, dass der Generalstaatsanwalt sein Stimmrecht in der Justizleitung für «eine Sanktionierung nicht genehmer Rechtsprechung durch Mittelkürzungen» ${ }^{113}$ nutzen könnte (einmal davon abgesehen, dass ein solches Stimmverhalten in der Justizleitung rechtswidrig wäre).

- Auch der Umstand, dass in der Justizleitung die Staatsanwaltschaft in der Person des Generalstaatsanwalts «vertreten» ist, vermag keine berechtigten Zweifel zu begründen. Es trifft zwar zu, dass insbesondere Unterordnungs- oder Überordnungsverhältnisse geeignet sind, den «begründeten Anschein von Rücksichtnahme und Abhängigkeit [zu] erwecken». ${ }^{114}$ Die Mitwirkung des Generalstaatsanwalts in der Justizleitung bedeutet jedoch nicht, jedenfalls was die rechtsprechende Tätigkeit anbelangt, dass es zu einer «Einordnung» der Gerichte in den Einflussbereich der Staatsanwaltschaft oder gar zu einer Unterordnung kommt. ${ }^{115}$ In Rechtsprechungsfragen steht die Justizleitung, wie gesehen, nicht an der Spitze der Justiz (vgl. Ziffer II.2.a.). In dieser für die richterliche Unabhängigkeit zentralen Hinsicht besteht kein hierarchisches Verhältnis der Über- bzw. Unterordnung. Der blosse Umstand, dass, einerseits, in einem Strafverfahren ein Vertreter der Staatsanwaltschaft vor Gericht als Partei auftritt und, andererseits, der Generalstaatsanwalt als Mitglied der Justizleitung Beschlüsse im Bereich der Justiz(selbst)verwaltung mitverantwortet, ist nicht geeignet, berechtigte Zweifel an der Unabhängigkeit des urteilenden Gerichts hervorzurufen. ${ }^{116}$

112 BGE 136 I 207 E. 3.1 S. 210. Diese und ähnliche Formulierungen finden sich in einer Vielzahl von Urteilen. Vgl. auch KIENER, Richterliche Unabhängigkeit, 61.

113 Siehe vorne Bst. c.

114 HurNi, Rz. 16.

115 Vgl. Hurni, Rz. 19.

116 Zur speziell gelagerten Konstellation, dass der Generalstaatsanwalt selbst vor Gericht auftritt, siehe sogleich im Text. 
[157] Diese Einschätzungen erfolgen, wie erwähnt, im Rahmen einer abstrakten Überprüfung der aktuellen Gesetzeslage, wie sie durch die Justizreform 2011 geschaffen wurde. Nicht a priori ausschliessen lässt sich, dass aufgrund besonderer Umstände in einem konkreten Einzelfall berechtigte Zweifel an der Unvoreingenommenheit eines beteiligten Richters aufkommen könnten, die in einem gewissen Zusammenhang mit einem Mitglied oder einem Beschluss der Justizleitung stehen. Unter dem Aspekt der richterlichen Unabhängigkeit reicht es allerdings grundsätzlich aus, wenn für einen solchen besonders gelagerten Einzelfall eine Lösung im Einzelfall gefunden werden kann (z.B. mithilfe von Ausstandsregeln). Es folgt daraus nicht zwingend die Notwendigkeit einer strukturellen Anpassung (z.B. durch generelle Korrektur hinsichtlich der heutigen gesetzlich vorgesehenen Zusammensetzung der Justizleitung). Eine angemessene pragmatische Lösung wird sich auch finden lassen für die in der Literatur erwähnte spezielle Konstellation, dass sich anlässlich eines Berufungsverfahrens eine Begegnung zwischen dem Generalstaatsanwalt und dem Obergerichtspräsidenten im Gerichtssaal abzeichnet. ${ }^{117}$ So oder so: Eine derart speziell gelagerte, bewältigbare Einzelkonstellation ist nicht geeignet, das mit der Justizreform 2011 geschaffene Selbstverwaltungsorgan und dessen Ausgestaltung prinzipiell infrage zu stellen. Um es mit den Worten des Bundesgerichts auszudrücken: «Der blosse Umstand, dass die Anwendung» einer Regelung «in besonders gelagerten Einzelfällen zu einem verfassungswidrigen Ergebnis führen könnte», rechtfertigt es für sich allein noch nicht, die fragliche Norm als verfassungswidrig einzustufen. ${ }^{118}$ Sinngemäss gilt dies auch hier.

[158] Diese Einschätzung findet in der folgenden Überlegung eine Bestätigung: Liesse man derart marginale Faktoren wie die Mitwirkung des Generalstaatsanwalts in der Justizleitung als Grund für berechtigte Zweifel an der richterlichen Unabhängigkeit genügen, so hätte man konsequenterweise die Unabhängigkeit des Verwaltungsgerichts infrage stellen müssen, solange die Justizverwaltung noch im Wesentlichen durch die zuständigen Verwaltungsbehörden wahrgenommen wurde. Denn vor Verwaltungsgericht tritt der Staat in einer Parteirolle auf. Müsste man dann nicht auch in dieser Konstellation von einem «Anschein von Rücksichtnahme und Abhängigkeit» sprechen? Wäre nicht auch hier eine «Sanktionierung nicht genehmer Rechtsprechung durch Mittelkürzungen» ${ }^{119}$ zu befürchten gewesen? Und müssten solche Befürchtungen nicht im Grunde auch heute noch präsent sein, zumal die Justizverwaltung auch mit der Justizreform 2011 nicht vollständig in die Sphäre der Judikative übergegangen ist (vgl. Ziffer II.5.), so dass man auch heute gewisse «Abhängigkeiten» orten könnte? Allerdings: Die Unabhängigkeit der (Verfassungsund) Verwaltungsgerichtsbarkeit wurde und wird gleichwohl nicht ernstlich und prinzipiell infrage gestellt, auch nicht des Anscheins wegen, und dies zu Recht.

[159] Bezeichnend ist im Übrigen, dass die im Rahmen der Vernehmlassung und in der Literatur vorgetragenen Sorgen und Kritikpunkte sich nicht auf konkrete Vorfälle beziehen, dies obwohl die neuen organisatorischen Strukturen inzwischen seit mehr als neun Jahren bestehen. Es werden hypothetische Beispiele geschildert und Bedenken abstrakter Natur vorgebracht. Eine konkrete und reelle Gefährdung der richterlichen Unabhängigkeit war bisher und ist auch gegenwärtig nicht zu erkennen. Die in der Literatur angeführten Konstellationen reichen nach heutigen Massstäben nicht aus, um von objektiv berechtigten Zweifeln an der Unvoreingenommenheit der Gerichte zu sprechen.

117 Beispiel bei Hurni, Rz. 11.

118 Zitat aus BGE 143 I 137 E. 2.2 S. 139.

119 Siehe vorne Bst. c. 
[160] Ein juristischer Gutachter ist kein Hellseher. Man kann nicht wissenschaftlich fundiert für alle Zukunft ausschliessen, dass es im Zusammenhang mit der Justizleitung nie zu Problemen kommen wird. ${ }^{120}$ Das angesprochene Risiko ist aber als vernachlässigbar einzustufen. Und selbst wenn: In einem solchen Einzelfall wird man eine Lösung finden können, die ohne Anpassung der organisatorischen Grundstrukturen auskommt. Eine kursorische Durchsicht der im Materialienverzeichnis aufgeführten Stellungnahmen und Berichte der Venedig-Kommission des Europarats zu Fragen der Stellung und der Unabhängigkeit von Gerichten und Strafverfolgungsbehörden führt zu keiner anderen Einschätzung. ${ }^{121}$ Die anlässlich der Diskussion zur Vernehmlassungsvorlage 2019 genannten Beispiele geben keinen Anlass zu objektiv berechtigten Befürchtungen betreffend die Unabhängigkeit der Gerichte; dies gilt erst recht, wenn man im Rahmen einer abstrakten Überprüfung, wie sie hier vorzunehmen ist (vgl. Ziffer IV.), von der Annahme ausgeht, dass die Mitglieder der Justizleitung die einschlägigen Normen verfassungstreu anwenden werden.

[161] Zusammenfassend ergibt sich: Die Zusammensetzung der Justizleitung und ihre Aufgaben und Befugnisse begründen auch dem äusseren Anschein nach keine berechtigten Zweifel an der unabhängigen und unparteilichen Entscheidfindung der Gerichte.

\section{Ergebnis: Vereinbarkeit der geltenden Regelung mit der Garantie der richterlichen Unabhängigkeit}

[162] Als Ergebnis ist festzuhalten: Der Grundsatz der richterlichen Unabhängigkeit wird durch die Bundesverfassung (Art. 30 Abs. 1 und Art. 191c BV), die Europäische Menschenrechtskonvention (Art. 6 Ziffer 1 EMRK) und durch die bernische Kantonsverfassung (Art. 26 Abs. 1 und Art. 97 Abs. 1 BV) gewährleistet. Im Zentrum des verfassungs- und völkerrechtlichen Schutzes steht die rechtsprechende Tätigkeit. Die Garantie der richterlichen Unabhängigkeit ist nicht nur beeinträchtigt, wenn ein Richter oder eine Richterin in dem zu entscheidenden Fall subjektiv voreingenommen ist, sondern auch schon dann, wenn objektiv der Anschein erweckt wird, dass die richterliche Entscheidfindung Fremdeinflüssen unterliegt. Gemäss Rechtsprechung und Lehre genügt nicht jeder Anschein. Es müssen berechtigte Zweifel bestehen, dass das fragliche Gericht nicht allein nach Recht und Gesetz entscheidet, sondern sachfremde Überlegungen in den zu treffenden Entscheid einfliessen lässt.

[163] Die Ausgestaltung der Justizleitung nach geltendem Recht (insb. Art. 17 ff. GSOG) steht mit den Vorgaben des übergeordneten Rechts in Einklang. Die Aufgaben und begrenzten Entscheidungs- und Weisungsbefugnisse der Justizleitung betreffen den Bereich der Selbstverwaltung. Angesichts ihrer Aufgaben und Instrumente vermag die Justizleitung nicht in einer unzulässigen,

120 Zur Befürchtung, dass den bernischen Strafgerichten von höheren Instanzen (Bundesgericht, EGMR) eines Tages die richterliche Unabhängigkeit abgesprochen werden könnte, vgl. Vernehmlassung des Obergerichts (vom 3. Juni 2019). Konkrete Anhaltspunkte, dass ein solcher Fall eintreten wird, gibt es nach Einschätzung des Verfassers nicht.

121 Siehe insbesondere Venice Commission, Report on the Independence of the Judicial System Part I: The Independence of Judges, CDL-AD(2010)004, insb. Ziffern III.7.-11. (Budget of the Judiciary, Freedom from undue external influence, Independence within the judiciary, The allocation of cases and the right to a lawful judge), sowie Venice Commission, Compilation of Venice Commission Opinions and Reports concerning Courts and Judges, CDL-PI(2019)008, insb. Ziffer IV. (Courts) und Ziffer V. (Council of Justice). 
die richterliche Unabhängigkeit beeinträchtigenden Weise auf die rechtsprechende Tätigkeit der bernischen Gerichte einzuwirken, auch nicht dem Anschein nach.

[164] Die Rolle der Justizleitung im Budgetprozess führt nicht zu einer Beeinträchtigung der richterlichen Unabhängigkeit, auch nicht dem Anschein nach. Im Budgetprozess und auch generell sind die Mitglieder der Justizleitung bei der Ausübung ihres Stimmrechts dem Recht verpflichtet; sie haben das Gesamtinteresse der Justiz zu wahren und die Garantie der richterlichen Unabhängigkeit zu respektieren. Das für die Beschlussfassung in der Justizleitung auf Reglementsstufe festgeschriebene Einstimmigkeitserfordernis (Art. 16 Abs. 1 JLR) begründet kein «Vetorecht» der Mitglieder der Justizleitung, weder in finanziellen noch in anderen Angelegenheiten.

\section{Beurteilung der Justizleitung gemäss Vernehmlassungsvorlage 2019}

\section{Ausgangslage und Fragestellung}

[165] Die Ausgangslage und die Fragestellung lassen sich wie folgt zusammenfassen:

- Die Vernehmlassungsvorlage 2019 strebt unter anderem an, das im Rahmen der Justizreform 2011 neu geschaffene Organ der Justizleitung auf Verfassungsstufe zu verankern (vgl. Ziffer II.8.).

- Zu klären ist die Frage der Rechtmässigkeit der Vorschläge für die Verankerung der Justizleitung auf Verfassungsstufe (vgl. Ziffer I.).

- Die Aufmerksamkeit wird somit in erster Linie jenen Bestimmungen der Vernehmlassungsvorlage gelten müssen, die der Justizleitung gewidmet sind (E-Art. 97a KV, E-Art. 97b KV sowie E-Art. 83a KV) oder sie doch zumindest erwähnen (E-Art. 76 Abs. 1 Bst. e KV und E-Art. 78 Abs. 1 Bst. b KV).

- Die geplanten Rechtsänderungen auf Gesetzesstufe (GSOG und weitere Erlasse) betreffen zwar zum Teil ebenfalls die Justizleitung. Sie können aber in Anbetracht der Fragestellung im Folgenden ausser Betracht bleiben. ${ }^{122}$

- Der Beurteilungsmassstab ist im Wesentlichen derselbe wie bei der Überprüfung des geltenden Rechts (Ziffern IV.-VI.). Im Zentrum stehen wiederum die Vorgaben der Bundesverfassung betreffend Gewaltenteilung und richterliche Unabhängigkeit sowie die Garantie der richterlichen Unabhängigkeit gemäss Art. 6 Ziffer 1 EMRK. Eine Änderung ergibt sich, weil die Kantonsverfassung - anders als bei der Beurteilung des geltenden Rechts - nun nicht Massstab, sondern Gegenstand der Prüfung ist.

[166] Wiederum erfolgt die Beurteilung losgelöst von einem konkreten Einzelfall, d.h. nach dem Muster einer abstrakten Normenkontrolle (vgl. Ziffer IV.2.). Eine Besonderheit der Untersuchung

122 Es geht dabei u.a. um den Geschäftsverkehr mit dem Grossen Rat (E-Art. 6a GSOG: Antrags- und Vertretungsrecht der Justizleitung; E-Art. 6b GSOG: Mitwirkung des Regierungsrates bei Geschäften der Justizleitung; E-Art. 6c GSOG: Information; E-Art. 6d GSOG: Zusammenarbeit zwischen Grossem Rat, Regierungsrat und Justizleitung) sowie um Konsequenzen der geplanten Verfassungsänderungen (z.B. Streichung von Art. 18 Abs. 2 GSOG) bzw. um Konsequenzen der neu eingefügten Bestimmungen (E-Art. 6a ff. GSOG) und um Konsequenzen der Klarstellungen betreffend den Geschäftsverkehr mit dem Grossen Rat sowie um Anpassungen terminologischer Natur (Vereinheitlichung). Auch die geplanten Änderungen im GRG (E-Art. 61 Abs. 2), im PG (E-Art. 104 Abs. 1a) sowie im FLG (E-Art. 48 Abs. 3 und 4 sowie E-Art. 56 Abs. 1 und 3) sind hier nicht von Belang. 
besteht darin, dass hier (anders als bei der Fragestellung 1) nicht bereits geltende, sondern geplante Vorschriften zu beurteilen sind. Heranzuziehen sind auch hier die anerkannten Regeln der (Verfassungs-)Auslegung, wobei zu berücksichtigen ist, dass man - weil erst ein Vorentwurf (Vernehmlassungsvorlage) vorliegt - bei der Auslegung noch nicht auf den definitiven Vortrag des Regierungsrats und auch nicht auf Äusserungen im Rahmen der parlamentarischen Beratungen zurückgreifen kann.

[167] Gegenstand der Überprüfung sind Vorschriften der Verfassungsstufe. Diese unterliegen, nach der Beratung und Beschlussfassung im Grossen Rat, der Volksabstimmung (obligatorisches Referendum) und müssen, nach der Gutheissung durch die Stimmberechtigten, auf Bundesebene noch das in Art. 51 Abs. 2 BV vorgesehene Gewährleistungsverfahren durchlaufen. Die Bundesversammlung (Art. 172 Abs. 2 BV) wird zu prüfen haben, ob die beschlossenen Änderungen der Kantonsverfassung mit den Vorgaben des Bundesrechts (inkl. Völkerrecht) in Einklang stehen.

\section{Inhalt und Tragweite der geplanten Verfassungsänderungen}

[168] Im Rahmen der Vorlage «Justizverfassung und Massnahmen aus der Evaluation Justizreform II» (Vernehmlassungsvorlage 2019) sollen insgesamt elf Bestimmungen der Kantonsverfassung neu geschaffen oder geändert werden. Diese Verfassungsänderungen «sind als Nachführung des auf Gesetzesstufe bereits seit der Justizreform II geltenden Rechts zu verstehen.» ${ }^{123}$ Statt von einer «Nachführung» kann man auch von einer «Heraufstufung» oder «Konstitutionalisierung» von heute auf der Gesetzesstufe angesiedelten Regelungen sprechen.

a.

Der Justizleitung gewidmete neue Bestimmungen

[169] Aufgrund der Fragestellung stehen zwei der Justizleitung gewidmete Bestimmungen im Zentrum (E-Art. 97a KV und E-Art. 97b KV).

aa) E-Art. 97a KV (Justizleitung)

[170] Die Bestimmung lautet:

1 Die Justizleitung ist das gemeinsame Organ von Obergericht, Verwaltungsgericht und Generalstaatsanwaltschaft.

2 Das Gesetz regelt die Zusammensetzung und die Zuständigkeit der Justizleitung.

[171] Diese Bestimmung schreibt eine bestehende gesetzliche Regelung (Art. 17 Abs. 1 GSOG) wörtlich auf Verfassungsstufe fest (Abs. 1) und erteilt dem Gesetzgeber einen Regelungsauftrag (Zusammensetzung und Zuständigkeit der Justizleitung; Abs. 2).

[172] Der Inhalt von Absatz 1 (Justizleitung als gemeinsames Organ von Obergericht, Verwaltungsgericht und Generalstaatsanwaltschaft) bewegt sich, wie bereits gesehen (vgl. Ziffern V. und

123 Vernehmlassungsentwurf «Vortrag Justizverfassung», Ziff. 1. 
VI.), im Rahmen der Vorgaben der Bundesverfassung und der EMRK. Durch die Verankerung auf Verfassungsstufe ändert sich an dieser Einschätzung nichts.

[173] Eine genauere Betrachtung erfordert der auf den ersten Blick eher unscheinbare Absatz 2. Grund dafür ist, dass der Regelungsauftrag sehr offen formuliert ist. Im Wortlaut dieses Absatzes findet sich keine Vorgabe beziehungsweise Beschränkung in Bezug auf das mögliche Tätigkeitsfeld der Justizleitung. Die hier angedeutete rechtsetzungstechnische Frage lässt sich einfacher klären, wenn die übrigen vorgeschlagenen Verfassungsänderungen untersucht und eingeordnet sind. Auf E-Art. 97a Abs. 2 KV wird zurückzukommen sein (vgl. Ziffer VII.3.).

bb) E-Art. 97b KV (Ausgabenbefugnisse der Justizleitung)

[174] Die Bestimmung lautet:

1 Die Justizleitung beschliesst über

a neue einmalige Ausgaben bis eine Million Franken,

b neue wiederkehrende Ausgaben bis 200000 Franken,

c gebundene Ausgaben.

[175] Diese Bestimmung soll die heute in Art. 18 Abs. 2 GSOG festgelegten Ausgabenbefugnisse der Justizleitung auf Verfassungsstufe festschreiben (ohne Veränderungen im Wortlaut). Im Gegenzug soll Art. 18 Abs. 2 GSOG gestrichen werden. Die neue Verfassungsbestimmung bedingt eine Anpassung redaktioneller Natur in Art. 76 KV (Finanzbefugnisse des Grossen Rats).

[176] Die vorgeschlagene Heraufstufung einer bestehenden gesetzlichen Regelung wirft weder unter dem Aspekt der Gewaltenteilung noch unter dem Aspekt der richterlichen Unabhängigkeit Probleme auf und wird im Folgenden nicht weiter untersucht.

cc) E-Art. 83a KV (Stellung der Justizleitung im Grossen Rat)

[177] Die dritte der Justizleitung gewidmete neue Bestimmung ist E-Art. 83a KV. Die Bestimmung lautet:

1 Die Justizleitung hat das Recht, dem Grossen Rat in den im Gesetz vorgesehenen Geschäften Anträge zu stellen.

2 Sie nimmt bei diesen Geschäften an den Sitzungen des Grossen Rates mit beratender Stimme teil.

3 Das Gesetz regelt die Mitwirkung des Regierungsrates bei der Vorbereitung der Geschäfte.

[178] Diese Bestimmung verankert das Antragsrecht der Justizleitung im Grossen Rat (bei eigenen Geschäften) sowie das Recht auf (und die Pflicht zur) Teilnahme an den Sitzungen mit beratender Stimme (bei eigenen Geschäften). Auch E-Art. 83a KV wirft unter dem Aspekt der Gewaltenteilung und unter dem Aspekt der richterlichen Unabhängigkeit keine Probleme auf und wird im Folgenden nicht weiter untersucht. 


\section{b. Weitere vorgeschlagene Verfassungsänderungen}

[179] Die anderen vorgeschlagenen Verfassungsänderungen sind von unterschiedlicher Bedeutung für die Beurteilung der Justizleitung und ihrer verfassungsrechtlichen Stellung.

aa) E-Art. 78 Abs. 1 Bst. b KV (Aufsicht über die Geschäftsführung)

[180] Ausdrücklich erwähnt werden soll die Justizleitung künftig in Art. 78 KV (Aufsicht): «Der Grosse Rat beaufsichtigt: [...] $b$ (neu) die Geschäftsführung der Justizleitung, der obersten Gerichte und der Generalstaatsanwaltschaft.». Es handelt sich um die verfassungsrechtliche Verankerung einer bisher in der Kantonsverfassung implizit und im GSOG explizit enthaltenen Regelung (Art. 13 GSOG; vgl. vorne Ziffer II.5.). Die geplante Ergänzung des Art. 78 KV führt eine Klarstellung herbei, soll jedoch, soweit ersichtlich, nichts an der Rechtslage ändern. Die parlamentarische Aufsicht über die Justiz steht in einem gewissen Spannungsverhältnis zu den verfassungsrechtlichen Unabhängigkeitsgarantien, ist aber nach allgemein geteilter Auffassung ein grundsätzlich zulässiges Instrument (vgl. vorne Ziffer VI.2.). Eine nähere Untersuchung erscheint unter diesen Umständen nicht erforderlich.

[181] Die weiteren geplanten Verfassungsänderungen erwähnen die Justizleitung nicht. Einige unter ihnen haben jedoch aufgrund ihres Regelungsthemas eine gewisse Bedeutung für die Frage der Vereinbarkeit der vorgeschlagenen verfassungsrechtlichen Verankerung der Justizleitung mit dem übergeordneten Recht. Dies trifft auf die folgenden Bestimmungen zu.

bb) E-Art. 97 Abs. 1 KV (Unabhängigkeitsgarantie)

[182] Die Bestimmung lautet:

Die Gerichte und die Staatsanwaltschaft sind in der Rechtsprechung und Strafverfolgung unabhängig und nur dem Recht verpflichtet.

[183] Gegenüber dem aktuellen Art. 97 Abs. 1 KV ergeben sich zwei Änderungen:

- Neu soll die (spezifische) Unabhängigkeit der Staatsanwaltschaft in der Strafverfolgung, bisher gesetzlich garantiert (Art. 4 GSOG), auch in der Kantonsverfassung verankert werden. Mit dieser zusätzlichen Abstützung bleibt der Kanton Bern innerhalb des Rahmens, den die Bundesverfassung und die EMRK in Bezug auf die Stellung der Staatsanwaltschaft abstecken (vgl. Ziffern V.2. und VI.3.). Die vorgeschlagene Änderung der Verfassung ist aus der Sicht des übergeordneten Rechts nicht zu beanstanden.

- Das geltende Recht umschreibt die Unabhängigkeitsgarantie mit folgenden Worten: «Die Unabhängigkeit der Gerichte ist gewährleistet.» In dieser Formulierung kommt die institutionelle Dimension der richterlichen Unabhängigkeit deutlich zum Ausdruck. Demgegenüber setzt der neue Wortlaut den Akzent auf die Rechtsprechung als spezifisch geschützte Tätigkeit der Gerichte - wie dies auf Bundesebene Art. 191c BV tut. Diese Akzentverschiebung ist aus der Sicht des übergeordneten Rechts nicht zu beanstanden, zumal gemäss Vernehmlassungsvorlage 2019 zusätzlich die Selbstverwaltung der Gerichte (E-Art. 97 Abs. 1a KV) und die Vertretung der Geschäfte der Justiz im Grossen Rat (E-Art. 83a KV) im Sin- 
Giovanni Biaggini, Die bernische Justizleitung auf dem verfassungsrechtlichen Prüfstand, in:

«Justice - Justiz - Giustizia» 2020/4

ne der institutionellen Unabhängigkeit in der Kantonsverfassung festgeschrieben werden sollen.

cc) E-Art. 97 Abs. 1a KV (Selbstverwaltung der Justiz)

[184] Die Bestimmung lautet:

Sie [d.h. die Gerichte und die Staatsanwaltschaft] verwalten sich selbst, soweit das Gesetz nichts anderes bestimmt.

[185] Die vorgeschlagene Bestimmung verankert neu den bisher (nur, aber immerhin) auf Gesetzesstufe (Art. 5 Abs. 1 GSOG) figurierenden Grundsatz der Selbstverwaltung auf Verfassungsstufe. Das übergeordnete Recht belässt den Kantonen, wie gesehen (vgl. Ziffer V.2.), bei der Zuordnung und Ausgestaltung der Justizverwaltung einen weiten Spielraum. Die Kantone werden weder durch die Bundesverfassung noch durch die EMRK dazu verpflichtet, den Gerichten (und der Staatsanwaltschaft) eine volle Selbstverwaltung zu garantieren. Es ist daher zulässig, wenn E-Art. 97 Abs. 1a KV andere gesetzliche Regelungen zulässt, d.h. es dem kantonalen Gesetzgeber erlaubt, bestimmte Aspekte der Justizverwaltung nicht den Gerichten (bzw. der Staatsanwaltschaft) selbst zuzuweisen. Die Grenzen dieses Spielraums werden durch die Relativierungsklausel («soweit das Gesetz nichts anderes bestimmt») nicht überschritten. Im Übrigen ist der kantonale Gesetzgeber bei der Inanspruchnahme dieser Relativierungsklausel verpflichtet, die Unabhängigkeitsgarantie gemäss E-Art. 97 Abs. $1 \mathrm{KV}$ sowie das übergeordnete Recht (insb. Art. 30 Abs. 1 und Art. 191c BV, Art. 6 Ziffer 1 EMRK) zu wahren.

dd) E-Art. 100a KV (Staatsanwaltschaft)

[186] Die Bestimmung lautet:

Die Staatsanwaltschaft nimmt die ihr im Gesetz zugewiesenen Aufgaben im Bereich der Strafverfolgung wahr.

[187] Die Verankerung der Staatsanwaltschaft als für die Strafverfolgung zuständige Behörde in der Verfassung ist unter dem Aspekt des übergeordneten Rechts unproblematisch. Die Platzierung der Bestimmung in Kapitel 5.5 - welches neu den Titel «Gerichte und Staatsanwaltschaft» (bisher: "Gerichte») tragen soll - unterstreicht, dass die Staatsanwaltschaft Teil der bernischen Justiz ist. Zugleich wird klargestellt, dass die Staatsanwaltschaft nicht als Teil der Exekutive anzusehen ist. Die Verfassung bringt damit ein Gewaltenteilungsverständnis zum Ausdruck, das, wie gesehen (vgl. Ziffer V.2.), im Rahmen des übergeordneten Rechts Platz hat. 
ee) Weitere Bestimmungen

[188] Nicht weiter von Interesse sind im vorliegenden Zusammenhang die geplanten Änderungen von:

- E-Art. 68 Abs. 1 und 2 KV (personelle Gewaltenteilung im Verhältnis zwischen Grossem Rat und Strafverfolgungsbehörden);

- E-Art. 98 KV und E-Art. 99 KV (Nachführung der Neuordnung im Bereich der Zivil- bzw. Strafgerichtsbarkeit auf Verfassungsstufe).

\section{c. Zwischenergebnis}

[189] Die nähere Betrachtung hat gezeigt, dass die im Rahmen der Vernehmlassungsvorlage 2019 vorgeschlagenen Verfassungsänderungen unter dem Aspekt des übergeordneten Rechts (Bundesverfassung, EMRK) keine zusätzlichen Probleme aufwerfen.

[190] Vom Regelungsgehalt her handelt es sich in der Tat im Wesentlichen um eine verfassungsrechtliche Festschreibung von heute bereits auf Gesetzesstufe bestehenden Regeln, begleitet von gewissen Klärungen (Antragsrecht) bzw. terminologischen und redaktionellen Anpassungen. Insoweit kann man in der Tat von einer Nachführung der Justizreform II auf Verfassungsstufe ${ }^{124}$ und von einer besseren Sichtbarmachung der staatsrechtlichen Stellung der Justizleitung und der Staatsanwaltschaft sprechen. Zugleich wird das Gewaltenteilungsverständnis des bernischen Verfassungsgebers verdeutlicht.

[191] Dass es sich um eine Nachführung bzw. Konstitutionalisierung von (im Wesentlichen) bereits bestehenden gesetzlichen Regelungen handelt, bedeutet nicht, dass die Verfassungsänderungen keine normative Relevanz hätten. Eine Heraufstufung und verfassungsrechtliche Verankerung hat praktische Konsequenzen, dies selbst dann, wenn der Wortlaut dabei nicht verändert wird:

- Die Bestimmung erlangt eine erhöhte Beständigkeit (Abänderung nur noch im erschwerten Verfahren der Verfassungsänderung).

- Sie bedarf der Gewährleistung des Bundes (Art. 51 Abs. 2 BV) und wird in einem formellen Verfahren auf ihre Vereinbarkeit mit dem Bundesrecht (inkl. Völkerrecht) überprüft.

- Sie prägt die Auslegung anderer Verfassungsbestimmungen mit (systematische Auslegung).

- Und sie gehört nicht mehr zu den Normen, die sich einer Überprüfung am Massstab der Kantonsverfassung stellen müssen, sondern gehört als kantonale Verfassungsnorm nunmehr zum Massstab, an dem sich die kantonale Gesetzgebung messen lassen muss.

[192] Diese rechtlichen Konsequenzen einer Konstitutionalisierung mögen, je nach Standpunkt, die rechtspolitische Würdigung und Wünschbarkeit der vorgeschlagenen Regelungen beeinflussen, ein zusätzliches Konfliktpotenzial im Verhältnis zur Bundesverfassung oder zur EMRK ergibt sich aus der Heraufstufung nicht.

124 Vgl. Vernehmlassungsentwurf «Vortrag Justizverfassung», Ziffer 1 und passim. 


\section{Insbesondere E-Art. 97a KV (Justizleitung)}

[193] Wie bereits erörtert (vgl. Ziffer VII.2.a.), überführt E-Art. 97a Abs. 1 KV die heute in Art. 17 Abs. 1 GSOG enthaltene Regelung mit unverändertem Wortlaut in die Kantonsverfassung. Diese Heraufstufung ändert nichts an der Einschätzung, wonach die Justizleitung als gemeinsames Organ von Obergericht, Verwaltungsgericht und Generalstaatsanwaltschaft mit dem übergeordneten Recht in Einklang steht.

[194] Die Verankerung der Justizleitung in der Kantonsverfassung hat die Nebenfolge, dass eine allfällige Änderung der Grundstruktur (Beteiligung von Obergericht, Verwaltungsgericht, Generalstaatsanwaltschaft) bzw. eine allfällige Abschaffung des gemeinsamen Organs nicht mehr Sache des Gesetzgebers, sondern Sache des Verfassungsgebers ist (vgl. vorne Ziff. 2.c). Die Verfahrenshürden sind höher (obligatorisches statt fakultatives Referendum; vgl. Art. 61 und Art. 62 KV, je Abs. 1 Bst. a). Nicht zu den Grundstrukturen gehört die Einstimmigkeitsregel (Art. 16 Abs. 1 JLR; siehe vorne Ziffer II.4.). Sie ist weder im Gesetz noch (gemäss Vernehmlassungsvorlage 2019) in der Kantonsverfassung festgeschrieben. Falls die Einstimmigkeitsregel zu praktischen Problemen Anlass geben sollte (siehe vorne VI.6.), so kann sie auch nach der Realisierung der vorgeschlagenen Reformen ohne vorherige Änderung der Kantonsverfassung modifiziert werden.

[195] Was den Regelungsauftrag gemäss E-Art. 97a Abs. 2 KV betrifft - «Das Gesetz regelt die Zusammensetzung und die Zuständigkeit der Justizleitung.» - , so fällt auf, dass der Verfassungstext nichts Näheres dazu sagt, welcher Art die Zuständigkeiten sind bzw. sein können, die der Gesetzgeber der Justizleitung übertragen darf bzw. soll. Der Wortlaut ist diesbezüglich offen formuliert. Eine Beschränkung auf die Aufgaben gemäss geltendem Recht ist dem Wortlaut nicht zu entnehmen, ebenso wenig eine Beschränkung auf Aufgaben der Justiz(selbst)verwaltung. Bei einer isolierten Lektüre der Vorschrift könnte daher der Eindruck entstehen, dass der Gesetzgeber der Justizleitung neben Aufgaben und Befugnissen im Bereich der Justizverwaltung (wie sie die Justizleitung heute besitzt) ohne Weiteres auch weitere Befugnisse, etwa im Bereich der Rechtsprechung oder der Kontrolle, übertragen könnte. Aus den bisher vorliegenden Materialien sind keinerlei Pläne dieser Art ersichtlich. Der Vernehmlassungsentwurf zum Vortrag des Regierungsrates geht, im Gegenteil, davon aus, dass die Justizleitung keine neuen Zuständigkeiten erhalten soll; es soll bei den aktuellen Aufgaben und Befugnissen bleiben, die alle im Bereich der Selbstverwaltung liegen. Im Wortlaut von E-Art. 97a Abs. 2 KV hat sich diese begrenzte Regelungsabsicht indes nicht niedergeschlagen.

[196] Offen formuliert ist prima vista der vorgeschlagene Regelungsauftrag (Abs. 2) auch in Bezug auf die Zusammensetzung der Justizleitung. Bei näherer Betrachtung zeigt sich indes, dass der Spielraum des Gesetzgebers enger ist, als es der blosse Wortlaut von E-Art. 97a Abs. 2 KV denken lässt. Denn die Verfassung gibt in E-Art. 97a Abs. $1 \mathrm{KV}$ vor, dass die Justizleitung das gemeinsame Organ von Obergericht, Verwaltungsgericht und Generalstaatsanwaltschaft ist. Der Gesetzgeber wird dadurch zwar nicht auf die gegenwärtige gesetzliche Lösung festgelegt (drei Mitglieder, und zwar jeweils die Spitze der drei beteiligten Behörden). Es steht dem Gesetzgeber jedoch nicht zu, bei der Regelung der Zusammensetzung eines der beiden obersten Gerichte oder die Generalstaatsanwaltschaft zu übergehen. Die Grundstruktur der Justizleitung ist somit durch E-Art. 97a Abs. $1 \mathrm{KV}$ vorgegeben. Und diese Grundstruktur steht, wie gesehen, mit den Vorgaben des übergeordneten Rechts in Einklang.

[197] Bei einer näheren Analyse erweist sich, dass auch der in E-Art. 97a Abs. 2 KV enthaltene Regelungsauftrag betreffend die Zuständigkeiten der Justizleitung mit den Vorgaben des übergeord- 
neten Rechts vereinbar ist. Die Bestimmung darf nämlich nicht allein gestützt auf den Wortlaut ausgelegt werden. Heranzuziehen sind auch die übrigen anerkannten Kriterien der Verfassungsauslegung. ${ }^{125}$ Dazu gehören das entstehungsgeschichtliche (historische), das systematische sowie das teleologische (regelungszweckbezogene) Element. Zudem muss, soweit auslegungsmethodisch möglich, auch das kantonale Verfassungsrecht in Einklang mit dem Bundesrecht und dem Völkerrecht interpretiert werden (verfassungs- bzw. völkerrechtskonforme Auslegung). Bei der Beurteilung der Vereinbarkeit einer Regelung mit dem übergeordneten Recht ist gemäss Rechtsprechung und Lehre weiter zu berücksichtigen, unter welchen Umständen die betreffende Bestimmung zur Anwendung gelangen wird. ${ }^{126}$

- Aus dem Kontext der Vernehmlassungsvorlage 2019 geht, wie bereits erwähnt, klar hervor, dass die Zuständigkeiten der Justizleitung sich im bisherigen Rahmen bewegen sollen. ${ }^{127}$ Mit E-Art. 97a Abs. 2 KV verfolgt der Verfassungsgeber nicht die Absicht, dem Gesetzgeber die Möglichkeit zu geben, die Justizleitung mit problematischen neuen Zuständigkeiten auszustatten.

- Dies zeigt auch die systematische Stellung von E-Art. 97a Abs. 2 KV im Rahmen der Vernehmlassungsvorlage 2019. Mit der Vernehmlassungsvorlage sollen die richterliche Unabhängigkeit (E-Art. 97 Abs. $1 \mathrm{KV}$ ) und die Selbstverwaltung der Justiz (E-Art. 97 Abs. 1a KV) bekräftigt und gestärkt werden. Unter systematischen Aspekten ist der Gesetzgeber bei der Umsetzung des in E-Art. 97a Abs. $2 \mathrm{KV}$ erteilten Regelungsauftrags verpflichtet, die Unabhängigkeit der Rechtsprechung und der Strafverfolgung zu respektieren (E-Art. 97 Abs. 1 KV). Die Unabhängigkeit von Rechtsprechung und Strafverfolgung steht somit nicht zur Disposition des Gesetzgebers, auch nicht bei der Umsetzung von E-Art. 97a Abs. 2 KV. ${ }^{128}$ $\mathrm{Zu}$ respektieren ist im Rahmen der systematischen Auslegung auch das kantonalverfassungsrechtlich gewährleistete "unantastbar[e] Recht auf unabhängige, unparteiische und vom Gesetz vorgesehene Richterinnen und Richter» (Art. 26 Abs. $1 \mathrm{KV}$ ).

- Im Übrigen ist der kantonale Gesetzgeber bei der Umsetzung von E-Art. 97a Abs. $2 \mathrm{KV}$ verpflichtet, die Bundesverfassung und die EMRK zu respektieren (bundesrechts- bzw. völkerrechtskonforme Auslegung und Umsetzung der Kantonsverfassung).

[198] Kurz: E-Art. 97a Abs. 2 KV darf für den Gesetzgeber kein Freipass sein - und ist kein Freipass -, um der Justizleitung per Gesetz beliebige Aufgaben zu übertragen. Eine auf E-Art. 97a Abs. $2 \mathrm{KV}$ gestützte Übertragung von Aufgaben, bei denen die Unabhängigkeit der Justiz beeinträchtigt wird, wäre klar unzulässig.

[199] Zusammenfassend ist festzuhalten, dass der Wortlaut von E-Art. 97a Abs. 2 KV - gemessen an der Regelungsabsicht - «überschiessend» formuliert ist. Die Bestimmung ist jedoch einer Auslegung zugänglich, die mit den Vorgaben des übergeordneten Rechts in Einklang steht. Es gibt aus heutiger Sicht keinen Anlass daran zu zweifeln, dass der bernische Gesetzgeber bei der Um-

\footnotetext{
125 Vgl. BiagGini, Komm. BV, Einleitung, N 18 ff.

126 Vgl. BGE 144 V 236 E. 2.2 S. 239; BGE 130 I 82 E. 2.1 S. 86. Vgl. vorne Ziffer IV.2.

127 Vgl. Vernehmlassungsentwurf «Vortrag Justizverfassung», Ziff. 6.1 (zu E-Art. 97a KV).

128 Entsprechendes gilt im Übrigen auch bei der Umsetzung der Relativierungsklausel in E-Art. 97 Abs. 2 KV, wonach die (Justiz-) Selbstverwaltung den Gerichten bzw. der Staatsanwaltschaft zusteht, «soweit das Gesetz nichts anderes bestimmt».
} 
setzung von E-Art. 97a Abs. 2 KV die Schranken des übergeordneten Rechts beachten wird. Die gebotene «einschränkende» Auslegung und Anwendung von E-Art. 97a Abs. 2 KV, die für eine Umsetzung in Einklang mit den Vorgaben des übergeordneten Rechts sorgt, ist nicht nur ohne Weiteres möglich, sondern unter den gegebenen Umständen auch hinreichend wahrscheinlich.

[200] Immerhin: Mit Blick auf die weiteren Schritte, die das Rechtsetzungsprojekt zu durchlaufen hat (parlamentarische Beratung, Volksabstimmung, Gewährleistungsverfahren auf Bundesebene), kann man sich fragen, ob nicht eine Klarstellung hinsichtlich der Tragweite der Bestimmung nützlich wäre. $\mathrm{Zu}$ denken wäre etwa an eine klarstellende Erklärung zuhanden der Materialien. Vielleicht noch besser wäre eine Verdeutlichung im Verfassungstext selbst. Diese Verdeutlichung könnte zum Beispiel in die Richtung gehen, dass klargestellt wird (sei dies in Abs. 1, sei dies in Abs. 2), dass es sich bei der Justizleitung um ein Organ der justiziellen Selbstverwaltung handelt, welches ausgewählte Zuständigkeiten «übergreifender» Natur im Bereich der Justiz(selbst)verwaltung wahrnimmt. Es geht bei einer solchen Präzisierung um eine Frage der Optimierung des Wortlauts der Vorschrift, nicht um die Behebung einer (verfassungs)rechtlichen Unzulänglichkeit.

\section{Ergebnis: Vereinbarkeit der vorgesehenen Verankerung der Justiz- leitung in der Kantonsverfassung mit den übergeordneten Vorgaben}

[201] Zusammenfassend ist festzuhalten, dass die im Rahmen der Vernehmlassungsvorlage 2019 angestrebte Verankerung der Justizleitung auf Verfassungsstufe mit den Vorgaben des übergeordneten Rechts (Bundesverfassung, EMRK) in Einklang steht.

[202] Es empfiehlt sich, die Formulierung von E-Art. 97a KV (Regelungsauftrag betreffend die Zuständigkeit der Justizleitung) zu überprüfen, da diese Bestimmung - gemessen an der Regelungsabsicht - «überschiessend» formuliert ist.

\section{Zusammenfassung}

[203] I. Ziel der vorliegenden Untersuchung war es, zu klären, ob die Justizleitung, wie sie mit der Justizreform 2011 geschaffen wurde und nun im Rahmen der Vernehmlassungsvorlage 2019 in der Kantonsverfassung verankert werden soll, vereinbar ist mit dem übergeordnetem Recht, insbesondere mit der Unabhängigkeitsgarantie zugunsten der Justiz und mit dem Grundsatz der Gewaltenteilung.

[204] Die wichtigsten Ergebnisse der vorliegenden Untersuchung lassen sich wie folgt zusammenfassen:

[205] II. Die bernische Justizleitung als «das gemeinsame Organ von Obergericht, Verwaltungsgericht und Generalstaatsanwaltschaft» ist ein Selbstverwaltungsorgan im Bereich der Justiz mit begrenztem Aufgabenbereich. Eine Besonderheit zeigt sich bei der Zusammensetzung. Zwei der drei Mitglieder des Kollegialorgans stammen aus der Judikative (Präsidentin bzw. Präsident des Ober- und des Verwaltungsgerichts), eines aus der Staatsanwaltschaft (Generalstaatsanwalt). Die drei gleichberechtigten Mitglieder der Justizleitung sind dem Gesamtinteresse verpflichtet. Das für die Beschlussfassung in der Justizleitung auf Reglementsstufe festgeschriebene Einstimmigkeitserfordernis (Art. 16 Abs. 1 JLR) begründet kein «Vetorecht» der Mitglieder der Justizleitung. 
[206] III. Die im Rahmen der Vernehmlassung und in weiteren Debattenbeiträgen vorgebrachten Kritikpunkte betreffen den Grundsatz der Gewaltenteilung (Stellung der Staatsanwaltschaft; Vermischung von Staatsfunktionen) sowie die Garantie der richterlichen Unabhängigkeit (mögliche Gefährdungen im Zusammenhang mit den Aufgaben und Befugnissen der Justizleitung bzw. mit der Ausgestaltung des Entscheidverfahrens).

[207] IV. Als Beurteilungsmassstab dienen die einschlägigen Vorgaben der Bundesverfassung (Art. 51 sowie Art. 30 Abs. 1 und Art. 191c BV), der Europäischen Menschenrechtskonvention (Art. 6 Ziffer 1 EMRK) und der bernischen Kantonsverfassung (Art. 66 Abs. 1 sowie Art. 26 Abs. 1 und Art. 97 Abs. 1 BV). Die Beurteilung der Rechtmässigkeit erfolgt nicht aus Anlass eines Einzelfalls, sondern losgelöst von einem konkreten Konflikt. Die Überprüfung orientiert sich an den Kriterien, die bei einer abstrakten Normenkontrolle üblich sind. Bei der Beurteilung wird davon ausgegangen, dass sich die für die Umsetzung und Anwendung zuständigen Behörden bzw. Amtsträger rechtskonform verhalten.

[208] V. Die im Rahmen der Justizreform 2011 beschlossene Übertragung bestimmter Aufgaben und Befugnisse der Justizverwaltung auf die Justizleitung (gemeinsames Organ von Obergericht, Verwaltungsgericht und Generalstaatsanwaltschaft) ist mit den Gewaltenteilungsvorgaben gemäss Art. 51 Abs. 1 BV bzw. Art. 66 Abs. 1 KV vereinbar.

[209] VI. Die Ausgestaltung der Justizleitung gemäss Justizreform 2011 steht mit der Garantie der richterlichen Unabhängigkeit in Einklang. Die unvoreingenommene gerichtliche Entscheidfindung wird nicht beeinträchtigt, auch nicht dem objektiven äusseren Anschein nach. Die Ausgestaltung der Justizleitung ist nicht geeignet, berechtigte Zweifel an der unabhängigen und unparteilichen Entscheidfindung der Gerichte zu wecken. Auch die Rolle der Justizleitung im Budgetprozess führt nicht zu einer Beeinträchtigung der richterlichen Unabhängigkeit.

[210] VII. Die im Rahmen der Vernehmlassungsvorlage 2019 angestrebte Verankerung der Justizleitung auf Verfassungsstufe steht mit den Vorgaben des übergeordneten Rechts (Bundesverfassung, EMRK) in Einklang. Die im Rahmen der Vernehmlassung und in weiteren Debattenbeiträgen vorgebrachten Kritikpunkte sind rechtspolitischer Natur.

Prof. Dr. iur. Giovanni Biaggini, Ordinarius für Staats-, Verwaltungs- und Europarecht an der Universität Zürich.

Der Aufsatz beruht auf einem im Auftrag der Direktion für Inneres und Justiz des Kantons Bern erstatteten Rechtsgutachten (April 2020). Die Belege in den Fussnoten beschränken sich auf das Nötigste. Der Verfasser dankt seinem Mitarbeiter RA Thomas Schaad, MLaw, für die wertvolle Unterstützung bei der Finalisierung des Aufsatzes. 


\section{Anhang}

\section{Abkürzungen}

\begin{tabular}{|c|c|}
\hline BSG & Bernische Systematische Gesetzessammlung \\
\hline BV & $\begin{array}{l}\text { Bundesverfassung der Schweizerischen Eidgenossenschaft vom } \\
\text { 18. April } 1999 \text { (SR 101) }\end{array}$ \\
\hline EGMR & Europäischer Gerichtshof für Menschenrechte \\
\hline EMRK & $\begin{array}{l}\text { Konvention vom } 4 \text {. November } 1950 \text { zum Schutze der Menschenrechte } \\
\text { und Grundfreiheiten (SR 0.101) }\end{array}$ \\
\hline $\begin{array}{l}\text { Evaluation } \\
\text { «Justizreform II» }\end{array}$ & $\begin{array}{l}\text { Ecoplan/Wenger Plattner, Evaluation der Justizreform II im Kanton } \\
\text { Bern (im Auftrag der Justizdelegation des Regierungsrats des Kantons } \\
\text { Bern), Schlussbericht (27. Mai 2016) }\end{array}$ \\
\hline FLG & $\begin{array}{l}\text { Gesetz über die Steuerung von Finanzen und Leistungen vom 26. März } \\
2002 \text { (BSG 620.0) }\end{array}$ \\
\hline GRG & $\begin{array}{l}\text { Gesetz über den Grossen Rat (Grossratsgesetz) vom 4. Juni } 2013 \text { (BSG } \\
151.21 \text { ) }\end{array}$ \\
\hline GSOG & $\begin{array}{l}\text { Gesetz über die Organisation der Gerichtsbehörden und der } \\
\text { Staatsanwaltschaft vom 11. Juni } 2009 \text { (BSG 161.1) }\end{array}$ \\
\hline IG & $\begin{array}{l}\text { Gesetz über die Information der Bevölkerung (Informationsgesetz) } \\
\text { vom 2. November } 1993 \text { (BSG 107.1) }\end{array}$ \\
\hline JFinR & $\begin{array}{l}\text { Reglement [der Justizleitung] über Steuerung von Finanzen und } \\
\text { Leistungen der Justiz (BSG 161.111.2) vom 27. April } 2010\end{array}$ \\
\hline JLR & Reglement der Justizleitung vom 26. Mai 2010 (BSG 161.111.1) \\
\hline JPersR & $\begin{array}{l}\text { Personalreglement der Gerichtsbehörden und der Staatsanwaltschaft } \\
\text { vom 22. Dezember } 2010 \text { (BSG 161.16) [von der Justizleitung erlassen] }\end{array}$ \\
\hline KFKG & $\begin{array}{l}\text { Gesetz über die Finanzkontrolle (Kantonales Finanzkontrollgesetz) } \\
\text { vom 1. Dezember } 1999 \text { (BSG 622.1) }\end{array}$ \\
\hline KV & Verfassung des Kantons Bern vom 6. Juni 1993 (BSG 101.1) \\
\hline $\mathrm{NEF}$ & Neue Verwaltungsführung \\
\hline PG & Personalgesetz vom 16. September 2004 (BSG 153.01) \\
\hline PV & $\begin{array}{l}\text { Personalverordnung [des Regierungsrats] vom 18. Mai } 2005 \text { (BSG } \\
153.011 .1 \text { ) }\end{array}$ \\
\hline $\begin{array}{l}\text { Vernehmlassungs- } \\
\text { entwurf «Vortrag } \\
\text { Justizverfassung» }\end{array}$ & $\begin{array}{l}\text { Vernehmlassungsentwurf zum Vortrag des Regierungsrates zur } \\
\text { Änderung der Verfassung des Kantons Bern sowie zur Änderung des } \\
\text { Gesetzes über die Organisation der Gerichtsbehörden und der } \\
\text { Staatsanwaltschaft (GSOG) [März 2019] }\end{array}$ \\
\hline VMV & $\begin{array}{l}\text { Verordnung über das Vernehmlassungs- und das Mitberichtsverfahren } \\
\text { vom 26. Juni } 1996 \text { (BSG 152.025) }\end{array}$ \\
\hline $\begin{array}{l}\text { Vortrag } \\
\text { «Justizreform II» }\end{array}$ & $\begin{array}{l}\text { Regierungsrat, Gesetzgeberische Umsetzung der Justizreform - Gesetz } \\
\text { über die Organisation der Gerichtsbehörden und der } \\
\text { Staatsanwaltschaft (GSOG), Einführungsgesetz zur } \\
\text { Zivilprozessordnung, zur Strafprozessordnung und zur } \\
\text { Jugendstrafprozessordnung (EG ZSJ), Vortrag des Regierungsrates, } \\
\text { in: Tagblatt des Grossen Rates des Kantons Bern, Aprilsession } 2009 \\
\text { (Beilage 17) }\end{array}$ \\
\hline
\end{tabular}




\section{Ausgewählte Literatur}

Auer Andreas, Staatsrecht der schweizerischen Kantone, Bern 2016.

Biaggini Giovanni, Bundesverfassung der Schweizerischen Eidgenossenschaft. Kommentar, 2. Aufl., Zürich 2017 (zit. Komm. BV).

Biaggini Giovanni, Gewaltenteilung im Verfassungsstaat, in: Giovanni Biaggini/

Thomas Gächter/Regina Kiener (Hrsg.), Staatsrecht, 2. Aufl., Zürich/St. Gallen 2015, § 17.

Ehrenzeller Bernhard u.a. (Hrsg.), Die Schweizerische Bundesverfassung Kommentar, 3. Aufl., Zürich/St. Gallen 2014 (zit.: SG-Komm. BV).

Eichenberger Kurt, Die richterliche Unabhängigkeit als staatsrechtliches Problem, Bern 1960.

Eichenberger Kurt, Justizverwaltung, in: Aargauischer Juristenverein (Hrsg.), Festschrift für den aargauischen Juristenverein 1936-1986, Aarau/Frankfurt a. M. 1986, 31 ff.

Frowein Jochen Abr./Peukert Wolfgang, Europäische Menschenrechtskonvention.

EMRK-Kommentar, 3. Aufl., Kehl a.R. 2009.

Gass Stephan/Kiener Regina/Stadelmann Thomas (Hrsg.), Standards on Judicial Independence, Bern 2012.

Grabenwarter Christoph/Pabel Katharina, Europäische Menschenrechtskonvention, 6. Aufl., München 2016.

Hurni Christoph, Justizleitung und unabhängige Justiz im Kanton Bern, in: «Justice - Justiz Giustizia» 2019/1.

Kälin Walter/Bolz Urs (Hrsg.), Handbuch des bernischen Verfassungsrechts, Bern 1995.

Karpenstein Ulrich/Mayer Franz C. (Hrsg.), EMRK. Kommentar, 2. Aufl., München 2015.

Keel Madeleine, Die Leitungsstrukturen der Justiz im Bund und in ausgewählten Kantonen - Eine Studie im Spannungsfeld von Führung und verfassungsrechtlichen Prinzipien, Diss. St. Gallen 2014.

Keller Helen, Schweizerische Rechtsstaatlichkeit im internationalen Vergleich, in: Oliver Diggelmann et al. (Hrsg.), Verfassungsrecht der Schweiz, Bd. II., Zürich 2020, IV.2., 935 ff.

Kiener Regina, Aspekte der parlamentarischen Justizaufsicht im Kanton Bern, in: Bernische Verwaltungsrechtsprechung (BVR) 1997, $385 \mathrm{ff}$.

Kiener Regina, Garantie des verfassungsmässigen Richters, in: Detlef Merten/Hans-Jürgen Papier (Hrsg.), Handbuch der Grundrechte in Deutschland und Europa, Band VII/2: Grundrechte in der Schweiz und in Liechtenstein, Heidelberg 2007, § 227.

Kiener Regina, Richterliche Unabhängigkeit, Habil., Bern 2001.

Kiener Regina/Cupa Basil, Hybrider Status - relative Unabhängigkeit, Zur institutionellen Stellung der Staatsanwaltschaft, in: Liber amicorum für Andreas Donatsch, Zürich 2012, 395 ff.

Kiener Regina/Kälin Walter/Wyttenbach Judith, Grundrechte, 3. Aufl., Bern 2018.

Kiener Regina/Rütsche Bernhard/Kuhn Mathias, Öffentliches Verfahrensrecht, 2. Aufl., Zürich/St. Gallen 2015. 
Lienhard Andreas, Die bernische Gerichtsbarkeit auf dem Weg zur Selbstverwaltung, in: Ruth Herzog/Reto Feller (Hrsg.), Bernische Verwaltungsgerichtsbarkeit in Geschichte und Gegenwart, 100 Jahre Verwaltungsgericht des Kantons Bern, Bern 2010, 405 ff.

Lienhard Andreas/Kettiger Daniel (Hrsg.), Justiz zwischen Management und Rechtsstaat, Ergebnisse aus dem Forschungsprojekt «Grundlagen guten Justizmanagements in der Schweiz», Bern 2016.

Lienhard Andreas/Kettiger Daniel, Die organisatorische Einordnung der Staatsanwaltschaft in die kantonale Behördenstruktur, in: «Justice - Justiz - Giustizia» 2008/2.

Lienhard Andreas/Kettiger Daniel, Die Selbstverwaltung der Gerichte, in: «Justice - Justiz Giustizia» 2013/3.

Mahon Pascal, Le principe de la séparation des pouvoirs, in: Daniel Thürer u.a. (Hrsg.), Verfassungsrecht in der Schweiz, Zürich 2001, $1011 \mathrm{ff}$.

Martenet Vincent, La séparation des pouvoirs, in: Oliver Diggelmann et al. (Hrsg.), Verfassungsrecht der Schweiz, Bd. II., Zürich 2020, IV.5., 999 ff.

Mettler Christoph, Staatsanwaltschaft. Position innerhalb der Gewaltentrias, Funktion im Strafprozess und aufsichtsrechtliche Situation sowie ein Vorschlag zur Neuordnung, Diss. Fribourg, Basel/Genf/München 2000.

Meyer-Ladewig Jens/Nettesheim Martin/von Raumer Stefan (Hrsg.), EMRK, Handkommentar, 4. Auflage, Baden-Baden 2017.

Müller Markus, Die innere Unabhängigkeit des Richters, in: Ruth Herzog/Reto Feller (Hrsg.), Bernische Verwaltungsgerichtsbarkeit in Geschichte und Gegenwart, Bern 2010, 527 ff.

Müller-Graf Thomas, Die Justizverwaltung -- Chance oder Gefahr für die richterliche Unabhängigkeit?, in: «Justice - Justiz - Giustizia» 2019/3.

Nuspliger Kurt/Mäder Jana, Bernisches Staatsrecht und Grundzüge des Verfassungsrechts der Kantone, 4. Aufl., Bern 2012.

Poltier Etienne, L'organisation et le fonctionnement interne de l'ordre judiciaire et des tribunaux, AJP 2011, $1018 \mathrm{ff}$.

Reiter Catherine, Gerichtsinterne Organisation: Best practices, Diss., Zürich 2015.

SeIler Hansjörg, Gewaltenteilung, Bern 1994.

Tschannen Pierre, Staatsrecht der Schweizerischen Eidgenossenschaft, 4. Aufl., Bern 2016.

Uebersax Peter, Gerichte des Bundes, in: Oliver Diggelmann et al. (Hrsg.), Verfassungsrecht der Schweiz, Bd. III., Zürich 2020, VI.6, 1757 ff.Venice Commission (Venedig-Kommission): siehe Materialien (Europarat).

Waldmann Bernhard/Belser Eva Maria/Epiney Astrid (Hrsg.), Bundesverfassung, Basler Kommentar, Basel 2015 (zit.: BS-Komm. BV). 


\section{Ausgewählte Materialien}

Herangezogen wurden insbesondere die folgenden Berichte und weiteren Dokumente:

Kanton Bern:

- Vernehmlassungsentwurf (März 2019) zum Vortrag des Regierungsrates zur Änderung der Verfassung des Kantons Bern sowie zur Änderung des Gesetzes über die Organisation der Gerichtsbehörden und der Staatsanwaltschaft (GSOG) (zit. Vernehmlassungsentwurf «Vortrag Justizverfassung»).

- Regierungsrat, Gesetzgeberische Umsetzung der Justizreform - Gesetz über die Organisation der Gerichtsbehörden und der Staatsanwaltschaft (GSOG), Einführungsgesetz zur Zivilprozessordnung, zur Strafprozessordnung und zur Jugendstrafprozessordnung (EG ZSJ), Vortrag des Regierungsrats, in: Tagblatt des Grossen Rates des Kantons Bern, Aprilsession 2009 (Beilage 17) (zit. Regierungsrat, Vortrag «Justizreform II»).

- Ecoplan/Wenger Plattner, Evaluation der Justizreform II im Kanton Bern (im Auftrag der Justizdelegation des Regierungsrats des Kantons Bern), Schlussbericht vom 27. Mai 2016 (zit. Evaluation «Justizreform II»).

- Tätigkeitsbericht 2018 der Gerichtsbehörden und der Staatsanwaltschaft des Kantons Bern.

Europarat

- Charte européenne sur le statut des juges, DAJ/DOC (98) 23 (8-10 juillet 1998).

- Comité des Ministres:

- Recommandation CM/Rec(2010)12 du Comité des Ministres aux Etats membres sur les juges: indépendance, efficacité et responsabilités (adoptée par le Comité des Ministres le 17 novembre 2010, lors de la 1098e réunion des Délégués des Ministres).

- Venedig-Kommission: ${ }^{129}$

- European Commission For Democracy Through Law (Venice Commission), Report on the Independence of the Judicial System: Part I - The Independence of Judges, Adopted by the Venice Commission at its 82nd Plenary Session (Venice, 12-13 March 2010)

CDL-AD(2010)004.

- European Commission For Democracy Through Law (Venice Commission), Report on European Standards as Regards the Independence of the Judicial System: Part II - The Prosecution Service, Adopted by the Venice Commission at its 85th plenary session (Venice, 17-18 December 2010) CDL-AD(2010)040.

- European Commission for Democracy Through Law (Venice Commission), Compilation of Venice Commission Opinions and Reports concerning Courts and Judges, CDL-PI(2019)008 (Stand: 21./22. Juni 2019).

129 Siehe https://www.venice.coe.int (Rubriken «Main reference documents» bzw. «Compilations of studies and opinions»). 
Giovanni Biaggini, Die bernische Justizleitung auf dem verfassungsrechtlichen Prüfstand, in: «Justice - Justiz - Giustizia» 2020/4

- European Commission for Democracy Through Law (Venice Commission), Compilation of Venice Commission Opinions and Reports concerning Prosecutors, CDL-PI(2018)001 (Stand 6./7. Oktober 2017). 